\title{
An analysis of health outcomes among sexual minorities with a focus on the HIV/AIDS epidemic among men who have sex with men in Belgium
}

Citation for published version (APA):

Vanden Berghe, W. J. M. E. (2013). An analysis of health outcomes among sexual minorities with a focus on the HIVIAIDS epidemic among men who have sex with men in Belgium. [Doctoral Thesis, Maastricht University]. Universitaire Pers Maastricht. https://doi.org/10.26481/dis.20131114wv

Document status and date:

Published: 01/01/2013

DOI:

10.26481/dis.20131114wv

Document Version:

Publisher's PDF, also known as Version of record

Please check the document version of this publication:

- A submitted manuscript is the version of the article upon submission and before peer-review. There can be important differences between the submitted version and the official published version of record.

People interested in the research are advised to contact the author for the final version of the publication, or visit the DOI to the publisher's website.

- The final author version and the galley proof are versions of the publication after peer review.

- The final published version features the final layout of the paper including the volume, issue and page numbers.

Link to publication

\footnotetext{
General rights rights.

- You may freely distribute the URL identifying the publication in the public portal. please follow below link for the End User Agreement:

www.umlib.nl/taverne-license

Take down policy

If you believe that this document breaches copyright please contact us at:

repository@maastrichtuniversity.nl

providing details and we will investigate your claim.
}

Copyright and moral rights for the publications made accessible in the public portal are retained by the authors and/or other copyright owners and it is a condition of accessing publications that users recognise and abide by the legal requirements associated with these

- Users may download and print one copy of any publication from the public portal for the purpose of private study or research.

- You may not further distribute the material or use it for any profit-making activity or commercial gain

If the publication is distributed under the terms of Article 25fa of the Dutch Copyright Act, indicated by the "Taverne" license above, 
An analysis of health outcomes among sexual minorities with a focus on the HIV/AIDS epidemic among men who have sex with men in Belgium

Een analyse van gezondheidsuitkomsten bij seksuele minderheden met een focus op de HIV/AIDS epidemie bij mannen die seks hebben met mannen in België 


\section{Colophon}

Chapter 2/3/5: These projects were co-funded by the Flemish government.

Chapter 4: This project number G.0198.06N was funded by the Fund for Scientific Research, Flanders, Belgium.

The data for chapters $2 / 3 / 4$ were collected by the author and collaborators at the Department of Sociology, Ghent University, Belgium.

Chapter 6: EMIS was funded by a grant of the European Commission under the EU Health Programme 20082013. Further funding was received from CEEISCat (Centre d'Estudis Epidemiològics sobre les ITS/HIV/SIDA de Catalunya, Spain); Department of Health for England; Maastricht University (The Netherlands); Regione del Veneto (Italy); and Robert Koch Institute (Germany). Further funding for the participation of men in specific countries was provided by: German Ministry of Health for Ukraine and Moldova; Finnish Ministry of Health for Finland; Norwegian Institute of Public Health for Norway; Swedish Board of Health and Welfare for Sweden; and Bundeszentrale für gesundheitliche Aufklärung (BZgA) for Germany. We would like to acknowledge the scientists who organised and conducted EMIS between 2009 and 2011: Axel J. Schmidt (Project coordination); Ulrich Marcus (Project initiation and supervision); Peter Weatherburn (Promotion co-ordination); Ford Hickson and David Reid (Technical implementation) en the European MSM Internet Survey network. We would also like to acknowledge our Belgian EMIS partners: Vladimir Martens at l'Observatoire du sida and Sensoa.

(C) Copyright Wim J. M. E. Vanden Berghe, Maastricht 2013

Production: Datawyse | Universitaire Pers Maastricht

ISBN 9789461592606 


\section{An analysis of health outcomes among sexual minorities with a focus on the HIV/AIDS epidemic among men who have sex with men in Belgium}

\section{Een analyse van gezondheidsuitkomsten bij seksuele minderheden met een focus op de HIV/AIDS epidemie bij mannen die seks hebben met mannen in België}

\section{Proefschrift}

ter verkrijging van de graad van doctor aan de Universiteit Maastricht, op gezag van de Rector Magnificus, Prof. dr. L.L.G. Soete, volgens het besluit van het College van Decanen,

in het openbaar te verdedigen

op donderdag 14 november 2013 om 14.00 uur

door

Wim J. M. E. Vanden Berghe

geboren op 15 november 1979 te Brugge

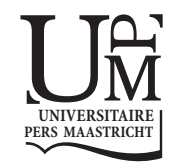




\section{Promotores}

Prof. dr. H. Hospers

Prof. dr. M. Laga (Instituut voor Tropische Geneeskunde, Antwerpen, België)

\section{Promotiecommissie}

Prof. dr. G.J. Kok, voorzitter

Dr. J. Mikolajczak (afdeling Team preventie en voeding, publieke gezondheid en gezondheidsbevordering, RIVM, Bilthoven)

Dr. J. Motmans

(Universiteit Antwerpen)

Prof. dr. R. Ruiter

Prof. dr. N.K. de Vries 


\section{Table of contents}

$\begin{array}{lll}\text { Chapter } 1 & \text { Introduction } & 7\end{array}$

Chapter 2 General and minority stress in a sexual minority population in 19 Flanders

Chapter 3 Minority specific determinants of mental well-being among Lesbian, Gay and Bisexual youth

Chapter $4 \quad$ Syndemic and other risk factors for unprotected anal intercourse among an online sample of Belgian HIV negative Men who have Sex with Men

Chapter 5 A venue-based HIV prevalence and behavioral study among men who have sex with men in Antwerp and Ghent, Flanders, Belgium, October 2009 to March 2010

Chapter 6 International mobility, sexual behavior and HIV-related characteristics of men who have sex with men residing in Belgium

Chapter 7 General discussion

References

Summary

Nederlandse samenvatting

Acknowledgements

Curriculum Vitae 

CHAPTER 1

Introduction 



\section{Background and social context}

In a number of countries in the Western world, the social and legal status of lesbian, gay and bisexual (LGB) individuals has recently evolved favorably. In Belgium, the possibility of legal co-habitation was opened up for same-sex couples in 1996. Then, in 2003, followed the inclusion of sexual orientation in anti-discrimination legislation, as well as the ratification of civil partnership for same-sex couples. Finally, child adoption by same-sex couples was voted in 2006. Notwithstanding these positive developments, this does not mean that LGB individuals no longer face problems as a result of adverse reactions within their family, at work, school or in other areas of the heteronormative society [1]. For example, a recent large scale survey among Flemish ${ }^{1}$ LGB individuals demonstrated that $22.5 \%$ had experienced negative reactions regarding their homosexuality in the work environment during the past year [2]. Also, a recent report on violence against LGBT individuals in Brussels city shows that $60 \%$ of all respondents experienced verbal abuse at least once and $10 \%$ were physically threatened, both during the month prior to the study [3]. Another local study showed that LGB youth is more often confronted with verbal abuse than their heterosexual counterparts [3]. Within this context, LGB individuals, youth in particular, continue to be at higher risk for health problems such as depression, suicidal ideation and suicide attempts [2]. Further, LGB individuals not only score lower on mental health measures compared to their heterosexual counterparts, but gay and other men who have sex with men (MSM) continue to be at higher risk for HIV and STI infection [4]. MSM is an acronym used to describe all men who have sex with men and not only those who identify as being homosexual- or bisexual. For Belgium, there is no systematic inquiry into sexual identification, attraction or behavior of the population. Because the latter three concepts are used interchangeably in an unstructured manner, produced estimates are difficult to compare. For instance, according to an early American publication by Alfred Kinsey approximately $37 \%$ of the population had ever had a same-sex sexual experience, measuring behavior [5]. More recently, general population surveys have found $2 \%$ to $3 \%$ of respondents that reported to identify as homo- or bisexual. The degree of sexual identification within a certain society is highly dependent on social acceptance and willingness to disclose. A recent Flemish study on sexual health showed that among a representative sample of the population, $8.2 \%$ identified more as homo- or bisexual while $10 \%$ of the men and $12,8 \%$ of the women ever had same-sex sexual contact [6]. The reported health issues do not only arise among those who identify as being homoor bisexual so focusing on behavior or attraction reaches more individuals potentially at risk for negative health outcome. A better and continuous understanding of the prevalence and the causes for disparate health outcomes among LGB's, and how these

\footnotetext{
${ }^{1}$ Flanders is the Northern, Dutch-speaking region of Belgium
} 
health outcomes interact, is needed to inform more effective interventions, both for implementation at Belgian and at international level.

This thesis describes results from several Belgian and European research projects on health outcomes among LGB individuals - gay and other MSM in particular. The focus of the thesis will be on mental health outcomes among LGB populations and secondly on sexual health among gay and other men who have sex with men. Within this second focus, interactions between mental and sexual health will be discussed. This introductory chapter will discuss the prevalence, determinants and explanatory model used in this thesis of different health outcomes among sexual minority populations in order to better situate the different empirical studies described in the following chapters.

\section{Health outcomes among sexual minorities}

\section{The Human Immunodeficiency Virus (HIV) and other Sexually transmitted Infections}

In most Western countries the yearly number of newly diagnosed HIV infections has been increasing since 1997, the year Highly Active Antiretroviral Therapy (HAART) was introduced. For Belgium, this increase peaked between 1997 and 2000 (+36\%), after which a more moderate rise was observed. According to the Belgian Institute of Public Health (BIPH) 1177 new HIV diagnoses were reported in 2011. Today, newly diagnosed HIV infections are predominantly found among MSM with a Belgian nationality and mostly heterosexual individuals coming from Sub-Saharan African countries [7].

The proportion of individuals of Belgian nationality with a newly diagnosed HIV infection has increased from $29,3 \%$ in 2002 to $42,7 \%$ in 2011 . This increase was mainly a consequence of the number of HIV infections among men who have sex with men that rose from 23,5\% in 2002 to 46,6\% of all infections in 2011 (see figure 1). In 2011, a majority of these men (82,1\%) were of Belgian nationality. Since 2004 , an increase in new HIV diagnoses through homo-or bisexual contact has also been noted among men not of Belgian nationality, mostly European men [7]. In Belgium, trends in HIV incidence are derived from registered diagnoses of HIV. However, such data have their limitations, as there is no additional background information for up to a third of registered new cases of HIV infection, and may not reflect the real scope of the epidemic ${ }^{2}$. In addition to HIV incidence estimates, population-based HIV prevalence estimates are needed to assess the burden of disease in MSM and to make realistic projections for healthservice needs and prevention planning (see chapter 4).

\footnotetext{
${ }^{2}$ Background information on HIV transmission mode is unknown for about $28 \%$ of reported cases between 2005 and 2011
} 


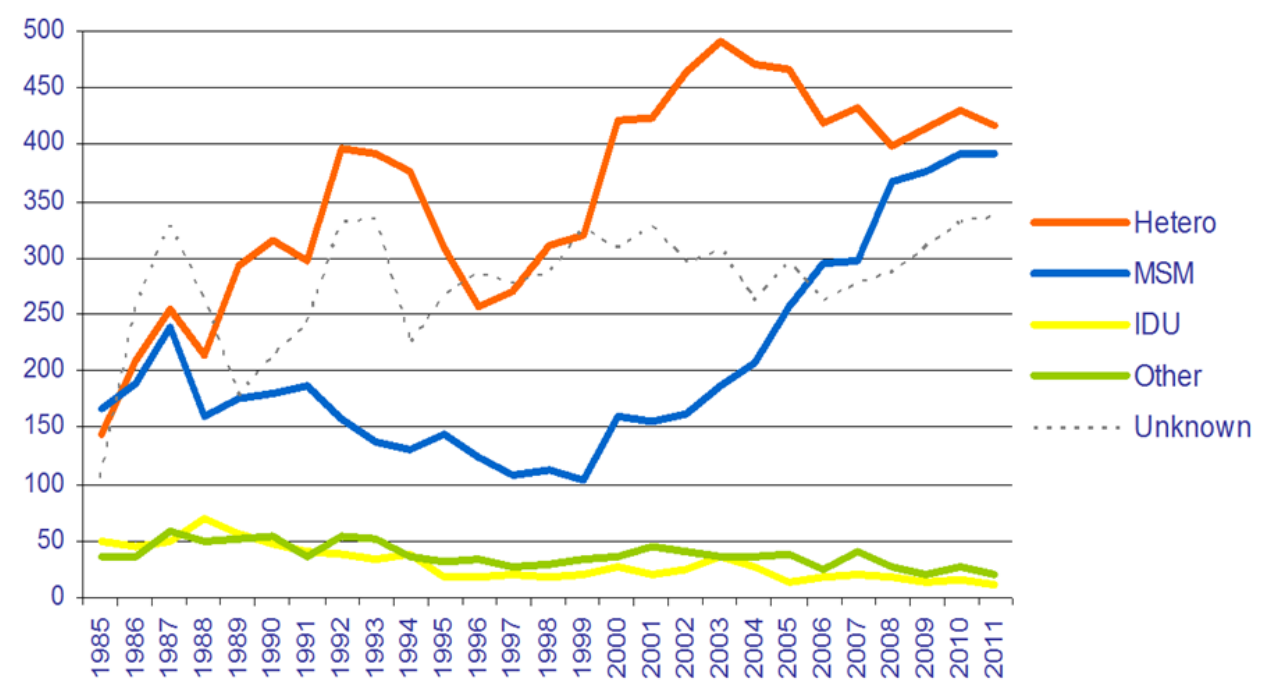

Figure 1: New HIV diagnoses by way of transmission, Belgium,1985 - 2011 (source: BIPH)

Next to HIV, according to the sentinel network of Belgian STI laboratories and clinicians, specific STI's are disproportionately detected among MSM. According to findings in that network, in $2011,80 \%$ of Gonorrhea cases ( $n: 87)$ and $88 \%$ of Syphilis cases $(n: 84)$ in men were diagnosed among MSM. More than half of the Syphilis cases (53\%) and $42 \%$ of Gonorrhea cases in men were diagnosed among HIV positive men. Some STI's epidemics are fairly recent such as Lymphogranuloma Venereum (21 LGV reported cases in Belgium for 2011) and Hepatitis C. The latter STI's are almost without exception found among HIV positive MSM [8-10].

\section{Determinants of unprotected anal intercourse}

The main transmission route through which MSM are infected with HIV is unprotected anal intercourse $(\mathrm{UAI})^{3}[11]$. In this thesis the definition of sexual risk behavior will be limited to the practice of UAI. Determinants of UAI can be found at different ecological levels (see chapter 3 to 5 ). Although this not the main focus, elements from different social-cognitive explanatory theories will be used within this thesis. One element is the concept of perceived severity connected to the Health Belief Model [12]. This model was one of the first in its kind and was used to model perceived threat of HIV infection (including perceived susceptibility and perceived severity) and expectations of the outcome of safe sex (including perceived benefits, perceived costs and perceived selfefficacy) in determining safe sex practice [13]. Two other models have played a central

\footnotetext{
${ }^{3}$ Anal intercourse without the use of a condom
} 
role in HIV research and prevention, the theory of reasoned action [14] and its successor, the theory of planned behavior [15]. These theories postulate that the intention (to perform safer sex) lies at the basis of practicing safer sexual behavior. This intention in turn - is influenced by attitudes and the subjective norm. The Theory of Planned Behavior adds perceived behavioral control (PBC) predicting intentions. PBC also has an unmediated, direct effect on behavior. The concepts derived from the models above will be studied in this thesis are perceived risk and subjective norm. Results on the effect of perceived risk on safer sex are mixed [13]. The lack of a consistent association between both variables among MSM has been attributed to the time lag between studies and the contextual evolution of the HIV epidemic among MSM. High perception of severity of HIV infection might have changed considerably between different studies including the introduction of HAART [16]. Notwithstanding these reservations in interpretation, different studies have demonstrated that a sexually risky behavioral pattern is influenced by the individual risk perception attributed to UAI. A lower risk perception of UAI practice is associated with a higher frequency of UAI [17;18]. The subjective norms regarding safe sex are related to the perceived peer norms regarding condom use as a potential indication of social pressure to comply with peers when it comes to preventive behavior [14].

Other studies on the determinants of UAI at the individual level show that some MSM are high sexual sensation seekers [19-22] or show more sexual compulsive behavior [23] and push their sexual boundaries further than others. Because of this specific personality profile, MSM who score high on sexual sensation seeking scales will perform riskier behavior and subsequently run a greater risk for HIV and STI infection than those with lower sensation seeking profiles [21;24]. Recent studies among MSM also show low condom use among certain subpopulations of HIV positive men confirming serostatus as a marker for UAI. Determinants of UAI based on interpersonal interaction include social support related to sexual identity development, influencing the adoption of safer sex practices. Vincke found that experiencing less social support related to gay identity formation and coming out is associated with riskier sexual behavior. Disapproval by significant others of being gay also led to higher levels of receptive anal intercourse without a condom [25]. Another major risk factor for HIV infection is having a higher number of male sex partners during a specific period. It is an indicator of the cumulative risk for HIV [26-29]. At the socio-cultural level, important factors associated with sexual risk are the media through which or the venues where MSM meet their partners for sexual contact. Some research has shown that finding partners on the Internet is a predictor for sexual risk [30] and frequenting specific sex clubs or cruising areas has been associated with reporting more sex partners and unprotected sex [31;32]. It has also been suggested that travel behavior and sexual mobility could potentially be an factor in the spread of HIV and sexually transmitted infections (STI) among European MSM [4;29]. However, little attention has been paid so far to investigate sexual behavior of gay men while travelling (see chapter 5 ). 


\section{Mental health outcomes}

An extensive body of research has reported on lowered mental health and depression in sexual minority populations (see chapter 1 to 3). In Belgium, research on mental health outcomes among sexual minorities has also been substantial. Notwithstanding the lack of longitudinal data on mental health, different local cross-sectional studies among sexual minority populations have demonstrated lowered mental health outcomes. A 2006 Flemish report on societal position of LGB's showed higher rates of depression among LGB's compared to their heterosexual counterparts [3]. Different prior studies had demonstrated increased risk of suicidal ideation among homosexual or bisexual young people and the association with depressive symptoms [4]. Local studies among gay youth attending a camp showed that $33 \%$ to $45 \%$ of LGB individuals have suicidal thoughts while growing up and $12.4 \%$ of gay boys had ever attempted suicide, compared to $5.9 \%$ of their heterosexual counterparts [33]. Further, the Welebi survey of 2009 showed that $56.6 \%$ of lesbian and bisexual girls thought at least once about putting an end to their lives while $14.4 \%$ had attempted suicide at least once [34]. It is suggested that one of the key factors related to lowered mental health is sexual identity development. Suffering from depression lowers sexual identity commitment. The increased risk of suicidal ideation among homosexual or bisexual young people is associated with depression and may lead to suicidal behavior, independent of sexual orientation, especially in the presence of a role model of suicidal behavior, and among those with unsatisfying friendships [33]. Determinants and the context of lowered mental health will be discussed in the next section of this general introduction on minority stress and syndemic theory as mental health outcomes have been frequently used as outcome variables in the different theoretical conceptual frameworks explaining health disparities among minority populations.

\section{Explaining health disparities among sexual minority populations}

It is suggested that negative health outcomes can potentially interact, creating a syndemic: co-occurring health outcomes that through interacting synergistic processes lower the overall health and increase susceptibility to other diseases [35-38]. Although also documented for the general population, LGB's are confronted with health problems such as depression, substance use, partner violence, sexual compulsivity and other health risks that have been reported to co-occur [39-41]. In this thesis the association between mental health and sexual risk among MSM will be explored in greater depth (see chapter 3). A 2001 review [42] showed a non-significant effect between negative affect and sexual risk although it was suggested that the lack of an association could have been due to the methodological approach that did not allow for more sensitive analyses [43]. Further, more recent studies have shown that feeling depressed is an 
important factor in explaining unprotected sex $[36 ; 44 ; 45]$. In the context of explanatory social-cognitive models such as the Theory of Planned Behavior [15], a depressive state of mind could interact with the perception of sexual risk and social norms regarding condom use (see chapter 4) [46;47].

To explain the occurrence and co-occurrence of negative health outcomes in this thesis, an ecological model is used. This model, the minority stress model, is based on the social stress model. The latter model integrates three different conceptual domains: the sources, the mediators and the manifestations of stress. Manifestations of stress, such as lowered mental health and HIV risk, have been discussed earlier. The sources, daily hassles and life events, can cause stress because it requires the individual to adapt to a new situation or life circumstance. These general stressors have adverse effects on the health of individuals, especially on mental health. Social support mechanisms are reported to mediate the effect of stress on mental health [48;49].

Largely based on the social stress paradigm and minority stress theory [50;51] the explanatory model in this thesis (see figure 2) suggests that health disparities and what is called "the syndemic condition", are a consequence of adverse social conditions. Minority stress theory models social-structural context and social stressors, particularly those related to prejudice and discrimination, determining adverse mental health outcomes. The minority identity influences this experience of minority stressors. Most research in this field does focus on mental health as an outcome [52;53]. Minority stress can be defined as the excess social stress that individuals from a certain minority group experience as a consequence of being part of that minority group. Some studies have used minority stress theory to model the effects of social discrimination on overall health outcomes among sexual minority individuals. Minority stress theory distinguishes between distal and proximal stress processes. Distal stressors are external to the individual such as explicit forms of discrimination at work while proximal stress processes are internal to the individual, and are a consequence of the distal stressors. Meyer [50;51] conceptualized three different forms of proximal minority stressors: concealment of the minority identity, internalized homonegativity and perceived stigma. A recent study showed that social structural factors such as a country's legal climate towards sexual minorities, the Gini coefficient ${ }^{4}$ and the level of urbanisation are associated with internalized homonegativity [54]. Health outcomes induced by sexual minority stressors such as internalized homonegativity, stigma consciousness include depressive symptoms, AIDS-related traumatic stress response, sexual problems, demoralization, guilt and suicide. Further, reporting more internalized homonegativity is associated with lowered condom use for anal intercourse [51;54;55]. The minority stress model also includes resiliency factors. The concept of resiliency among LGB populations has been described as the process encompassing positive adaptation with-

\footnotetext{
${ }^{4}$ The Gini coefficient is commonly used as a measure of inequality of income or wealth
} 
in the context of significant adversity. One of the most frequently studied resiliency concepts is social support. This support can come from family and friends or from significant others [56]. Social support has been shown to buffer, moderate and mediate the detrimental effects of life stress [49;57] and is therefore an important protective factor in explaining the effect of stressors on mental health outcomes [58] Also, change in social support over time seemed to be more important than its initial levels confirming the life-course effect of social support[59]. Especially for adolescent LGB youth, the role of social support in coping with the potential struggle of sexual identity development and social acceptance can be twofold. These young people look for support among their family and friends but fear rejection at the same time [60]. Therefore, the experience of unsupportive social interactions also has to be taken into account $[61 ; 62]$ (see chapter 2 and 3 ).

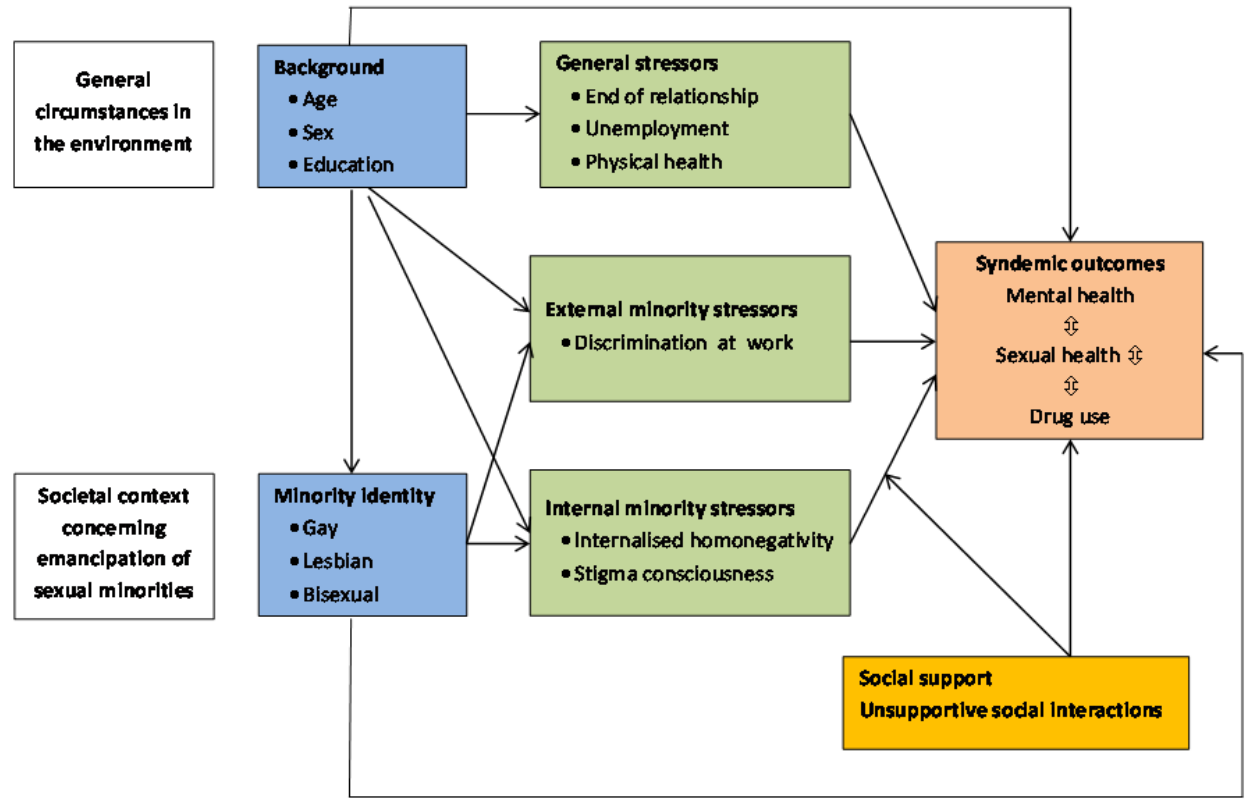

Figure 2: Explaining health disparities among sexual minority populations (based largely on the minority stress model [51;55]) 


\section{Data sources}

The different studies in this thesis use data from the following research projects:

The Zzzip survey (2004-2006)- See chapter 2 and 3

In 2004, the Flemish government wanted more insight into the lives of LGB's in Flanders. Following this call, the department of sociology at Ghent University developed the Zzzip survey. Because of the hidden character of the target population, a combination of an online survey and a standard postal survey was used. The inclusion aim was to move beyond identification as gay, lesbian, or bisexual, but to invite all who had experienced same-sex attraction or sexual behavior. To attract potential participants a social marketing campaign was set up called, Zzzip. The central message in the campaign enticed potential participants "to unzip themselves". The respondents were invited to complete an online questionnaire at www.Zzzip.be. The website was online for three months and a total of 10558 respondents started the questionnaire, of whom 5091 were not exclusively heterosexual. Of the latter group, 2741 completed the questionnaire. Of the 500 paper versions that were sent out, 180 were returned. The average completion time online was 45 minutes. More information on this project and the full description of indicators can be found in the official report [2].

\section{Frequently Asked Questions I (FAQIT)- See chapter 4}

In the context of a research project funded by the Fund for Scientific Research Flanders, the department of sociology at Ghent university set up FAQ, short for Frequently Asked Questions. This survey aimed at better understanding and monitoring the rise in HIV diagnoses and sexual risk behavior among MSM in Flanders. Dutch speaking MSM were motivated through an offline (posters in MSM venues) and online recruiting campaign (mailing lists, banners and news items on gay related internet sites) to fill in a questionnaire on www.faqit.be. It took the respondents on average 42 minutes to complete the survey. The initial dataset consisted of 1768 respondents.

\section{Frequently Asked Questions II (FAQIT II)- See chapter 5}

In 2009 the Flemish government wanted a better understanding of the HIV epidemic among MSM and commissioned the Institute of Tropical Medicine, Antwerp to set up a project. The Frequently Asked Questions II (FAQ ${ }^{2}$ ) study design was a cross-sectional collection of blood samples and behavioral data, between October 2009 and March 2010. The study implemented time-location sampling to recruit men present at various gay venues in Antwerp and Ghent. A total of 649 MSM participated in the study: 167 at cruising venues ${ }^{5}, 219$ at regular gay clubs/venues and 263 at young MSM venues.

\footnotetext{
${ }^{5}$ Venues where sexual contact on site is facilitated.
} 
The European Men who have sex with men Internet Survey (EMIS) - See chapter 6 The European MSM Internet survey recruited participants between June 4th and August 31rd, 2010. MSM from 38 different European countries, the 27 EU Member States, included, completed an online questionnaire on sexual health, which was presented in 25 languages. An offline and online recruitment campaign was organised with the support of many LGBT ${ }^{6}$ organizations and gay social online networks Gayromeo, Manhunt, Qruiser, Qguys and Gaydar. In total 174209 MSM participated in the study. Respondents completed the questionnaire in an average of 20 minutes. More information on the EMIS project and in particular on its design and methodology can be found on www.EMIS-project.eu and in a recent publication by Weatherburn et al. [63]. The Belgian EMIS sample comprised 3982 men.

\section{Thesis outline}

The chapters in this thesis each look at different aspects of explaining health disparities among LGB populations and in particular gay and other MSM living in Belgium. Chapter 2 and 3 are based on the results of the Zzzip project, a population based online study on the societal position of LGB's in Flanders. Chapter 2 uses social and minority stress theory to analyze and discuss the effects of both general and minority stressors on mental health among a general population of LGB's. Chapter 3 also uses minority stress theory in conceptualizing and modeling minority specific determinants of mental health disparities among LGB youth. Chapter 4 functions as a key chapter in looking at cooccurrence of mental and sexual health related problems in the context of syndemic theory among population of Flemish men who have sex with men. The data for this study was collected by means of the Internet during the first Frequently Asked Questions (FAQ) study, an online study on sexual health among MSM in Flanders. In chapter 5 the results of a venue- based bio-behavioral HIV prevalence study in Flanders (FAQ ${ }^{2}$ ) are presented. Chapter 6 will discuss international mobility, HIV related characteristics and sexual behavior of MSM residing in Belgium. For this study the Belgian results of the European Men who have sex with Men Internet Study (EMIS) will be used. Finally, results from the different chapters and studies will be discussed next to possible directions for the future of health interventions among LGB populations and HIV prevention among MSM for Belgium and Europe.

\footnotetext{
${ }^{6}$ Lesbian, Gay, Bisexual, Transgender
} 



\section{CHAPTER 2}

\section{General and minority stress in a sexual minority population in Flanders}

This chapter is largely based on a publication co-authored by Nele Cox, Alexis Dewaele and John Vincke and has been published in the Journal of LGBT Health Research, 2009; 4(4):181-94 under the title General and Minority stressors in an LGB population in Flan$\operatorname{ders}^{7}$

\footnotetext{
${ }^{7}$ Reference: Cox N, Vanden Berghe W, Dewaele A and Vincke J; General and Minority stressors in an LGB population in Flanders; Journal of LGBT Health Research, 2009; 4(4):181-94
} 

In 1973, homosexuality was omitted from the Diagnostic and Statistical Manual of Mental disorders. From that moment on, research on homosexuality as a mental illness gradually shifted to the study of mental health of lesbian, Gays and bisexuals and the causes of lowered mental health that are deeply rooted in the societal environment [64]. The study of social stressors became an important theoretical field in explaining health and wellbeing disparities [56]. Pearlin's social stress model [49] identifies and details the interrelationship of social and personal experiences, which are hypothesized as relevant in explaining mental health risk. The model outlines the experience of stress caused by personal and social life events and daily hassles, mediated by social support and coping strategies. Research suggests that psychosocial resources are beneficial for improving mental health. For example, symptoms of depression and anxiety tend to decrease as social support increases [65]. Evidence for coping strategies suggests that coping styles are situation-specific: what works for one stressful situation may cause health related problems in another. The response to stress is a combination of individual and contextual conditions. Some individuals will react to stress without negative health outcomes, but for others experiencing stress will lead to distress. Defining a situation as stressful will depend on an individual's perception of both the situation and his or her ability to respond to it. In investigating social stress systematically, researchers have focused on commonalities in experience across individuals and situations. Commonalities in stress reactions can subsequently be found the individual and the societal level, including socioeconomic and demographic factors [66;67].

\section{Demographic background characteristics and mental health outcomes}

Evidence on sex differences in mental disorder prevalence is consistent [56;68]: In most studies women report higher levels of anxiety and depression than men[69]. Theories on gender-based exposure to social stressors explain women's elevated distress as the consequence of inequality and disadvantage [69]. With regard to the relationship between age and mental health, research has shown that depression is lowest for middleaged individuals, higher among younger and older age groups and highest among the oldest. Average depression scores seem to reach their lowest level around age 45. An explanation for the U-shaped relationship between age and depression can be found in the scope of the adult life cycle: certainty about marital, employment and economic status flattens out the age-dependent curve at middle-age [70]. Next to sex and age, socioeconomic status also needs to be taken into account when explaining mental health disparities. Evidence on the negative association between education and psychological distress is very strong in epidemiological research on mental health [71]. On average, the well-educated seem to report higher levels of mental and physical health while poorly educated persons seem to suffer more from depression, anxiety, and physical pain [72]. However, there has been little research on the influence of demographic background characteristics like sex, age and education among LGB populations. 


\section{Sexual identity and mental health outcomes}

An identity can be described as the mental image people have of themselves. One of the many identities related to a person's self-image is that of sexual identity. Sexual identity refers to the self-concept an individual organizes around their own sexual orientation [73;74]. The sexual identity develops through engaging in sexual behavior; creating attitudes around sexual experiences and sexuality while navigating the social, emotional, and physical challenges of sexual behavior in the process [75]. When an LGB individual's self-perception is related to romantic or sexual situations, it is called an LGB identity [76]. Within the so called heteronormative modern society [1], heterosexuality is the assumed sexual identity. As a consequence, young people grow up with the presumption of being heterosexual. Being LGB is thus experienced as a deviant state of sexual identity, which can cause distress $[77 ; 78]$. Next to a lesbian or gay identity, individuals can also identify themselves as bisexual, meaning that they are sexually oriented toward both sexes. All labels of sexual identity that fall between an exclusively homosexual and exclusively heterosexual orientation are labeled as bisexual. However, the label of being bisexual can have different meanings. Individuals that are oriented toward one sex, so called monosexuals, often resist being labeled bisexual. Further, many gay men or lesbians believe that bisexuals fear the stigma attached to being labeled as gay or lesbian [79]. The belief that bisexuals are somehow confused about their sexual identity is also widespread [80]. Consequently, more stressful outcomes for bisexuals versus monosexuals could be expected as a result of denial, or the expected stigma associated with their sexual identity. Reported and expressed sexual identities are influenced by both psychological and societal factors. Although men are more likely to label themselves as gay, young women tend to report more uncertainty about their sexual identity. They are more likely to consider themselves as bisexual, experience more same-sex attraction, and act on it at a later age in life [81]. Therefore, young women are more likely than their male counterparts to be attracted to both sexes, to identify themselves as bisexual and to be unsure of their sexual identity $([81 ; 82]$. Given these sex differences in sexual identity formation, it is possible that sexual identity has a different impact on the mental health of women versus men. Research indicates that lesbian and bisexual women are more likely to report lowered mental health compared to their male counterparts and young LGB's seem to be at greater risk for mental health problems such as depressive symptoms, multiple psychiatric disorders and suicidal behavior ([83]. These findings are explained by the development of a non-heterosexual identity during puberty and young adulthood that causes considerable distress [84-87]. This study will investigate the interaction between sex and sexual identity and the effect on mental health outcomes among an LGB population. 


\section{General and minority stressors}

Next to differences in health outcomes according to background characteristics and sexual identity, stressful experiences also affect people $[49 ; 88]$. Individual stressful experiences are defined as events and conditions that cause change and require the individual to adapt to a new situation or life circumstance. Experiencing those daily hassles or life events can cause mental health problems [49;56;66]. It is important to recognize impact differences of general versus minority stressors. Social stressors are conditions in the social surroundings that can cause stress and that often stem from holding a minority position in society [49]. This leads us to the concept of minority stress defined as the excess stress individuals from stigmatized social categories are exposed to as a result of victimization, stigmatization, and discrimination experienced related to their particular social position [88;89]. The concept of LGB minority stress is based on the premise that LGB individuals who are living in a heteronormative society, are subjected to chronic stress related to social stigmatization of LGB's. In this context, minority stress comes on top of the general stressors that are experienced by all [88]. Diplacido [90] reviewed the existing evidence on stress among LGB's and identified two types of LGB minority stress. Firstly, the external stressors or negative events and daily hassles resulting from the social status of an individual, such as experiences of discrimination or negative treatment in society. Rosser and Ross [91] found that the relationship between life events and emotional distress is stronger among gay than heterosexual men. Next to these external LGB minority stressors, Diplacido [90] identified a second type of minority stressor, namely internal LGB minority stressors. These are stressors that manifest themselves at the psycho-cognitive level because of the societal position of that individual. These stressors often represent more chronic strains, such as internalization of cultural stereotypes about homosexuality. Two main internal stressors are explored. First of all, LGB's have to deal with internalized homonegativity. LGB's, just like heterosexuals, are raised in a heteronormative society with anti-homosexual biases. They may internalize these negative attitudes towards homosexuality [92]. These biases set in motion other psychological processes eventually leading to the development of prejudice. Internalized homonegativity can be overt, for example, individuals may blame themselves for being sick or inferior because of their homosexuality. This can lead to self-destructive or abusive behaviors and is extremely destabilizing. The covert types of homonegativity are more prevalent. In this case, the affected individuals seem accepting of their own sexual identity to the outside world, yet self-sabotage their life path in a variety of subtle ways, e.g., they use their sexuality as an excuse not to perform at school or work, or they tolerate discriminatory or abusive treatment from others. Covert internalized homonegativity also operates at community level. Some LGB's have unrealistic behavioral standards and can be very negative and critical towards other members of the LGB community who do not meet their expectations, reflecting their own discomfort. These negative attitudes about homosexuality have a direct influence on their personal life, their attitudes towards same-sex sexual and 
emotional attraction, same-sex sexual behavior and same-sex intimate relationships. The umbrella concept for the internalization of these negative attitudes is called internalized homogenativity. Different studies showed that internalized homonegativity relates to depression, self-esteem issues, and general psychological distress [51;90;92;93]. Next to internalized homonegativity, LGB's can experience stigma consciousness. There are two aspects to stigma: stigmatized individuals can assume that their presupposed abnormality is known or is an evident feature of their appearance. On the other hand, they can also assume that it is neither known nor immediately visible to others. The stigmatized individual possesses a stigma, an undesirable difference from what is expected by the environment [94]. In the case of LGB's, stigma has specific effects, in the first place because LGB's are not born as minority individuals. They grow up like anyone else, thinking they are heterosexuals. It is only when they develop their LGB identity and come out as LGB that they attain a minority status. Secondly, LGB identity is seen as a concealable stigma, meaning that LGB's can hide their stigma. This possibility to hide one's membership of the minority group can prevent prejudice and discrimination. On the other side, the ambiguity of social positioning and the fear of potential discovery can cause a range of cognitive, affective, and behavioral problems [95]. Stigma consciousness refers to the extent to which people expect to be stereotyped by others. High levels of stigma consciousness reflect an expectation that one will be stereotyped, irrespective of the actual behavior [96]. The concept of stigma consciousness helps to explain the stress-enhancing effect of stigma. The more someone perceives themselves as stigmatized, irrespective of the fact that stigmatization arises from firsthand experience; the greater the need is to anticipate such stereotyping. This anticipation of stereotyping can have negative effects on health and psychosocial functioning $[55 ; 97 ; 98]$. Ross [98] found that anticipated social rejection better predicts psychological distress than does actual negative experiences. Therefore, it is expected that stigma consciousness is significantly associated with depressive symptoms [88;93]. The study in this chapter investigates mental health outcomes in an LGB population, and how and to what extent both general and minority stressors are related to mental health outcomes. We also focus on the role of sexual identity within this social stress process.

\section{Method}

\section{Hypotheses}

Based on the theoretical model of the study, nine hypotheses are tested:

1. Lesbian and bisexual women score higher on depressive outcomes than gay and bisexual men.

2. Younger LGB's score higher on depressive outcomes than older LGB's. 
3. LGB's with less education score higher on depressive outcomes than higher educated LGB's.

4. Bisexuals have higher average levels of depressive outcomes than lesbian or gay respondents.

5. The impact of sexual identity on depressive outcomes is different in women versus men.

6. Experiencing general stressors increases the probability of depressive outcomes.

7. Experiencing external minority stressors increases the probability of depressive outcomes.

8. Reporting more internalized homonegativity is associated with more depressive outcomes.

9. Reporting more stigma consciousness is associated with more depressive outcomes.

\section{Study Sample}

The Zzzip survey dataset was used. This survey was set up starting October 2004 and administered in February 2005. Zzzip was a wide-ranging inquiry into the conditions of LGB life in Flanders. The aim was to recruit not only those who identify as gay, lesbian, or bisexual, but all who have experiences same-sex attraction or sexual behavior. $A$ large-scale social marketing campaign was set up called Zzzip. The central message in the campaign enticed potential participants "to unzip themselves," to show who they were and what they stood for. The respondents were invited to complete an online questionnaire at www.Zzzip.be. Our original sample ( $\mathrm{n}: 2917)$ contained 1,940 men and 977 women between 14 and 84 years of age, with an average age of 31.8. Because we focus on discrimination at work, we limited our study sample to respondents with work- experience. This reduces the dataset to 2,280 cases, of which 1,565 are men and 715 are women. The average age is 34.8 (SD: 11.2 ); $28 \%$ are younger than $26 ; 18 \%$ of the respondents are older than 45 . All educational levels are represented; however, the majority $(70.8 \%)$ has a college or university degree.

\section{Measures}

\section{Dependent variable}

To measure depressive symptoms, we used [99] Radloff's (1977) Center of Epidemiologic Studies Depression scale (Cronbach's Alpha: 0.95). The scale contains 20 items, with a minimum score of 0 and a maximum score of 60 . 


\section{Independent variables}

To measure sexual identity, we asked the respondents to indicate how they would describe their own sexuality using the Kinsey scale. This scale scores from 0 (exclusively heterosexual) to 6 (exclusively lesbian or gay). The respondents that identified as exclusively heterosexual were excluded from the survey. A total of $84.4 \%$ of the respondents identified themselves as almost exclusively lesbian or gay resulting in a highly skewed distribution. The mean score is 5.5, with a standard deviation of 0.9. General stressors were measured by means of several general life event items in the domains of work (unemployment), health (physical pain and state of health), and relationships (termination of a romantic relationship). Dummy variables were created based on whether respondent's did or did not experience these particular life events. The life events were subsequently included into a scale, a high score indicating the experience of more general life stressors (see table 2.1). The experience of external minority stressors was limited to discrimination at work. The items in this scale covered discrimination at work and included being discharged, being denied a job, being denied a promotion, and experiencing negative attitudes of colleagues (see table 2.1). Finally, two scales conceptualizing internal minority stress were used. To measure stigma consciousness, we used [96] Pinel's (1999) Stigma Consciousness Scale (SCS). The reliability analysis revealed a Cronbach's alpha of 0.75 . We measured internalized homonegativity using Mayfield's [100] internalized homonegativity inventory (IHNI) for gay men. We adapted the scale for use by both men and women and based on the results in the pre-test we curtailed the measure to 10 items (Cronbach's Alpha: 0.80).

\section{Statistical analyses}

To study the effect of sex, age, and education we performed a univariate analysis of variance (ANOVA). Correction for multiple comparisons was implemented by applying the Bonferroni correction (see table 2.2). To test the hypotheses, a hierarchical stepwise regression technique was used, based on Pearson's correlations output (see table 2.3) with CES-D (Center of Epidemiologic Studies Depression scale) as the dependent variable (see table 2.4). In Step 1, the background variables sex, age, and education were entered to control for their effects. We included sexual identity in the second block. Our external stress indicators were added in the third step and the internal minority stressors were added in Step 4. We then included some interaction terms to verify the impact of sex on the relation between sexual identity and depression. For this step, we standardized our interaction variables and performed separate regression analyses. 
Table 2.1 Components of external stress indexes - proportions (general and minority stressors)

\begin{tabular}{|c|c|c|c|c|}
\hline & \multicolumn{4}{|c|}{ Experienced } \\
\hline & \multicolumn{2}{|l|}{ Yes } & \multicolumn{2}{|l|}{ No } \\
\hline & $\mathbf{N}$ & $\%$ & $\mathbf{N}$ & $\%$ \\
\hline \multicolumn{5}{|l|}{ General stressors } \\
\hline Bad health & 337 & 14.8 & 1943 & 85.2 \\
\hline Physical pain during last month & 255 & 11.2 & 2025 & 88.8 \\
\hline Unemployment & 153 & 6.7 & 2127 & 93.3 \\
\hline End of a relationship & 84 & 3.7 & 2196 & 96.3 \\
\hline Index general stress & 602 & 26.4 & 1678 & 73.6 \\
\hline \multicolumn{5}{|l|}{ Minority stressors (discrimination at work) } \\
\hline Ever not been accepted for a job due to your sexual orientation & 267 & 11.7 & 2013 & 88.3 \\
\hline Ever been maltreated at work due to your sexual orientation & 214 & 9.4 & 2066 & 90.6 \\
\hline Ever been dismissed due to your sexual orientation & 205 & 9 & 2075 & 91 \\
\hline Co-workers been negative about your sexual orientation & 511 & 22.4 & 1769 & 77.6 \\
\hline Index external minority stress & 807 & 35.4 & 1473 & 64.6 \\
\hline
\end{tabular}

\section{Results}

\section{Descriptive Statistics, Univariate Analyses of Variance, and Bivariate Correlations}

Mean depression score was 13.9 (table 2.2), with a standard deviation of 11.8 and a skewness of 0.8 . To overcome this asymmetric form, we used the squared CES-D scores in a linear regression (M: 3.4;SD: 1.8). Scoring higher than 16 on CES-D signals a heightened risk of distress and depression. Scores above 21 indicate an ongoing depression [101]. Univariate analysis of variance and $t$-tests showed that with regards to depressive symptoms, women ( $M$ : 15.4) scored slightly higher on than men (M: 14.2; $M$ difference: 1.2, $\mathrm{p}<0.05)$, respondents with less education (M: 16.7) scored significantly higher than highly educated respondents ( $M$ : 13.7; $M$ difference: 2.9, $p<0.001$ ), and LGB's under 26 years old (M: 16.4) scored significantly higher than LGB's between 27 and 45 years old ( $\mathrm{M}$; 13.9; $\mathrm{M}$ difference: $2.5, \mathrm{p}<0.001)$ and older than 45 years old $(\mathrm{M}$ : 14.2; $\mathrm{M}$ difference: $2.2, p<0.05)$. Regarding sexual identity, the results show that women $(M=$ 5.3) identify significantly less as exclusively homosexual compared to men (M: 5.6, M difference: $0.3, p<0.001$ ). The youngest age group ( $M$ : 5.4 ) identify more as bisexual compared to middle age group ( $M$ : 5.5; Mean difference: 0.1, $p<0.05$ ) and as more bisexual compared to the group older than 45 ( $M$ : 5.6; $M$ difference: 0.2, $p<0.001$ ). Lower educated respondents (M: 5.5) identify less as exclusively homosexual compared to the higher educated respondents ( $M$ : 5.4; $M$ difference: 0.1, $p<0.05$ ). Table 2.1 gives a short overview of the components of general and minority stress, including the frequency with which respondents did experience those hassles. Concerning the experi- 
ence of general life event stressors, we found that many respondents had not experienced any of the events within the given time period (73.6\%). With regard to experiencing external LGB minority stressors, $64.6 \%$ of the respondents said they had not experienced any discrimination at work. Lower educated respondents scored significantly higher on general stress experience ( $\mathrm{M}$ : 0.5; $\mathrm{M}$ difference: $0.2, \mathrm{p}<0.001$ ) as well as on external LGB minority stressors ( $M$ : 0.6; $M$ difference: $0.1, p<0.001$ ) compared to their highly educated counterparts. Bivariate correlations (table 2.3) show a significant association between external general stress and depressive outcomes (rgenstr: 0.34; $\mathrm{p}<0.01$ ) and between external minority stress and depressive outcomes (rminstr: 0.24; $\mathrm{p}<0.01$ ). The internal minority stressors-stigma consciousness (M: 26.0; SD: 9.9) and internalized homonegativity (M: 11.1; SD: 7.2)-are normally distributed. Univariate analysis of variance shows that stigma consciousness and internalized homonegativity seems to be equally distributed across sex, age, and educational level. Both variables are positively correlated with the dependent variable depressive symptoms (rstigma: $0.30 ; \mathrm{p}<0.01$; rIHNI: 0.30; $\mathrm{p}<0.01$ ). Experiencing more internal minority stress is associated with higher scores on depression. 


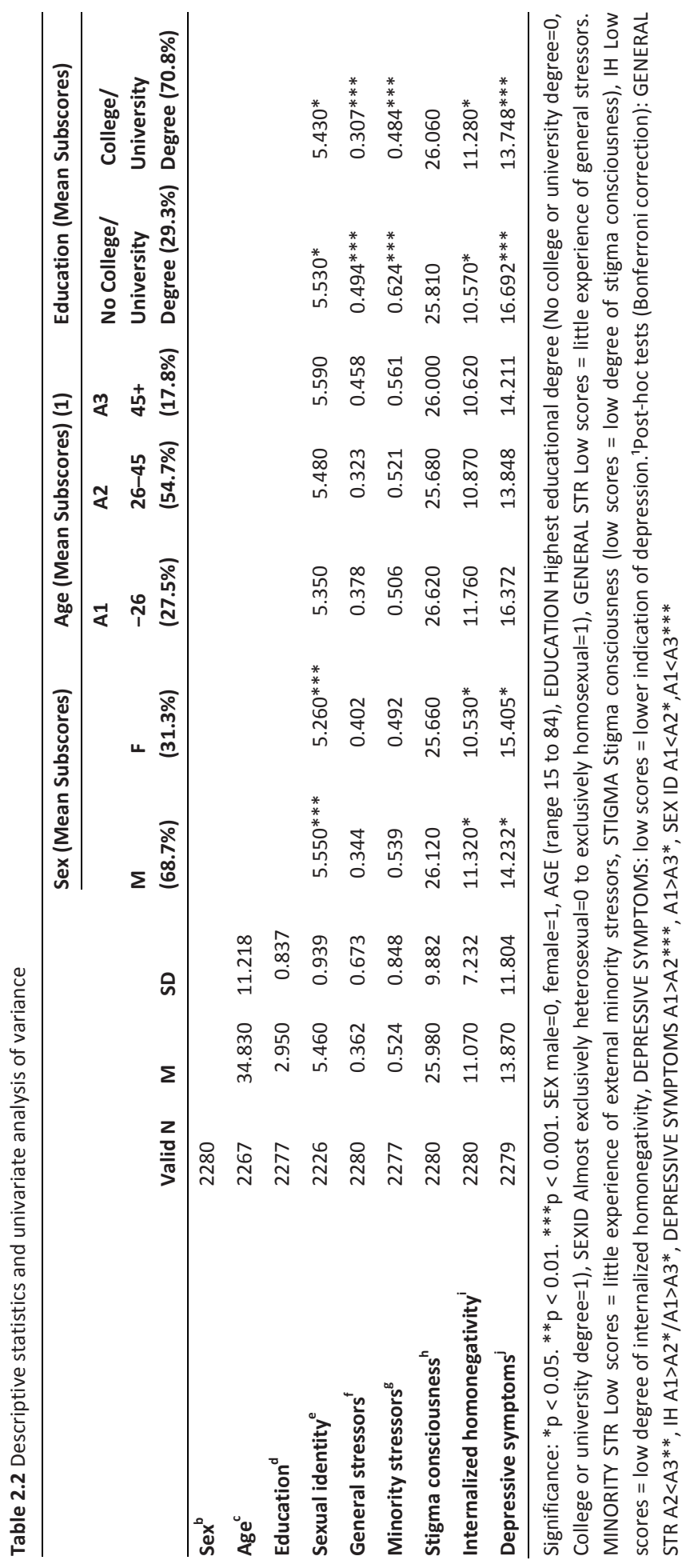


Table 2.3 Correlation matrix (Pearson's correlation)

\begin{tabular}{|c|c|c|c|c|c|c|c|c|c|}
\hline & 1 & 2 & 3 & 4 & 5 & 6 & 7 & 8 & 9 \\
\hline 1 Sex & 1 & & & & & & & & \\
\hline 2 Age & $-0.06 * *$ & 1 & & & & & & & \\
\hline 3 Education & 0.02 & $-0.08 * *$ & 1 & & & & & & \\
\hline 4 Sexual Identity & $0.14 * *$ & $0.09 * *$ & $-0.07 * *$ & 1 & & & & & \\
\hline 5 General Stressors & 0.04 & 0.02 & $-0.17 * *$ & 0.02 & 1 & & & & \\
\hline 6 Minority Stressors & -0.03 & 0.01 & $-0.07 * *$ & $0.07 * *$ & $0.17^{* *}$ & 1 & & & \\
\hline 7 Stigma consciousness & -0.02 & -0.03 & 0.03 & 0.01 & $0.17^{* *}$ & $0.38^{* *}$ & 1 & & \\
\hline 8 Internalised homonegativity & $-0.05^{* *}$ & $-0.06 * *$ & $0.05^{*}$ & $-0.18^{* *}$ & $0.05^{*}$ & $0.06^{*}$ & $0.36^{* *}$ & 1 & \\
\hline 9 Depressive symptoms & $0.04^{*}$ & $-0.07 * *$ & $-0.12 * *$ & $0.04^{*}$ & $0.34 * *$ & $0.24 * *$ & $0.30 * *$ & $0.30 * *$ & 1 \\
\hline
\end{tabular}

Significance ${ }^{*} p<0.05$. ${ }^{* *} p<0.01$. SEX male=0, female=1, AGE (range 15 to 84), EDUCATION Highest educational degree (No college or university degree=0, College or university degree=1), SEXID Almost exclusively heterosexual=0 to exclusively homosexual=1), GENERAL STR Low scores = little experience of general stressors. MINORITY STR Low scores = little experience of external minority stressors, STIGMA Stigma consciousness (low scores = low degree of stigma consciousness), IH Low scores = low degree of internalized homonegativity, DEPRESSIVE SYMPTOMS: low scores = lower indication of depression.

\section{Multivariate Analysis}

The full model explained $23.4 \%$ of the total variance of depression (see Table 2.4). Age ( $\beta$ age: $-0.07 ; p<0.001$ ) and education ( $\beta$ educ: $-0.11 ; p<0.001$ ) both had a negative impact on depressive outcomes: Young respondents scored higher on depressive symptoms, as did the lower educated respondents. Surprisingly, no sex differences were revealed within the analyses $(p>0.05)$. Bisexuals scored somewhat higher on depressive symptoms than those individuals identifying more as homosexual ( $\beta$ sexed: -0.05 , $p<0.05)$. Adding the internal minority stressors in step 3 resulted in the effect of sexual identity on depression being no longer significant ( $\beta$ : $0.01 ; p>0.05)$. Positive significant effects were found for the effect of external general life stressors on depressive outcomes. Controlled for demographic background and sexual identity, more general stressors are associated with more depressive outcomes (Bgeneralstr: 0.28; $p<0.001$ ). Experiencing more discrimination at work was also significantly related to reporting more depressive symptoms ( $\beta$ minstr: 0.18; $\mathrm{p}<0.001$ ). In step 4 internal minority stressors were added to the model. We observed a significantly positive association between both internal stressors and depressive symptoms, confirming the last two hypotheses. Respondents who felt stigmatized scored significantly higher on depressive symptoms ( $\beta$ stigma: 0.19; $p<0.001$ ), as did respondents who experienced more internalized homonegativity ( $\beta$ homoneg: 0.20; $p<0.001$ ). Finally, we introduced an interaction effect in our model to test the hypothesis that the interaction of sex and sexual identity on depressive outcomes. The interactional term between sex and sexual identity indicates a difference in the impact of sexual identity on depressive outcomes for women versus 
men $(\beta:-0.05 ; p<0.01)$. For women, bisexuality is significantly related to depressive outcomes $(\beta:-0.11, p<0.01)$. This effect is not found in men.

Table 2.4 Multivariate Statistics: stepwise hierarchical linear regression

\begin{tabular}{|c|c|c|c|c|c|}
\hline & \multicolumn{5}{|l|}{ Step } \\
\hline & 1 Beta & 2 Beta & 3 Beta & 4 Beta & $5^{a}$ Beta \\
\hline Sex (female) & 0.02 & 0.01 & -0.00 & 0.02 & 0.02 \\
\hline Age & $-0.07 * *$ & $-0.07 *$ & $-0.07 * *$ & $-0.05 * *$ & $-0.05^{* *}$ \\
\hline Education & $-0.11 * * *$ & $-0.11 * * *$ & $-0.06 * *$ & $-0.08 * * *$ & $-0.08 * * *$ \\
\hline Sexual identity & & $-0.05^{*}$ & $-0.05^{*}$ & 0.01 & -0.02 \\
\hline General stressors & & & $0.28 * * *$ & $0.25^{* * *}$ & $0.25 * * *$ \\
\hline Minority stressors & & & $0.18^{* * *}$ & $0.11 * * *$ & $0.11 * * *$ \\
\hline Stigma consciousness & & & & $0.19 * * *$ & $0.21 * * *$ \\
\hline Internalized homonegativity & & & & $0.20 * * *$ & $0.20 * * *$ \\
\hline Sex $\times$ Sexual identity & & & & & $-0.05^{* *}$ \\
\hline Adjusted $\mathrm{R}^{2}$ & 0.02 & 0.02 & 0.14 & 0.23 & 0.23 \\
\hline $\mathbf{R}^{2}$ change & $0.07 * * *$ & $0.00 *$ & $0.12 * * *$ & $0.09 * * *$ & $0.00 * *$ \\
\hline
\end{tabular}

Dependent variable: CES-D depressive outcomes (Squared - transformation). Significance $*_{p}<0.05$. $* * p<$ $0.01 . * * p<0.001$. SEX male=0, female=1, AGE (range 15 to 84), EDUCATION Highest educational degree (No college or university degree $=0$, College or university degree $=1$ ), SEXID Almost exclusively heterosexual=0 to exclusively homosexual=1), GENERAL STR Low scores = little experience of general stressors. MINORITY STR Low scores = little experience of external minority stressors, STIGMA Stigma consciousness (low scores = low degree of stigma consciousness), IH Low scores = low degree of internalized homonegativity, DEPRESSIVE SYMPTOMS: low scores = lower indication of depression. The displayed coefficients are standardized beta weights at each step. a This is a separate analysis with standardized interaction variable sexual identity. A Separate analysis with standardized interaction term of Sex and Sexual identity

\section{Discussion}

This study found further evidence for individual and social determinants of depressive symptoms conceptualized within a adapted version of the minority stress model among a Flemish LGB population.

In the general population, women, youth and those lower educated score higher on depressive outcomes. In this study, no significant differences between men and women regarding depressive outcomes were found. It is possible that LGB men and women, indeed, have similar levels of depression, and that the explanation for the lack of sex differences can be found in biological factors related to mental health risks and sexual orientation as has been suggested [102;103]. We did find that that younger LGB's suffer more from depressive outcomes than older LGB's. LGB youth particular seem to be at increased risk of mental health problems [60]. The last background variable considered was educational level. In our study, education as a measure of socioeconomic status 
has a strong impact on depression; this is fully in line with past research, which has repeatedly confirmed the strong relationship between socioeconomic position and psychological distress [71;72].

Associations of mental health with sexual identity were also investigated. Bisexuality was significantly related to poorer mental health in women, but not in men. This is another indication of sex differences with regard to sexual identification. Men and women deal with sexuality in distinct ways and also cope with stress differently. However, the effect is small and significance could also be the result of a type-1 error. When conducting separate analyses for the effect of the interaction of sex and age on sexual identity, we see that the impact of identifying as bisexual on depressive outcomes is greatest for middle-aged women. Further exploration of this finding is needed. Looking at the experience of general and minority stress, our hypotheses, which focus on the impact of stressful experiences and minority stressors on mental health outcomes, were confirmed. Although experiences of general and minority-related life events and daily hassles both result in higher levels of depression, general stress experiences (poor health, unemployment, the end of a relationship, etc.) causes a significantly higher depression level.

Respondents who feel stigmatized score significantly higher on depressive symptoms. LGB's who are more conscious of the stigma on their minority groups will anticipate this stigma more, which can cause a great deal of stress and result into higher degrees of depression. Also, LGB's that have internalized the negative attitudes towards homosexuality score significantly higher on the depression scale. Previous research showed that both stigma consciousness and internalized homonegativity have a negative impact on mental health [90;92;97;98;104;105]. These findings about external and internal LGB minority stressors may reflect the values and norms in Flemish society. During the last decade, much has changed for LGB's in Flanders. Belgium, together with the Netherlands and Spain, is at the forefront of European countries where LGB rights are recognized. Belgian antidiscrimination legislation was adapted to include discrimination on the basis of sexual orientation. Legal action can now be taken against those engaging in overt discrimination of LGB's for example, at work. This may reduce overt expression of discrimination. Although a majority in Flemish population tends to be accepting of homosexuality, one could argue that Flemish society is still characterized by heteronormativity and aversive prejudice [106]. This means that there is still a difference between what people say and how they act when it comes to discrimination. Individuals may have a positive attitude toward homosexuality, but tend to behave in a stereotypically heteronormative manner [6]. Internal stressors are much more difficult to control because they are based on subtle processes inherent to the socialization process of an individual. Internal minority stressors remain very important sources of stress. As long as societies are heteronormative, stressors such as internalized homonegativity and stigma consciousness will remain significant predictors of stress outcomes, including depression. The results of this study should be interpreted in light of 
the following limitations and strengths. The Zzzip survey is cross-sectional data, which makes longitudinal or life course research impossible. Furthermore, due to an already lengthy questionnaire, we had to limit our model, which meant that we were not able to include all variables concerned. Next, we only focused on depressive symptoms as a stress outcome. In a possible future Zzzip survey, not only internalized stress outcomes-such as depression, feelings of loneliness and self-esteem - but also externalized stress outcomes like deviant behavior (at school, towards alcohol, criminality, etc.) will be included. Additionally, although general and minority stressors were compared, different life areas were covered. General external stressors consisted of events that happened in the domains of work, health, and relationships, whereas the minority stressor variable was limited to discrimination at work. To get a more detailed view of the effect of external general and minority stressors, more complete scales should be used, for example, the life event scale of Tennant and Andrews [107] for general stressors, and an updated version of SCALES of Rosser and Ross [91] for minority daily hassles and life events. This study also offers a number of strengths. First of all, Zzzip is a large and diverse sample. The sample contains 2,280 respondents, reflecting the diversity of LGB populations. Secondly, our model highlighted specific impact of background variables in the social stress model, an impact that is taken for granted in most research. Finally, our study focused on both general and minority stress, with an emphasis on the importance of minority stress, an issue that has been largely ignored in much LGB-specific research. 



\section{CHAPTER 3}

\section{Minority specific determinants of mental well-being among lesbian, gay and bisexual youth}

This chapter is co-authored by Nele Cox, Alexis Dewaele and John Vincke and has been published in the Journal of Applied Social Psychology, 2010; 40(1):153-166, under the same title 8

\footnotetext{
${ }^{8}$ Reference: Vanden Berghe W, Cox N, Dewaele A, Vincke J; Minority specific determinants of mental wellbeing among Lesbian, Gay and Bisexual youth; the Journal of Applied Social Psychology, 2010; 40(1):153-166
} 

Within most parts of the Western world the societal situation of lesbian, gay, or bisexual (LGB) men and women has evolved favorably. Gay and lesbian rights have been extended, and in some countries include the right to marriage and adoption. In other countries, registered partnership and antidiscrimination measures have been taken. This does not mean, however, that individual LGB's no longer experience problems due to generalized heteronormativity and to negative reactions in their work, family or school environment. In particular, the younger generations, from 16 to 26 years old, are particularly at risk of major depression, generalized anxiety disorder, conduct disorder, nicotine dependence, multiple disorders, suicidal ideation, and suicide attempts [83]. These generations are maturing in a social environment that is rapidly changing, certainly with regard to LGB issues. Further, notwithstanding progressive social developments, youth research points out that depressive symptoms and suicidal behavior among LGB youth are frequent problems [108]. The study in this chapter will look at how the experience of LGB-specific minority stress affects the mental well-being of LGB youth. It will also look at what roles positive confidant support and negative social interactions play in this process.

\section{LGB Youth: A Population at Risk of Mental Health Problems}

Generally, adolescence and early adulthood can be very stressful due to the numerous life transitions that take place during these phases of the life cycle. The situation for LGB youth is even more problematic because of surplus stress they experience as a result of being part of a sexual minority $[109 ; 110]$. Consequently, LGB youth are at increased risk of mental health problems [111-113].

The concept of minority stress, in this case LGB-specific minority stress, refers to the determinants of these mental health outcomes. LGB-specific minority stress was first conceptualized as a result of a "marginal" minority status. LGB-specific minority stress differs from other kinds of minority stress because of the potentially hidden character of sexual identity [114]. More recent research conceptualizes the broader term minority stress as the excess stress individuals from stigmatized minority groups experience as a result of being part of that group. This excess stress is brought about through minority-specific determinants or stressors. Concerning sexual minorities, the following types of stressors have been noted: (a) external, objective stressful events and conditions, e.g., discrimination at work; (b) expectations of such stressful events; and (c) the internalization of negative societal attitudes regarding sexual minorities, as well as the perceived need to conceal one's sexual orientation. These different types of LGB-specific minority stress cause negative mental health outcomes [88].

The present study focuses on two kinds of internal minority stress. The first dimension we consider is stigma consciousness [96]. This refers to the sensitivity LGB's have, regarding the collective disapproval of personal characteristics or beliefs that are against cultural norms, in this case being LGB. Stigma consciousness affects the expec- 
tation of stressful events and the awareness of being stigmatized. Gay men appear to experience higher levels of stigma consciousness than lesbians. Gay stigma also has a negative effect on positive self-perceptions because of its negative impact on group identity, and is directly associated with lower self-esteem, lesser well-being, and higher psychological distress [115]. The second internal stressor we focus on is internalized homonegativity. This can be defined as internalized negative attitudes that LGB individuals possess about their own sexuality, reflecting societal views concerning LGB's [100]. Internalized homonegativity has been perceived as a major risk factor in dealing with LGB youths' mental health issues [116]. This study investigates how stigma consciousness and internalized homonegativity impact mental health in a LGB youth population.

\section{LGB-specific Confidant Support Within a LGB Youth Population}

Social support has a key negative effect on depression $[48 ; 49 ; 55 ; 57]$. Young adults who perceive low levels of social support tend to report significantly more depressive symptoms than those with higher levels of social support $[117 ; 118]$. One specific variant of social support is confidant support.

Confidant support refers to the availability of persons to whom one can turn to talk about personal problems. Generally, one could say that it is the support one receives from significant others. For example, Goldfried and Goldfried [119] underlined the importance of parental support in the lives of LGB individuals. Partners, friends, and other family members can also function as "confidants." A number of studies targeting lesbian and gay young adults have also shown the importance of higher levels of LGBspecific confidant support and the extent to which it is associated with lower levels of depression and hopelessness, and raised self-esteem [58;108].

Building on the concept of LGB-specific confidant support, it is clear that not only the quantitative aspect of support is important but also the more qualitative aspects. The latter dimension is clearly demonstrated in the concept of unsupportive social interactions [61]. Social support research has mostly focused on its beneficial effects, whereas the negative influences of support have been neglected. Studies have shown that unsupportive social interactions account for a significant amount of the variance in psychological and physical symptoms, controlling for the variance explained by stress and social support among college students [61]. These studies indicate that unsupportive social interactions concerning specific life events can lead to frustration, anger, and disappointment, thereby lowering self-esteem and producing negative attitudes toward others.

\section{Research Questions}

In this study, we consider the effects of stigma consciousness and internalized homonegativity on the mental well-being of LGB youth. We expect that higher levels of 
LGB stigma consciousness and internalized homonegativity will be associated with lower levels of mental well-being. In addition to these internal stressors, we focus on confidant support and unsupportive social interactions. On the basis of the general literature, we expect to find that both will have a main effect. We expect that having confidants will result in less depression, and that experiencing unsupportive interactions will lead to higher depression.

\section{Method}

\section{Data Collection: The ZZZIP Survey}

With all of the major social and political changes over the last few years, the Flemish government wanted more insight into the lives of LGB's in Flanders (the northern, Dutch-speaking part of the federate state of Belgium). The department of sociology at the University of Ghent took on this assignment and in the autumn of 2004 administered the ZZZIP survey. Because of the hidden character of the target population, a combination of an online survey and a standard postal survey was the best methodological choice. The online survey portion was integrated into a specific Internet site (www.Zzzip.be), and an accompanying recruitment campaign was developed. It was important that the social marketing that founded this campaign was directed toward people with same-sex orientation, behavior, or identity, but was not exclusively connected to the label of LGB. It was imperative for us to recruit not only those individuals who identified themselves as being LGB, but also anyone who experienced same-sex attraction. The latter group is sometimes neglected within research because they are harder to reach and even less visible than LGB's. We had a greater chance of reaching them through online surveys because of the anonymous character of the Internet. The website was online for three months and when the online survey concluded, 10,558 respondents had started the questionnaire, of which 5,091 were not exclusively heterosexual. Of the latter group, 2,741 filled it in completely. Of the 500 paper versions that were sent out, 180 were returned. The average completion time online was 45 minutes. The present study uses the ZZZIP data.

\section{Participants}

In total, 2,921 LGB's, including those who did not identify themselves as such, participated in the ZZZIP study. However, the present research is based on 820 LGB individuals under 26 years old who participated in the survey, of whom 504 (61\%) were male and 316 (39\%) were female. The mean age was 21.5 years old. We used the Kinsey ([5]scale to have respondents define their own sexuality. This is a 7-point Likert scale with answers ranging from exclusively heterosexual to exclusively homosexual. No re- 
spondents were exclusively heterosexual; $3 \%$ saw themselves as predominantly but not exclusively heterosexual, $7 \%$ as bisexual, $34 \%$ as predominantly but not exclusively homosexual, and $56 \%$ as exclusively homosexual. Concerning education, $64 \%$ had a college or university degree, $30 \%$ had a high school diploma, and $6 \%$ had a lower degree.

\section{Measures}

\section{Independent}

Stigma consciousness. To identify the extent to which respondents expected to be stigmatized by others, we used the stigma consciousness questionnaire for gay men and lesbian women (SCQ; [96]). Cronbach's alpha was 0.76. (range 0-60, 10 items)

Internalized homonegativity. To measure internalized homophobia, we used the internalized homonegativity inventory (IHNI) for gay men [100]. In this particular scale, the term homophobia has been replaced by homonegativity, relieving the whole concept of its psychiatric context. We adapted the scale to relieve the contents of its male perspective and again curtailed the measure to 11 items in view of our lengthy questionnaire and the context of a LGB youth population. Cronbach's alpha was 0.80. (range 0-44, 11 items)

LGB-specific confidant support. To measure LGB-specific confidant support, we used a 4-item scale. The respondents could indicate whether there is (a) somebody with whom they could talk when they felt excited, worried, nervous, or depressed; (b) somebody they could turn to when they needed advice; (c) somebody they could trust to talk to about themselves; or (d) someone they could turn to when they had an important personal problem. We clearly stated in the introduction of the scale that the support that was measured concerned LGB-specific issues. For this scale, Cronbach's alpha was 0.97. (range 0-16, 4 items)

The LGB-specific unsupportive social interactions inventory. We measured unsupportive social interactions concerning specific LGB problems. We used 12 items from the unsupportive social reactions inventory (USII; [61]). We had to decrease the number of items in the original scale because of the already lengthy questionnaire, and chose those items that could easily fit within a LGB youth context. Cronbach's alpha was 0.88. (range 0-36, 12 items)

\section{Dependent}

We defined mental well-being as the level of self-reported depression. The Center of Epidemiologic Studies Depression (CES-D) scale consists of 20 items, and its strength lies in its nonclinical nature. The respondent is asked to score how frequently he or she felt a certain way during the past week on a 4-point scale [99]. As in most research using the CES-D, the internal consistency of this scale was very high, with a Cronbach's alpha value of 0.94 . (range $0-60,20$ items) 


\section{Procedures}

\section{Comparing Means}

In order to compare mean scale values of depressive symptoms, internalized homonegativity, LGB-specific unsupportive social interactions, LGB-specific confidant support, and stigma consciousness on the basis of sex (male or female), age (younger than 21 or 21 years old or older; we used 21 as a threshold age because most people at that age are transitioning from study to work, from living with parents to living on their own), and education (with or without a college or university degree), we used independent sample $t$ tests.

\section{Bivariate Analysis}

To explore the possible associations between the different variables included in the model, we calculated Pearson's correlations.

\section{Multivariate Analysis}

We performed a hierarchical linear regression to examine possible one-way, linear effects of internalized homonegativity, stigma consciousness, LGB-specific confidant support, and LGB-specific unsupportive social interactions on the dependent variabledepressive outcomes-while controlling for the other independent variables.

\section{Results}

\section{Mean Differences}

The $t$ tests indicated mean differences on some of the scales to be included in the analysis, on the basis of sex, age, and education. Table 3.1 shows all mean scores differentiated on the basis of sex (male or female), age (under 21 years old or between 21 and 26 years old), and education (with or without a college or university degree).

All of the following findings are significant on the 0.01 level. Women $(18,00)$ scored higher on the depression scale $(t=-3.182)$ than men (15.17). Respondents younger than 21 years old indicated experiencing more feelings of depression (19.04; $t=-4.974)$, more unsupportive behavior $(9.81 ; t=-2.678)$ from others, and less LGB-specific confidant support $(13.04 ; t=2.66)$ than respondents 21 years old or older did. Respondents with no college or university degree scored higher levels of depressive symptoms (17.17; $t=-3.527$ ) and LGB-specific unsupportive social interactions (9.45; $t=-2.968)$, and less LGB-specific confidant support (13.68; $t=2.644)$, than those with a degree did. 
Table 3.1 Mean Scores and Mean Differences (t tests)

\begin{tabular}{|c|c|c|c|c|c|c|c|c|}
\hline & \multirow[b]{2}{*}{ Mean } & \multirow[b]{2}{*}{ SD } & \multicolumn{2}{|l|}{ Sex } & \multicolumn{2}{|l|}{ Age } & \multicolumn{2}{|l|}{ Education } \\
\hline & & & $\mathbf{M}$ & $\mathbf{F}$ & $<21$ & $\geq 21$ & $\begin{array}{l}\text { No coll./ } \\
\text { univ. degr. }\end{array}$ & $\begin{array}{l}\text { Coll./ } \\
\text { univ. degr. }\end{array}$ \\
\hline Depressive symptoms & 16.58 & 12.71 & $15.17^{*}$ & $18.00 *$ & $19.04 *$ & $14.62 *$ & $17.17^{*}$ & $13.71^{*}$ \\
\hline $\begin{array}{l}\text { Internalized } \\
\text { homonegativity }\end{array}$ & 12.37 & 7.61 & 12.22 & 11.92 & 12.53 & 11.85 & 11.85 & 12.62 \\
\hline $\begin{array}{l}\text { Unsupportive social } \\
\text { interactions }\end{array}$ & 9.14 & 6.13 & 8.83 & 9.45 & $9.81^{*}$ & $8.62 *$ & $9.45^{*}$ & $8.01 *$ \\
\hline Confidant support & 13.61 & 4.04 & 13.86 & 13.85 & $13.04^{*}$ & $14.13^{*}$ & $13.68 *$ & $14.46^{*}$ \\
\hline Stigma consciousness & 26.61 & 9.17 & 27.26 & 25.96 & 27.06 & 26.58 & 26.80 & 26.58 \\
\hline
\end{tabular}

* significant $(p<0.001)$ difference in mean score.

\section{Bivariate Analysis}

The bivariate analysis showed significant $(p<0.01)$ correlations between all LGB-specific stressors and depressive symptoms (see Table 3.2). The results were as expected. Higher levels of depressive symptoms were associated with higher levels of internalized homonegativity, stigma consciousness, and LGB-specific unsupportive social interactions, on the one hand, and with lower levels of LGB-specific confidant support, on the other hand.

Table 3.2 Bivariate Correlations

\begin{tabular}{llllll}
\hline Variables & $\mathbf{1}$ & $\mathbf{2}$ & $\mathbf{3}$ & $\mathbf{4}$ & $\mathbf{5}$ \\
\hline 1. Internalized homonegativity & - & $0.34^{*}$ & $0.18^{*}$ & $-0.31^{*}$ & $0.31^{*}$ \\
2. Stigma consciousness & - & $0.28^{*}$ & $-0.21^{*}$ & $0.31^{*}$ \\
3. Unsupportive social interactions & & - & $-0.30^{*}$ & $0.40^{*}$ \\
4. Confidant support & & & - & $-0.27^{*}$ \\
5. Depressive symptoms & & & & - \\
\hline
\end{tabular}

$* p<0.001$.

\section{Hierarchical Regression Analysis}

The theoretically assumed causal relations in our model were tested through hierarchical regression analysis [55]. The different steps in the analysis are needed to evaluate the effect of the internal minority stressors on depressive symptoms and to see how both social support concepts come into play as one cluster, Apart from the independent variables-internalized homonegativity, stigma consciousness, LGB-specific unsupportive social interactions, and LGB-specific confidant support-and the dependent variable-depressive symptoms-we included demographic variables of age and sex in the model. Education was left out here to simplify the model (table 3.3). A log 
transformation was performed on the dependent depression variable prior to the analysis to avoid problems caused by the distribution of the variable concerned (before transformation, skewness: 0.7; kurtosis: -0.2). Age and sex were added in step 1 and were therefore controlled for during the rest of the analysis but will not be discussed further. Our theoretical model determined that in step 2 the LGB-specific internal stressors cluster should be added. Stigma consciousness and internalized homonegativity both had independant significant effects of more or less equal size. (Beta: 0.25 and 0.23 , respectively; $p<0.001$ ). Thus, if respondents experienced more internalized homonegativity or stigma consciousness, they reported more depressive symptoms.

Adding LGB-specific confidant support and LGB-specific unsupportive social interactions to the model (step 3), we observed a significantly negative association between LGB-specific confidant support and depressive symptoms. Further, we perceived that the concept of LGB-specific unsupportive social interactions had a strong positive significant effect on depressive symptoms. Within the social support cluster, the effect of LGB-specific unsupportive social interactions on depressive symptoms was significantly larger (Beta: 0.25) than the effect of LGB-specific confidant support (Beta: -0.08). This means that having someone to interact with concerning LGB-related topics indeed has a lowering influence on depression rates, but the nature of those interactions, in this case unsupportive interaction, tends to be even more important. In other words, within this explanatory model, higher levels of LGB-specific unsupportive social interactions form the greatest cause for higher levels of depressive symptoms among LGB youth.

As shown in table 3.3, all independent variables accounted for a total of $29 \%$ of the variance in LGB youths' depressive symptoms, controlled for age and sex.

Table 3.3 Stepwise Hierarchical Regression with CES-Depression Scale as Dependent Variable

\begin{tabular}{lllllll}
\hline & Step 1 & & Step 2 & \multicolumn{2}{c}{ Step 3 } \\
\cline { 2 - 7 } & B & B & B & B & B & B \\
\hline Age & -0.1 & $-0.19^{*}$ & -0.01 & $-0.17^{*}$ & -0.01 & $-0.14^{*}$ \\
Sex: female & 0.03 & $0.10^{*}$ & 0.04 & $0.12^{*}$ & 0.03 & $0.11^{*}$ \\
Internalized homonegativity & & & 0.01 & $0.23^{*}$ & 0.00 & $0.19^{*}$ \\
Stigma consciousness & & & 0.00 & $0.25^{*}$ & 0.00 & $0.18^{*}$ \\
Confidant support & & & & -0.00 & $-0.08^{*}$ \\
Unsupportive social interactions & & & & & 0.01 & $0.25^{*}$ \\
$\mathbf{R}^{2}$ (increase) & 0.07 & & 0.22 & $\left(0.15^{*}\right)$ & 0.29 & $\left(0.07^{*}\right)$ \\
\hline
\end{tabular}

$* p<0.001$. 


\section{Discussion}

The study in this chapter centered on LGB-specific determinants of mental well-being among LGB youth and the relative nature of the concept of support for the target group in dealing with these LGB-specific stressors. The present research was conducted on the basis of a subsample of LGB youth younger than 26 years old from the ZZZIP database, a government-funded study into the lives of gay males, lesbians, and bisexuals in Flanders. The results add to further evidence validating the minority stress approach in explaining health disparities among sexual minority populations.

The $t$ tests showed significant mean differences in depressive symptoms between men and women, between respondents less than 21 years old and 21 years or older, and between respondents with and without a college or university degree. Women, respondents 21 years old or older, and respondents without a college or university degree indicated a higher degree of depressive symptoms. Significant mean differences on the basis of age and highest attained degree were also found for LGB-specific unsupportive social interactions and LGB-specific confidant support. The respondents who were younger than 21 years old and without a college or university degree experienced significantly more LGB-specific unsupportive social interactions and less LGB-specific confidant support. Bivariate analysis made apparent significant correlations between all LGB-specific stressors and depressive symptoms and confirmed the main effect hypotheses.

Next a hierarchical regression analysis was performed, controlling for age and sex. When predicting depressive symptoms, we found the highest beta was for LGB-specific unsupportive social interactions, with higher levels of LGB-specific unsupportive social reactions being associated with higher levels of depressive symptoms. Significant effects were also found for internalized homonegativity, stigma consciousness, and LGBspecific confidant support, with higher levels of internalized homonegativity and stigma consciousness and lower levels of LGB-specific confidant support being associated with an increased indication of depressive symptoms. A lot of time and information was required of the respondents since the ZZZIP database would eventually be used to support equal opportunity policy. Consequently, we had to shorten several of the scales and drop some questions to avoid respondent drop out. We should also stress that the data was mainly collected by means of the Internet. Shortcomings that result from using this kind of method are apparent, extreme self-selection and underrepresentation of older age groups to name two major examples [120]. However, in order to maximize diversity within this large sample of LGB's, we adapted several other kinds of data collection strategies like on site promotion of the website at LGB venues and sending out paper versions of the questionnaire. The differences in mean score in the selfreport of depressive symptoms on the basis of sex, age, and education are typical within mental health studies [101], although this LGB population had much higher average scores than heterosexual groups in similar research [121]. Of the LGB respondents, 
$36.8 \%$ scored above the clinical cutoff point of 16 , constituting a risk for clinical depression, and $22.9 \%$ above the cutoff of 23 , constituting a high risk for depression. These findings contribute to the ongoing concern about mental health problems among LGB youth. Further, stigma consciousness, or being conscious of the stigma attached to being part of LGB minorities, and internalized homonegativity, the internalization of societal negative attitudes toward LGB's, are substantial predictors of depressive outcomes and should be studied more closely in terms of future prevention and information campaigns. Further, we found evidence in the significant effect of confidant support that having someone to talk to and/or rely upon seems to be pivotal in shielding a LGB youth from stressful experiences. We also broadened the concept of confidant support by adding LGB-specific unsupportive social interactions to supportive social interactions, viewing these as two dimensions of the support structure. It should be stressed that it is not only the support of confidants that is of major significance in dealing with the mental well-being of LGB youth, but also the nature of those supportive interactions, in which case the direct effect of LGB-specific unsupportive interactions is even more important. Unsupportive social interactions seem to be an important hindrance in the lives of LGB youth; experiencing distancing, minimizing, and bumbling on the part of others, and blaming others' reactions for the problems they have can heavily impact LGB's' mental well-being. It is clear, therefore, that the concept of unsupportive interactions has its rightful place within minority stress models. On the whole, it seems that a more positive social climate toward LGB's in general is not enough to help young LGB's with their mental struggles on an individual level. LGB's will always be a minority and mental health issues will remain a part of that minority status, especially for LGB youth. Further, growing social acceptance of LGB's could lead to minimizing the personal issues LGB youth continue to have to deal with. In the future, our research model should be expanded by adding objective external minority stressors for example the experience of discrimination on the basis of sexual orientation. Further, it is important that policy and research focus not only on the mere presence of social support but also take into account possible social interactions that are unsupportive. 



\section{CHAPTER 4}

\section{Syndemic and other risk factors for} unprotected anal intercourse among an online sample of Belgian HIV negative men who have sex with men

This chapter is co-authored by Christiana Nöstlinger and Marie Laga and has been published in AIDS and Behavior, 2013; DOI: 10.1007/s10461-013-0516-y under the same title. $^{9}$

\footnotetext{
${ }^{9}$ Reference: Vanden Berghe W, Nöstlinger C, Laga M; Syndemic and other risk factors for unprotected anal intercourse among an online sample of Belgian HIV negative Men who have Sex with Men; AIDS and Behavior, 2013; DOI: 10.1007/s10461-013-0516-y
} 

Gay, bisexual, and other men who have sex with men (MSM) continue to be disproportionately affected by HIV/AIDS. Belgium, as many Western European countries, is confronted with a rise in the number of registered diagnoses of new human immunodeficiency virus (HIV) infections in MSM [122]. Increased uptake of HIV testing cannot fully explain this phenomenon and several factors may contribute to increased rates of new HIV infections among MSM, including sexual risk taking [27;122-124] combined with a high prevalence of HIV infection in some networks of MSM [29]. Next to these former factors related to sexual behavior, MSM also face other health problems, such as a higher level of depressive feelings compared to their heterosexual counterparts $[125 ; 126]$. The different health problems MSM are facing have been conceptualised within syndemic theory [36], stipulating that synergistic interactions of two or more coexistent diseases result into excess disease burden [37;38]. Next to higher HIV prevalence and a higher reporting of depressive symptoms and other mental health problems, there is also evidence of substance dependence [28;39;127;128] and sexual compulsivity [23;45;129-132] often occurring simultaneously among MSM. These syndemic health outcomes have to be situated within a broader, ecological framework conceptualizing MSM as a sexual minority. Minority stress theory stipulates that MSM are confronted with a social and contextual climate leading to higher levels of internalized homophobia, perceived stigma, and prejudice (violence and/or discrimination) impacting their overall health [51;55]. For the Belgian context, causal relationships have been found between the determinants mentioned above and mental health [126].

Some studies have investigated the relationships between unprotected sex and elements of these syndemics, in particular depression, and this evidence has been inconsistent [42]. However, more recent studies have shown that feeling depressed is an important factor in explaining unprotected sex $[36 ; 44 ; 45]$. Yet, the dynamics of these relationships, in particular for the Belgian context, are not yet fully understood. For the present study unprotected sex is defined as unprotected anal penetrative intercourse (UAI). Risk factors for UAI among MSM are found at individual, interpersonal and sociocultural levels. At the individual level studies show that some MSM are high sexual sensation seekers [19-22] or are show more sexual compulsive behavior [23] and push their sexual boundaries further than others. Because of this specific personality profile, MSM who score high on sexual sensation seeking scales will perform riskier behavior and subsequently run a greater risk for HIV and STI infection than those with lower sensation seeking profiles [21;24]. A sexually risky behavioral pattern is also influenced by the individual risk perception attributed to specific sexual practices. In this case we can differentiate between insertive and receptive unprotected anal intercourse. A lower risk perception of either UAI practice is associated with more UAI [17;18]. Welldocumented theoretical risk perception models have been applied to explain the relationship between condom use and other related behaviors but depressive symptoms and other syndemic factors were rarely included. Using condoms is also dependent on the perceived peer norms regarding this preventive behavior as a potential indication 
of social pressure to comply with peers [15]. Recent studies have theorized that negative affect among MSM with depression may lead to negative cognitions and beliefs, interacting with perceived social norms and risk perception related to condom use $[46 ; 47]$. At the interpersonal level sexual behavioral patterns can be analysed. A major risk factor for HIV infection is having a higher number of male sex partners during a specific period. It is an indicator of the cumulative risk for HIV [26-29]. In the context of syndemics, sources of social support are important in moderating the consequences of stressors on mental and other health outcomes [48;51;126]. More support from friends, family and significant others has been shown to be associated with less depression [62]. Less is known about the effect of having an unsupportive partner on condom use and its potential interaction with depressive symptoms. At the socio-cultural level, important factors associated with sexual risk are the media through which or the venues where MSM meet their partners for sexual contact. Some research has shown that finding partners on the Internet is a predictor for sexual risk [30] and frequenting specific sex clubs or cruising areas has been associated with reporting more sex partners, more substance abuse and unprotected sex [31;32].

The study in this chapter aims to improve understanding of the multifactorial causes of sexually risky practices (defined as UAI) among HIV negative MSM having had anal sex with at least one casual partner in the last 6 months. We investigate the relationships between syndemic factors and risk factors at the individual, interpersonal and socio-cultural level for the practice of UAI, with a focus on depressive symptoms. Potential moderating effects will also be explored. A better insight into these complex relationships could usefully inform current HIV prevention strategies.

\section{Research questions}

For a sample of Belgian HIV negative MSM having had anal sex with at least one casual partner in the last 6 months the following questions have been investigated:

- What are the main effects of syndemic and other risk factors and what is the cumulative effect of all syndemic factors on unprotected anal intercourse? Which syndemic factors are associated?

- Do depressive symptoms moderate risk perception of UAI when explaining unprotected anal intercourse? Do depressive symptoms moderate perceived social norms of condom use when explaining unprotected anal intercourse?

- Does having less unsupportive social interactions from a sex partner moderate depressive symptoms when explaining unprotected anal intercourse? 


\section{Methods}

\section{Sample and recruitment}

The initial dataset consisted of 1768 respondents who were recruited online during the 2008 FAQ campaign. FAQ, short for Frequently Asked Questions, aimed at better understanding and monitoring the rise in HIV diagnoses and sexual risk behavior among MSM in Flanders. Dutch speaking MSM were motivated through an offline (posters in MSM venues) and online recruiting campaign (mailing lists, banners and news items on gay related internet sites) to fill in a questionnaire on www.faqit.be. It took the respondents on average 42 minutes to complete the survey. Those with inconsistent response patterns were filtered out. For this study, we used a subset of 591 HIV negative respondents, who had at least one episode of anal penetrative sex with a casual partner in the last 6 months.

\section{Measures}

\section{Background characteristics}

Respondents reported their age, highest level of education completed and current relationship status.

\section{Syndemic factors}

These factors are defined as synergistic health outcomes among MSM that often occur simultaneously:

Depressive symptoms - To measure self-reported depressive symptoms, the Center of Epidemiologic Studies Depression (CES-D) scale was used, consisting of 20 items. The CES-D scale is one of five scales most frequently used to measure self-reported depression in non-clinical populations [133]. Respondents were asked to score how frequently they felt a certain way during the past week on a four-point scale [99]. Cronbach's alpha was 0.97 (empirical range 0-60, 20 items). The CES-D variable was dichotomised according to whether respondents score above or below the cut-off point of 21 on the CES-D scale, with scores above indicating symptoms of acute depression [133;134].

Drug use - Drug use was measured by the item: "Which of the following drugs did you use just before or during sex during the last 6 months (Alcohol, Erection enhancers such as Viagra, Poppers, Cocaine, GHB/GBL, Speed, XTC)"? Cocaine, GHB/GBL, Speed, XTC were grouped under the term partydrugs referring to the types of drugs used frequently in the festive scene for MSM.[29]

Sexual sensation seeking - To assess a person's propensity to seek out novel or risky sexual stimulation 20 items from the Sexual Sensation Seeking scale were used.[19] Cronbach's alpha was 0.97 (range 0-80, 20 items). 


\section{Sexual behavior}

The respondents were asked to report their sexual activities during the last 6 months. Of relevance in the present study are the following questions on sexual behavior during the last six months: "How many casual male partners did you have?"; "How many times did you use a condom when a casual partner penetrated you?"; "How many times did your casual partner use a condom when penetrating you?"; "Where or how do you meet men if you want sex?".

\section{Risk perception regarding unprotected anal sex}

The respondents scored respectively both insertive and receptive unprotected anal sex on a five-point Likert scale from safe to dangerous.

\section{HIV test history and HIV status}

The respondents were asked when they were last tested for HIV and if tested to report on result of that HIV test.

\section{Social support}

To measure social support the Multidimensional Scale of Perceived Social Support [135] was used. The scale was chosen because it measures perceived support from family, friends, and a significant other, or perceived global support. The respondents could indicate on a seven-point Likert scale whether or not they agreed with items on social support. For this scale, Cronbach's alpha was 0.99 (range 0-36, 12 items).

\section{Unsupportive social interactions inventory.}

Taking into account other dimensions of social support, we can also measure unsupportive social interactions (USI). USI were measured using the 12 item unsupportive social reactions inventory [62]. Cronbach's alpha was 0.99 (range 0-36, 12 items).

\section{Perceived social norms regarding condom use}

Perceived social norms regarding condom use were measured by two different items: "Do you think your best friend would want you to use condoms when having anal sex?"; Do you think other men present at this venue would want you to use condoms? (five-point Likert scale, ranging from definitely not - definitely).

\section{Data analysis}

Data analysis was performed using IBM SPSS statistics version 20. The sample was divided in to two groups based on whether or not respondents had unprotected anal intercourse with a casual partner in the last 6 month. To compare differences in UAI with a casual partner for all risk factors, Chi-squares $\left(\chi^{2}\right)$ or Mann-Whitney-U tests were performed. We then examined the relationships between syndemic factors using Spearman's rho correlation. Univariate and multivariate logistic regression were used to test the explanatory model. Interactions were calculated on the basis of theoretical 
assumptions. These interaction terms were tested separately together with both main effects. In the table 4.3 only the result for the interaction term is mentioned. The significance level for all tests was set at $95 \%(p=0.05)$.

The Hosmer-Lemeshow test was calculated to test goodness of fit for the multivariate logistic regression model. This test assesses whether or not the observed event rates match expected event rates in the mentioned subgroups of the model population.

\section{Results}

\section{Sample description and bivariate analysis}

Table 4.1 presents the descriptive date for all MSM that had experienced one episode of anal penetrative sex with a casual partner during the last six months split up by UAI practice. Participants $(\mathrm{N}=591)$ reported a mean age of approximately 35 years (SD 11.11), $35.8 \%$ had completed some form of higher education and $43.5 \%$ had a steady partner. Of all respondents, $34 \%$ reported at least one episode of UAI with a casual partner. More men who performed UAI, had completed higher education compared to men who did not report UAI (35.4\% vs. $29.7 \%$; $p<0,001)$. No significant differences were found by UAI practice for age, relationship status and the number of partners, ever and during the last six months (table 4.1) 
Table 4.1 Descriptive statistics and bivariate analysis by UAI practice

\begin{tabular}{|c|c|c|c|c|c|c|c|}
\hline & \multirow{3}{*}{$\begin{array}{l}\text { All } \\
\text { respondents } \\
(\mathrm{N}=591) \\
100.00\end{array}$} & \multicolumn{6}{|c|}{$\begin{array}{l}\text { Unprotected anal intercourse with a casual partner in the } \\
\text { last } 6 \text { months }\end{array}$} \\
\hline & & Yes & $(\mathrm{N}=\mathbf{2 0 1})$ & No & $(\mathrm{N}=391)$ & Test statistic* & $\mathrm{P} * *$ \\
\hline & & $\mathbf{N}$ & 34.00 & $\mathbf{N}$ & 66.00 & & \\
\hline \multicolumn{8}{|l|}{ Background } \\
\hline Age & $34.83(11.11)$ & 200 & 35.42 & 388 & 34.31 & 1.284 & 0.1 \\
\hline Higher education (\%) & 35.80 & 92 & 46.00 & 116 & 29.70 & 15.15 & $<0.001$ \\
\hline Steady relationship (\%) & 43.50 & 77 & 38.30 & 179 & 45.80 & 3.02 & 0.082 \\
\hline \multicolumn{8}{|l|}{ Syndemic factors } \\
\hline Depressive symptoms (CES-D>21) (\%) & 29.30 & 72 & 36.00 & 99 & 25.40 & 7.12 & 0.008 \\
\hline Sexual sensation seeking (mean(sd)) & $47.26(11.74)$ & 200 & 50.89 & 391 & 45.28 & 1.443 & $<0.001$ \\
\hline \multicolumn{8}{|l|}{ Drug use } \\
\hline Alcohol (\%) & 31.90 & 69 & 34.50 & 125 & 32.00 & 0.365 & 0.546 \\
\hline Poppers (\%) & 23.10 & 50 & 25.00 & 90 & 22.90 & 1.368 & 0.242 \\
\hline Erectile enhancers (VIAGRA....) (\%) & 5.30 & 10 & 5.10 & 21 & 5.30 & 0.012 & 0.912 \\
\hline Partydrugs (Cocaine. GHB/GBL...)(\%) & 3.20 & 5 & 2.50 & 13 & 3.20 & 0.183 & 0.669 \\
\hline \multicolumn{8}{|l|}{ Number sex partners } \\
\hline Lifetime (median category) & 11 to 50 & 226 & 51 to 100 & 200 & 11 to 50 & 0.728 & 0.731 \\
\hline During the last 6 months (mean(sd)) & 9.70 & 226 & 10.54 & 358 & 9.23 & 1.258 & 0.302 \\
\hline \multicolumn{8}{|l|}{ Risk perception } \\
\hline Risk perception UAl receptive (mean(sd)) & $4.46(1.04)$ & 190 & 4.22 & 383 & 4.56 & 6.976 & $<0.000$ \\
\hline Risk perception UAI insertive (mean(sd)) & $4.27(1.19)$ & 190 & 4.06 & 379 & 4.37 & 4.318 & 0.001 \\
\hline \multicolumn{8}{|l|}{ Social support \& social norms condom use } \\
\hline Social support (mean(sd)) & $58.48(16.14)$ & 198 & 56.92 & 386 & 59.18 & 0.919 & 0.082 \\
\hline $\begin{array}{l}\text { Unsupportive social interactions - } \\
\text { Significant other (mean(sd)) }\end{array}$ & $20.07(9.36)$ & 188 & 22.02 & 374 & 19.05 & 1.454 & 0.001 \\
\hline $\begin{array}{l}\text { Perceived social norm condom use - } \\
\text { Sex clubs/Cruising areas (mean(sd)) }\end{array}$ & $3.67(1.1)$ & 188 & 3.28 & 374 & 3.91 & 11.926 & $<0.001$ \\
\hline $\begin{array}{l}\text { Perceived social norm condom use - } \\
\text { Peers (mean(sd)) }\end{array}$ & $4.58(0.72)$ & 176 & 4.34 & 364 & 4.72 & 12.374 & $<0.001$ \\
\hline \multicolumn{8}{|l|}{ Meeting sex partners } \\
\hline Internet (\%) & 81.90 & 173 & 85.90 & 311 & 79.50 & 3.919 & 0.048 \\
\hline Sex clubs/Cruising areas (\%) & 62.50 & 125 & 62.10 & 262 & 67.00 & 1.516 & 0.218 \\
\hline
\end{tabular}

*Test statistics: $U$ value for continuous variables, $\chi^{2}$ for categorical variables (Age, Education, Steady relationship, Depressive symptoms and drug use)

**p values: Mann-Whitney $U$ test for continuous variables and $\chi^{2}$ for categorical variables 


\section{Syndemic factors}

Of all respondents, $29.3 \%$ scored above the cut-off point of 21 on the CES-D indicating symptoms of more severe depression [134]. Comparing drug use and depressive symptoms by UAI practice, men who performed UAI reported significantly more symptoms of depression ( $36 \%$ vs. $25.4 \%$; $p<0.01$ ) than those who did not perform UAI. No significant differences for drug use were found. Overall, $31.9 \%$ of respondents reported using alcohol and $23.1 \%$ reported using poppers just before or during sexual contact. Men who performed UAl scored higher on the sexual sensation seeking scale than those who never performed UAI (Means (Ms): 50.8 vs. 45.2; $p<0.001$ )

Table 4.2 shows the bivariate associations by means of Spearman's Rho between the different syndemic factors: depressive symptoms, alcohol use, drug use (poppers, Erection enhancers, partydrugs) and sensation seeking. Depressive symptoms were significantly correlated with sexual sensation seeking (Spearman's Rho 0.19, p<0.01), alcohol use (Spearman's Rho 0.11, p<0.01), and also with the use of partydrugs (Spearman's Rho 0.09, $p<0.05)$. Sensation seeking was significantly correlated to all other factors. The use of alcohol and the different types of drugs are all significantly intercorrelated.

Table 4.2 Spearman's correlations of syndemic factors

\begin{tabular}{|c|c|c|c|c|c|c|}
\hline & 1 CES-D>21 & 2 Sex. Sens. & 3 Alcohol & 4 Poppers & 5 Erect. Enh. & 6 Partydrugs \\
\hline 1 & 1.00 & $.19 * *$ & $.11^{* *}$ & -0.02 & -0.05 & $.09 *$ \\
\hline$p$ & . & 0.00 & 0.01 & 0.65 & 0.23 & 0.03 \\
\hline 2 & & 1 & $.11^{* *}$ & $.16^{* *}$ & $.09 *$ & $.11^{*}$ \\
\hline$p$ & & . & 0.01 & 0.00 & 0.03 & 0.01 \\
\hline 3 & & & 1 & $.13^{* *}$ & $.08^{*}$ & $.13^{* *}$ \\
\hline$p$ & & & . & 0.00 & 0.04 & 0.00 \\
\hline 4 & & & & 1 & $.14^{* *}$ & $.18^{* *}$ \\
\hline p & & & & . & 0.00 & 0.00 \\
\hline 5 & & & & & 1 & $.21^{* *}$ \\
\hline p & & & & & . & 0.00 \\
\hline 6 & & & & & & 1 \\
\hline
\end{tabular}

** Correlation is significant at the 0.01 level (2-tailed).

* Correlation is significant at the 0.05 level (2-tailed).

\section{Other risk factors}

When comparing risk perception of UAI, men who performed UAI perceived less risk for both the practice of insertive (Ms: 4.06 vs. 4.37; $\mathrm{p}=0.001$ ) and receptive anal sex (Ms: 4.22 vs. $4.56 ; p<0.001)$. On the interpersonal level, men who performed UAI experienced more unsupportive social exchange with a partner (Ms: 22.02 vs. 19.05; $p<0.001$ ) than men did not have UAI. Men having UAI also perceived significantly fewer social 
norms conducive to condom use both when present at a sex club or cruising area (Ms: 4.34 vs. $4.72 ; p<0.001$ ) or among their peers (Ms: 4.34 vs. $4.72 ; p<0.001$ ). Men who practiced UAI met their sex partners more often through the Internet (Ms: $85.9 \%$ vs. 79.5\%; $p<0.05)$.

\section{Univariate and Multivariate logistic analysis}

Results of the univariate and multivariate logistic regression model predicting UAI practice are presented in table 4.3. Univariate analysis showed that a higher education $(\mathrm{OR}=2.05,95 \% \mathrm{Cl}$ 1.46-2.88; $\mathrm{p}<0.001$ ), more depressive symptoms (OR=1.66, $95 \% \mathrm{Cl}$ 1.16-2.37; $\mathrm{p}<0.01$ ), more sexual sensation seeking (scoring in the highest quartile, $\mathrm{OR}=1.04,95 \% \mathrm{Cl} 1.03-1.06 ; \mathrm{p}<0.001)$, and more unsupportive social interactions from a partner (OR=1.03, 95\% Cl:1.01-1.05; $\mathrm{p}<0.001)$, were associated with higher odds of UAI while perceiving less risk both for receptive $(O R=0.75,95 \% \mathrm{Cl} 0.64-0.88 ; p<0.001)$ and insertive anal sex $(\mathrm{OR}=0.84,95 \% \mathrm{Cl} 0.73-0.96 ; \mathrm{p}<0.01)$ and fewer social norms conducive to condom use both of peers $(\mathrm{OR}=0.45,95 \% \mathrm{Cl} 0.35-0.59 ; \mathrm{p}<0.001)$ and of men present at sex clubs or cruising areas (OR=0.56, 95\% Cl 0.47-0.66; $p<0.001)$, decreased the odds of UAI. A cumulative index for all syndemic factors was calculated demonstrating that scoring higher on depressive symptoms, sensation seeking and having used alcohol and all types of drugs increased the odds of UAl with 2,36. (OR=2.36, 95\% Cl 1.23-4.55; $\mathrm{p}<0.01)$. This index was not included in the final model.

In the multivariate model having a higher education $(\mathrm{OR}=1.65,95 \% \mathrm{Cl} 1.06-2.57$; $p<0.05)$, more sensation seeking $(O R=1.05,95 \% \mathrm{Cl} 1.03-1.07 ; p<0.001)$ and perceiving less social norms regarding condom use both for peers $(\mathrm{OR}=0.61,95 \% \mathrm{Cl} 0.5-0.76$; $\mathrm{p}<0.001)$ and of men present at sex clubs or cruising areas (OR=0.61, 95\% $\mathrm{Cl} 0.45-0.83$; $\mathrm{p}<0.001)$ remained significant main effects on having UAI. Based on theoretical assumptions interaction terms were tested for depressive symptoms and respectively risk perception of UAl both insertive and receptive, and unsupportive social interactions from a partner. Interacting effects were tested in separate models including both main effects and the interaction terms. None of the potential moderating effects were significant. 
Table 4.3 Univariate and Multivariate logistic regression with UAI as the dependent variable

\begin{tabular}{|c|c|c|c|c|c|c|c|c|}
\hline \multirow{3}{*}{$\begin{array}{l}\text { Background } \\
\text { Age }\end{array}$} & \multicolumn{4}{|c|}{ Univariate } & \multicolumn{4}{|c|}{ Multivariate } \\
\hline & \multirow{2}{*}{$\begin{array}{l}P \\
0.642\end{array}$} & \multirow{2}{*}{$\begin{array}{l}\text { OR } \\
0.91\end{array}$} & \multicolumn{2}{|c|}{$95 \% \mathrm{Cl}$} & \multirow{2}{*}{$\begin{array}{l}\mathbf{P} \\
0.903\end{array}$} & \multirow{2}{*}{$\begin{array}{l}\text { OR } \\
1.04\end{array}$} & \multicolumn{2}{|c|}{$95 \% \mathrm{Cl}$} \\
\hline & & & 0.60 & 1.37 & & & 0.59 & 1.83 \\
\hline Higher education & 0.000 & 2.05 & 1.46 & 2.88 & 0.027 & 1.65 & 1.06 & 2.57 \\
\hline \multicolumn{9}{|l|}{ Syndemic factors } \\
\hline Depressive symptoms (CES-D>21) & 0.006 & 1.66 & 1.16 & 2.37 & 0.806 & 0.94 & 0.58 & 1.54 \\
\hline Sexual sensation seeking & 0.000 & 1.04 & 1.03 & 1.06 & 0.000 & 1.05 & 1.03 & 1.07 \\
\hline Alcohol use & 0.742 & 1.06 & 0.75 & 1.51 & 0.350 & 0.80 & 0.50 & 1.28 \\
\hline Drug use (Erectile enhancers, Poppers, Partydrugs) & 0.778 & 1.14 & 0.46 & 2.83 & 0.767 & 0.84 & 0.27 & 2.66 \\
\hline Cumulative index of all syndemic factors & 0.010 & 2.36 & 1.23 & 4.55 & & & & \\
\hline \multicolumn{9}{|l|}{ Risk perception } \\
\hline UAI receptive & 0.000 & 0.75 & 0.64 & 0.88 & 0.058 & 0.75 & 0.55 & 1.01 \\
\hline UAl insertive & 0.013 & 0.84 & 0.73 & 0.96 & 0.122 & 1.02 & 1.00 & 1.04 \\
\hline \multicolumn{9}{|l|}{ Social support \& social norms condom use } \\
\hline Unsupportive social interactions - partner (USIP) & 0.001 & 1.03 & 1.01 & 1.05 & 0.335 & 1.15 & 0.87 & 1.51 \\
\hline $\begin{array}{l}\text { Perceived social norm condom use (PSN) - } \\
\text { Sex clubs/Cruising areas }\end{array}$ & 0.000 & 0.56 & 0.47 & 0.66 & 0.000 & 0.61 & 0.50 & 0.76 \\
\hline Perceived social norm condom use (PSN) - Peers & 0.000 & 0.45 & 0.35 & 0.59 & 0.002 & 0.61 & 0.45 & 0.83 \\
\hline \multicolumn{9}{|l|}{ Interaction terms } \\
\hline Depressive symptoms * Risk perception UAI receptive & & & & & 0.442 & 1.01 & 0.99 & 1.03 \\
\hline Depressive symptoms * Risk perception UAI insertive & & & & & 0.486 & 0.99 & 0.98 & 1.01 \\
\hline Depressive symptoms * USIP & & & & & 0.631 & 1.00 & 1.00 & 1.00 \\
\hline Depressive symptoms * PSN Sex clubs/Cruising areas & & & & & 0.761 & 1.00 & 0.98 & 1.02 \\
\hline Depressive symptoms * PSN Peers & & & & & 0.511 & 1.01 & 0.98 & 1.04 \\
\hline
\end{tabular}

\section{Discussion}

The study in this chapter investigated relationships between syndemic and other risk factors at the individual, interpersonal and socio-cultural level and UAI practice among a sample of HIV negative MSM who have had at least one episode of anal penetrative sex with casual partners in the last six months prior to the study.

The results of this study provides further evidence of syndemic theory and confirm the significant association between depressive symptoms and UAI practice among subgroups of men who have sex with men [36;45]. We found more depressive symptoms, and more sexual sensation seeking among men who performed UAI than those who did not. Although we did not find significant differences for the use of alcohol and other drugs by UAI practice, the different syndemic factors intercorrelated significantly with the use of partydrugs. This is in line with findings from other research $[36 ; 39 ; 44 ; 136]$. However, it must be stressed that direct associations between UAI and drug use have 
been found more often among HIV positive MSM than HIV negative men $[29 ; 31 ; 32 ; 137 ; 138]$. Further research is needed to understand the complexity and vicious circle of the associations among syndemic factors. The use of drugs or alcohol is potentially part of coping with minority and other stressors for MSM [139-141] and mental health is a main outcome of the minority stress model. On the other hand, some drugs like Erection enhancers and Poppers are used in the context of enhancing sexual pleasure and this is not always an indicator of substance dependency [142-144]. Further, the socio-cultural context also needs to be taken into account. Meeting other men through the Internet is established in this study as a predictor for UAI practice corroborating similar findings of other studies [30;145]. In addition, in our sample there was no difference for meeting in sex clubs or cruising areas by UAI practice. Other venue-based research found significantly more UAI especially in venues with a high HIV prevalence. In these contexts, HIV positive men visiting particular sex clubs reported less condom use, more serosorting and more factors connected to syndemics $[44 ; 138]$. Future qualitative research could provide more in depth information on how syndemic factors, coping strategies and socio-cultural factors interact.

The current study showed that a lower risk perception of UAI both insertively and receptively, is associated with more UAI and it has been reported earlier that this is especially the case for young MSM [146] Research on mental health has demonstrated that lesbian, gay, bisexual and transgender youth score higher on depressive symptoms and suicidal behavior compared to heterosexual youth [126;147] but we found no evidence that depressive symptoms moderates the effect of risk perception of UAI on UAI practice.

Research has demonstrated that minority stress related factors $[51 ; 126 ; 148 ; 149]$ have a negative effect on mental health outcomes, such as high rates of distress and depression, attempted suicide, experiences of discrimination, stigma and violence among different social and minority groups. Sources of social support moderate the effect of stressors such as stigma consciousness and internalized homonegativity on mental health outcomes among sexual minority populations [126]. Findings from the current study show that perceived social support is not associated with UAI practice. However, more unsupportive social interaction with a significant other is associated with depression [126] and in this study, with UAI practice, though no moderating effect of these unsupportive social interactions and depressive symptoms on UAI could be demonstrated. The role of the broader social support network seems to be important for mental health but having a supportive partner is instrumental for both improving mental health and deferring from UAI. Further, the influence of group related interaction is also made apparent by the great importance of perceived social norms of condom use by friends or peers, which also is in line with other research [148;150]. However, within the syndemic framework, no evidence was found for interacting effects of depressive symptoms with perceived social norms in explaining UAI practice. 
Some limitations can be noted for this study. The study was cross-sectional while the measures in this study have shown a higher validity within a longitudinal framework. Secondly, data were collected by means of the Internet. While this method bears advantages such as easy access to target groups and anonymity, its shortcomings are selfselection and underrepresentation of older age groups, or other groups who have no access to computers [151]. This has to be taken into account when interpreting the outcomes of analyses. A third limitation is temporal disparity in relation to the different items and scales that were used. For instance the CES-D items are based on feelings during the last week, while questions on sexual behavior referred to the last 6 months. Different recall times may be possibly confusing for respondents eventually leading to different levels of recall bias. A fourth limitation is the sole focus on anal penetrative intercourse though we did split up between receptive and insertive anal sex practice for the perception of risk. Finally, the list of drugs used in this study is not a reflection of all types of drugs used in real life so we may have missed important types.

In conclusion, our findings show that multifactorial, intertwined factors contribute to the explanation of UAI among MSM at risk for HIV infection. These findings underline the need for an integrated sexual health approach for MSM. As evidence for the presence of syndemics is accumulating there is a need to move towards a new holistic framework in the age of combination prevention, as others have also suggested [47;152]. These syndemics make the implementation of HIV/STI prevention strategies more complex. However, evidence has suggested that there is a potential for multiplebehavior interventions to have greater impact on public health than single-behavior interventions [153;154]. Addressing mental health, substance abuse and the higher propensity to take sexual risks in this population is pivotal in controlling the HIV epidemic. Further research on the different dynamics of these syndemics is needed alongside a tailored preventive approach for specific subgroups such as Young MSM [155], HIV positive men $[44 ; 128 ; 132 ; 156]$ and HIV negative men at greater risk for HIV/STI infection. In these different contexts a multilevel and temporal prevention approach also implies analysing and improving individual, interpersonal and socio-cultural risk factors and in the case of young MSM, in a syndemic life-course perspective. In addition, new preventive interventions for MSM need to be developed focussing on social norming regarding sexual risk behavior and condom use. These interventions should be functional at the level of the individual, the social network and the community. Further, in supporting MSM in developing positive coping strategies to deal with the psychosocial problems related to sexual risk behavior, researchers and service providers should aim at understanding the resilience among the same target group. Adopting a balanced, salutogenetic approach and investigating protective factors could help in formulating new preventive interventions. 



\section{CHAPTER 5}

\section{A venue-based HIV prevalence and behavioral study among men who have sex with men in Antwerp and Ghent, Flanders, Belgium, October 2009 to March 2010}

This chapter of co-authored by Christiana Nöstlinger, Anne Buvé, Greet Beelaert, Katrien Fransen and Marie Laga and has been published in Eurosurveillance, 2011;16(28), under the same title. ${ }^{10}$

\footnotetext{
${ }^{10}$ Reference: Vanden Berghe W, Nöstlinger C, Buvé A, Beelaert G, Fransen K, Laga M; A venue-based HIV prevalence and behavioral study among men who have sex with men in Antwerp and Ghent, Flanders, Belgium, October 2009 to March 2010; Eurosurveillance, 2011;16(28)
} 

In most western countries, the number of diagnoses of new human immunodeficiency virus (HIV) infections in men who have sex with men (MSM) continues to rise [157]. In France, for example, it has been estimated that each year an additional 1\% of MSM become infected with HIV - an increase described as detrimental to the collective health of future MSM communities [158]. In Belgium, 1,135 new HIV infections in the general population were reported in 2009 to the Belgian Federal Institute for Public Health [3], the highest number ever in a year. About $82 \%(n=244)$ of the new infections among men with Belgian nationality $(n=297)$ occurred in MSM. An analysis by age group revealed that younger MSM (aged 15-34 years) were disproportionally affected [159]. An increased uptake of HIV testing cannot fully explain this phenomenon [124] several factors may contribute to increased rates of new HIV infections among MSM, including sexual risk taking [160] combined with a high prevalence of HIV infection in some networks of MSM [161]. In Belgium, as in many western countries, trends in HIV incidence are derived from registered diagnoses of HIV. However, such data have their limitations (as there is no additional background information for up to a third of registered new cases of HIV infection [159]) and may not reflect the real scope of the epidemic. In addition to HIV incidence estimates, population-based HIV prevalence estimates are needed to assess the burden of disease in MSM and to make realistic projections for health-service needs and prevention planning. More data are also needed on different types of MSM settings, as they are important for targeting prevention efforts. The only HIV prevalence estimates for MSM in Belgium to date have relied on selfreported HIV status. In Flanders, 5.6\% ( $n=1,736)$ of MSM in 2007 self-reported as HIV positive; among French-speaking residents of Brussels, 9\% $(n=942)$ of MSM in 2006 reported being HIV infected [162;163]. However, data for both studies were mainly collected through a variety of MSM websites and therefore do not give representative prevalence estimates. For Wallonia, no data are available.

In order to address several gaps in data for Flanders, in 2008 the Flemish Ministry of Wellbeing, Public Health and Family commissioned a population-based study on the prevalence of HIV infection and behavior of MSM in Antwerp and Ghent, Flanders. This chapter reports on the results of the study carried out between October 2009 and March 2010.

\section{Methods}

\section{Study design and estimated sample size}

This study was carried out in the framework of 'Frequently Asked Questions' (FAQ), a series of behavioral and epidemiological research projects on HIV and other sexually transmitted infections (STIs) among MSM in Flanders [163]. The FAQ 2009 study design was a cross-sectional collection of blood samples and behavioral data, collected be- 
tween October 2009 and March 2010. We set out to use time-location sampling to recruit men present at various venues in Antwerp and Ghent where MSM meet. This method has been shown to be successful in targeting hard-to-reach populations such as MSM [164].

Three main types or strata of MSM venues were defined on the basis of the age of the men who visited the venue and whether sexual contact was possible in the venue. The first stratum (cruising venues) comprised venues where sexual contact on site was possible, such as gay saunas, 'cruising' bars and sex clubs. The second (regular gay clubs/venues) consisted of more general MSM venues such as gay dance clubs or gay bars, where it is not possible to have sexual contact on site. The third (young MSM venues) consisted of settings where younger MSM meet, such as events organised by the regional organisation for lesbian, gay, bisexual and transgender youth, where sexual contact on site is also not permitted.

An inventory of all MSM venues in the Flemish cities of Antwerp and Ghent was then compiled from information obtained from the Internet and from community advisers, giving a total of 23 venues (10 cruising venues, nine regular gay bars/venues and four young MSM venues). Before the randomisation process, two types of enumeration were performed. Type I enumeration determined whether the venues gathered from the formative research were in fact venues that MSM attend. Next, type II enumeration was carried out to determine the number of eligible persons who attend a venue on a particular day and at a particular time period. On the basis of the enumeration data, 12 venues MSM venues (five cruising venues, five regular gay bars/venues and two young MSM venues) were randomly selected, without replacement, out of the list of 23, using STATISTICA v10. However, only seven owners or venue organisers agreed to collaborate: three cruising venues, two regular gay clubs/venues and two young MSM venues. The sample size for each stratum was calculated assuming a hypothetical prevalence of HIV infection of $15 \%$ for MSM at cruising venues and $5 \%$ in those at venues in the other two strata, as found in other studies [164-166]. In order to obtain a precision of $2.5 \%$, it was estimated that a total of 684 MSM would be required: 292 from cruising venues, 196 from regular gay clubs/venues and 196 from young MSM venues.

For the data collection, 12 volunteers were recruited from organisations involved in the prevention of HIV infection and other STIs and from community-based gay organisations. They received a half-day training on data collection procedures and ethical issues, to ensure optimal quality of data collection.

The volunteers were present at the venues on a Wednesday, Friday, Saturday or Sunday. Standardised time segments were used: three segments of three hours per location. Within the study period, time segments and days were randomised for data collection using STATISTICA $v$ 10. A team consisting of a principal investigator and up to three volunteers (depending on the size of the venue) visited each selected venue. 


\section{Study population}

Respondents were recruited according to the following inclusion criteria: being male, aged 18 years or older and having had more than one same-sex sexual contact in the previous 12 months. Exclusion criteria were being physically or mentally unable to give informed consent and/or complete the questionnaire used to collect behavioral data (described below), having already participated in the study or showing signs (in speech and movement) of excessive drug or alcohol use.

\section{Procedures and data collection}

According to the principles of time-location sampling, the selection of MSM was random. The volunteers at the venue approached every other person entering or passing by the volunteers. The potential respondent was asked to participate: if they agreed, written informed consent was obtained. MSM who approached the volunteers were given some information on the research project and on HIV/STI prevention, but the volunteers explained that self-selection was not possible. During the training of the volunteers, the issue of selection bias had been discussed. Also, time-location sampling does limit selection bias, as there is multilevel randomisation. Respondents were asked to complete a self-administered paper questionnaire available in Dutch and French. The questions $(n=32)$ were designed to gather data on socio-demographic characteristics, sexual orientation, partnership status, sexual contact according to partnership status, number of partners, condom use and position during anal sexual contact, sexual geography (i.e. places MSM frequent or strategies used to find partners), testing behavior for HIV and other STIs, HIV status, history of other STIs and drug use. Questions on sexual activity were based on the United Nations General Assembly Special Session on HIV/AIDS (UNGASS) indicators [167]. The questions were pretested for clarity and feasibility among an MSM community test group during September 2009. Completing the questionnaire took the respondents about 10 minutes. A different volunteer then collected a blood sample onto filter paper by means of a finger prick. As this method avoids using venous blood, it is therefore much less invasive - an important issue in the context of venue-based studies to encourage participation. A similar sampling procedure was used successfully in Montreal, Canada, and Paris, France [165;168]. After each time segment of data collection, the samples and questionnaires were stored at the Institute of Tropical Medicine in Antwerp. All data were collected anonymously: a code linked a blood sample to the corresponding questionnaire. We checked for previous participation and the dataset was additionally checked for similarities in individual profiles (age and postal code) to exclude double entries. The volunteers emphasised to the respondents that the HIV tests that would be carried out would not be used for diagnostic purposes. Respondents were given leaflets containing information on HIV testing and testing locations and an incentive was provided (a drink would be offered at the test, worth about three euros). 


\section{Laboratory testing}

Blood samples were analysed at the AIDS Reference Laboratory of the Institute of Tropical Medicine, using Vironostika HIV Ag/Ab (BioMérieux), a fourth-generation test, and Enzygnost Anti HIV 1/2 Plus (Siemens), a third-generation test. If both tests were reactive, the sample was considered as HIV infected. Samples giving discordant results were considered as indeterminate and were not included in the analyses $(n=4)$.

\section{Statistical analysis}

Data were analysed with SPSS $v$ 18. Differences in proportions and means between different groups were tested for statistical significance using analysis of variance (ANOVA) and Tukey's post-hoc test.

\section{Ethical approval}

Ethical approval for the study was obtained from the Institutional Review Board of the Institute of Tropical Medicine, Antwerp, and the Ethics Committee of the University Teaching Hospital, Antwerp.

\section{Results}

\section{Socio-demographic characteristics of study participants}

A total of 649 MSM participated in the study: 167 at cruising venues, 219 at regular gay clubs/venues and 263 at young MSM venues. Of the 649 questionnaires received, three were invalid; 582 of those who completed the questionnaire agreed to have their blood taken. Participation rates were calculated as the total number of respondents that participated divided by the total number of men approached by a recruiter, expressed as a percentage. The participation rate for completing the questionnaire was $58 \%$ $(n=167)$ at the cruising venues, $75 \%(n=219)$ at regular gay clubs/venues and $70 \%$ $(n=263)$ at the young MSM venues. Because of the quantitative nature of the study, extra qualitative information on refusals was not obtained. Mean age was highest among men recruited at the cruising venues (38.5 years) and, as expected, lowest in those recruited at the young MSM venues (26.9 years) (table 5.1). At the cruising venues, $10.0 \%$ ( $n=17)$ of men were aged under 25 years; at the regular gay clubs/venues, this percentage was $25.0 \%(n=55)$ and at the young MSM venues, $40.0 \%(n=105)$. Overall, $75.3 \%(n=489)$ of respondents were of Belgian nationality, $18.3 \%(n=119)$ were Dutch and $1.2 \%(n=8)$ were French nationals; the remaining men $(n=99)$ had different nationalities. About $64 \%(n=415)$ had a degree. The vast majority of men $(94.1 \%$; 
$\mathrm{n}=611)$ were exclusively or primarily attracted to other men, while $2.6 \%(\mathrm{n}=17)$ were equally attracted to men and women.

Prevalence of HIV infection and undetected HIV infections

At the cruising venues, $16.1 \%$ of men $(n=26)$ reported that they were HIV infected; the corresponding percentages for the regular gay clubs/venues and the young MSM venues were $5.8 \%(n=12)$ and $3.2 \%(n=8)$, respectively (table 5.2$)$. The proportion of men who did not know their HIV status was similar at the cruising venues and the regular gay clubs/venues: $16.1 \%(n=26)$ and $17.5 \%(n=36)$, respectively. This was significantly lower than at the young MSM venues, where $26.0 \%$ of men $(n=64)$ reported they did not know their HIV status.

The prevalence of HIV infection was highest among the respondents at the cruising venues, $14.5 \%$ (22 of 152). It was $4.9 \%$ (10 of 205) among those at the regular gay clubs/venues and $1.4 \%$ (3 of 221) at the young MSM venues (table 5.2). The differences between strata were significant. Overall, $14.3 \%(n=5)$ of HIV-positive MSM thought they were HIV negative or were unaware of their status. This proportion was different in the different strata: at the cruising venues, $5.0 \%$ of men $(n=1)$ were unaware of their HIVpositive status; at the regular gay clubs/venues, this percentage was $30.0 \%(n=3)$ and at the young MSM venues, $25.0 \%(n=1)$. These differences were not statistically significant, but the numbers were small. Five HIV-negative men self-reported being HIV positive. Four other respondents had discordant results between the two HIV tests. Table 5.2 also presents HIV prevalence by age group in the different types of venue. Prevalence was highest among men at the cruising venues, in all age groups. The prevalence in men aged 25 years or younger and in men 40 years or older was similar in regular gay clubs/venues and in young MSM venues. 


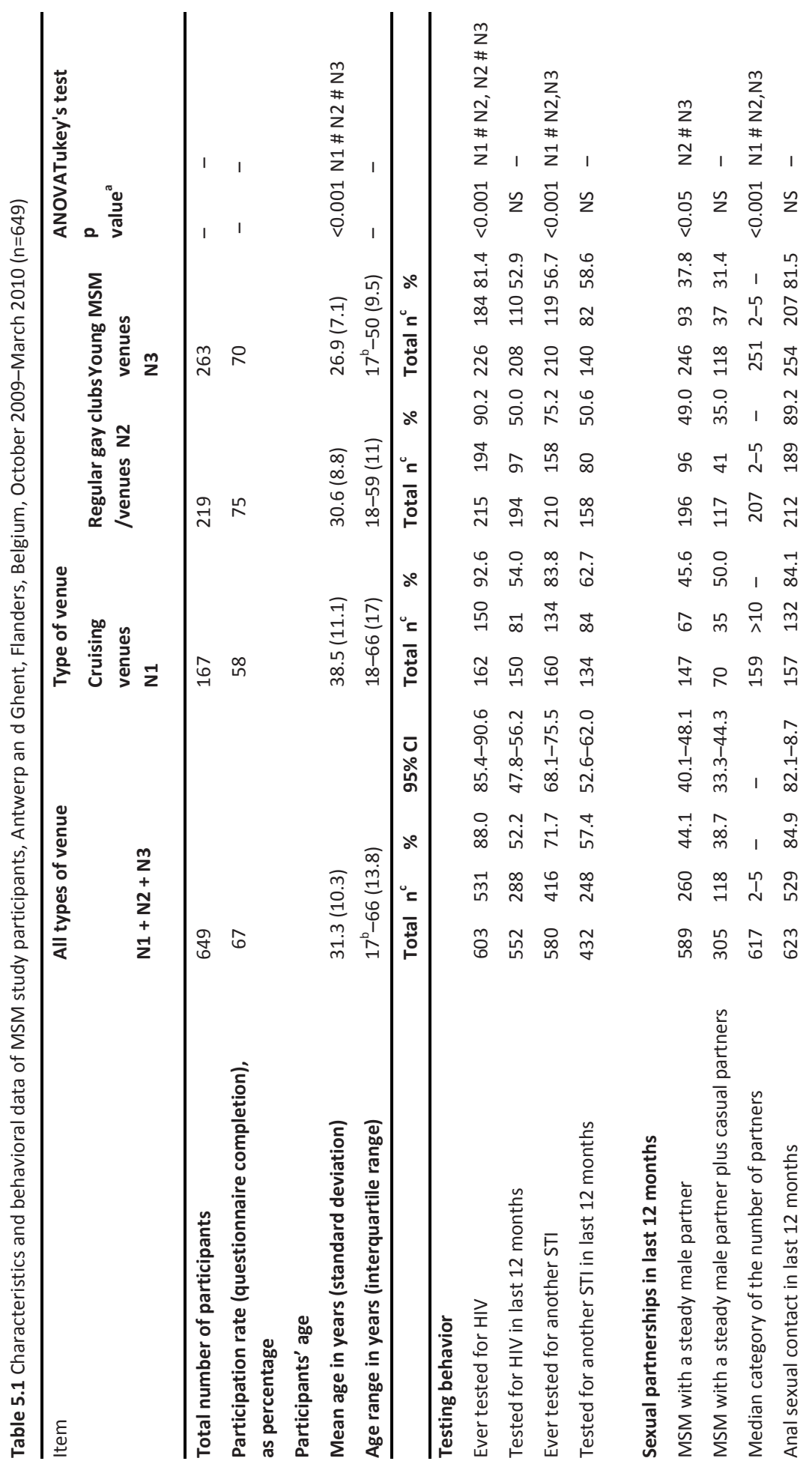




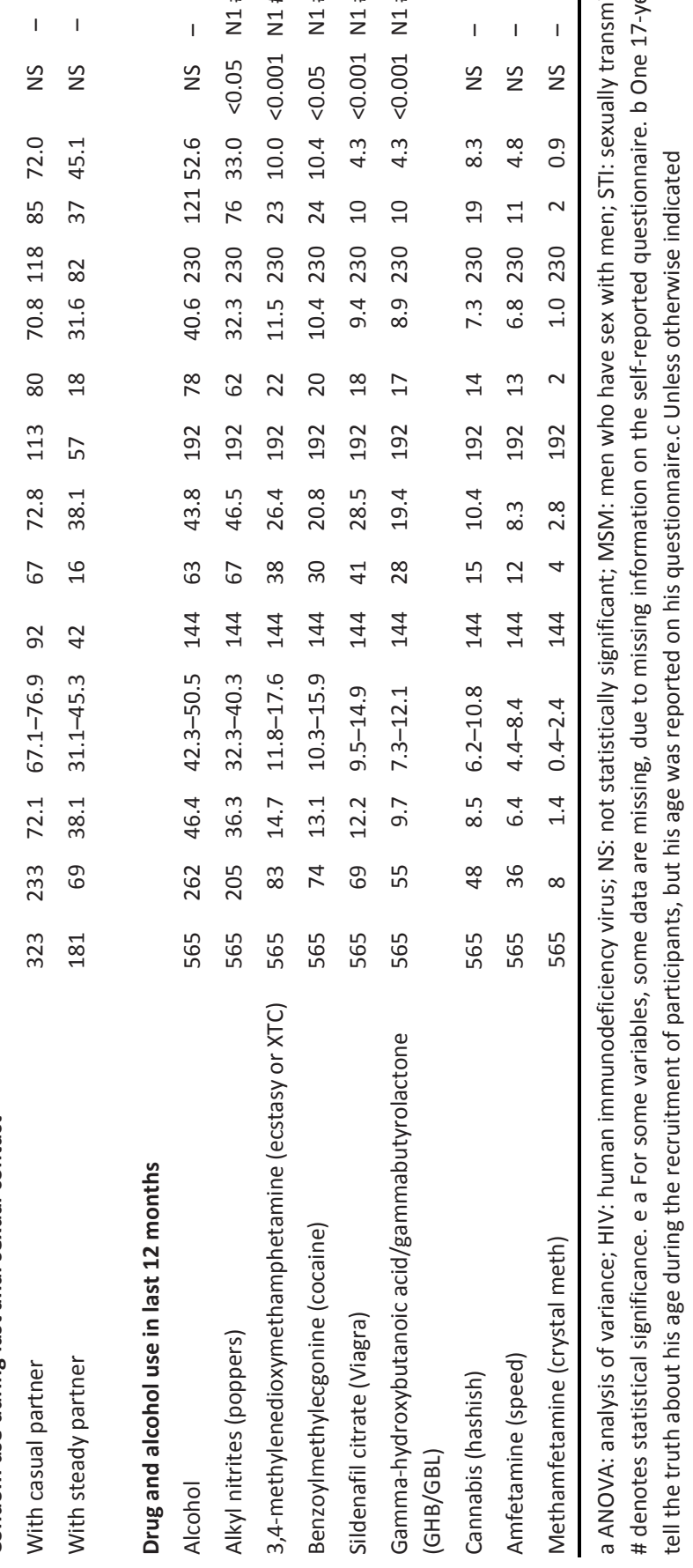




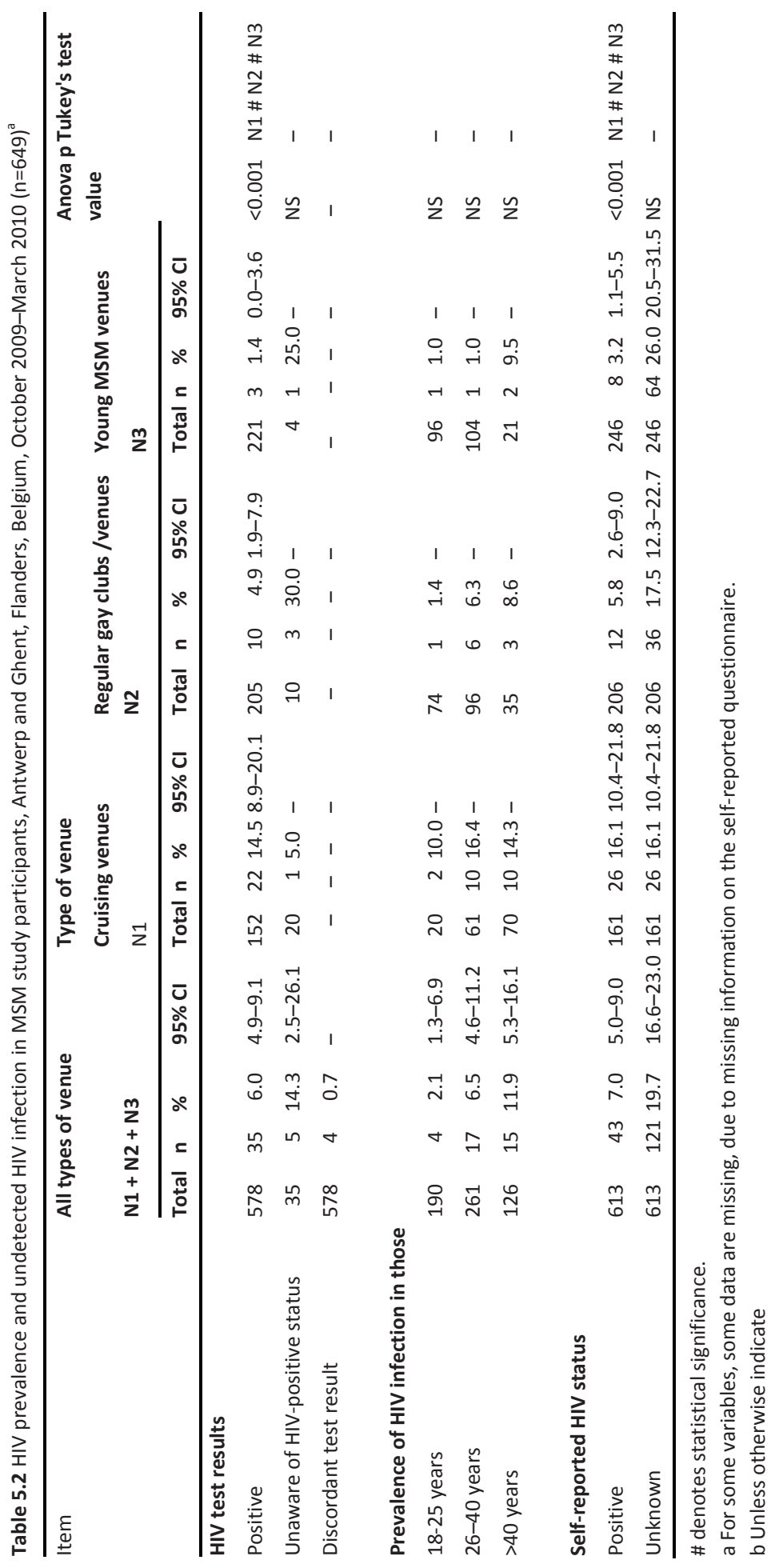




\section{Testing for HIV infection and other STIs}

Overall, $88.0 \%$ ( $n=531)$ had ever been tested for HIV and about half had been tested in the previous 12 months. Men at young MSM venues were least likely to have ever been tested (81.4\%; $n=184)$, while the percentage of men ever tested was similar at the cruising venues (92.6\%; $n=150$ ) and the regular gay clubs/venues $(90.2 \% ; n=194)$ (table 5.1). Testing rates ever for STIs were also high: $83.8 \%(n=134)$ for respondents at cruising venues, which was significantly higher than among those at regular gay clubs/venues (75.2\%; $n=158$ ) and young MSM venues (56.7\%; $n=119)$. Overall, $57.4 \%$ $(n=248)$ of respondents had been tested for STIs other than HIV in the previous 12 months (table 5.1). Of the respondents who had been tested for other STIs, about $16.5 \%(n=41)$ had been diagnosed with one or more STIs; for men recruited at cruising venues, this was $28.6 \%(n=24)$. The most frequently reported STIs among those tested were gonorrhoea $(10.1 \% ; n=29)$, chlamydial infection $(9.1 \% ; n=26)$ and syphilis $(8 \%$; $n=23)$. There were 13 cases of hepatitis $B(4.5 \%)$ and eight cases of hepatitis $C(2.8 \%)$. Significantly more syphilis cases were reported in respondents in cruising venues $(15.4 \%$, Tukey's test $p<0.05)$ compared with the other two strata $(4.8 \%$ in regular gay clubs/venues and $5.8 \%$ in young MSM venues, $n=6$ ). Chlamydial infection was significantly less likely to be reported by respondents from young MSM venues (in $3.9 \%(n=4)$ of respondents, whereas the percentage was $9.5 \%(n=10)$ in regular gay clubs/venues and $15.4 \%(n=12)$ in cruising venues; Tukey's test $p<0.05)$. During the previous 12 months, $24.0 \%(n=10)$ of the respondents diagnosed with an STI other than HIV were diagnosed with at least one other STI.

\section{Sexual partnerships and sexual behavior}

A total of 260 (44.1\%) of the respondents reported having had a steady male partner in the previous 12 months. For those in the younger MSM venues, this was $37.8 \%$ ( $n=93$ ) (table 5.1). Of all respondents who reported a steady relationship, about one third $(n=118)$ had also had casual sexual partners in the previous 12 months; for respondents at cruising venues, this was $50.0 \%(n=35)$. The median category of number of sexual partners in the previous 12 months was two to five for respondents at regular gay clubs/venues and young MSM venues, which was significantly lower than that for respondents in cruising venues, where the median category was more than 10 . Overall, $84.9 \%(n=529)$ of the respondents reported having had anal sexual contact during the previous 12 months. One third acted almost exclusively as the receptive partner, slightly more reported insertive anal sexual contact and about one third reported both. A total of $61.9 \%(n=112)$ of the respondents had not used a condom with their steady partner at the last sexual encounter. There were no differences by respondent's HIV status in condom use during the last anal sexual contact. However, when having anal 
sexual contact with a casual partner or a sex-buddy (a sexual partner who was known to the person, but was not their steady partner), HIV status seemed to affect condom usage: among HIV-negative respondents $(n=552), 412$ (74.6\%) consistently used a condom during their last anal sexual contact with casual partners, compared with $44.1 \%$ $(n=15)$ among the HIV-positive respondents. There were no significant differences between respondents by type of venue in the self-reported strategies that were used to search for sexual partners. Our results indicate that few MSM look for sexual partners in only one single type of venue or use only one strategy exclusively: respondents in all venue types found sexual partners through the Internet, via friends or at regular gay clubs or bars, although respondents in the young MSM venues were significantly more numerous at regular gay clubs or bars and had used the Internet more frequently to find sexual partners during the last 12 months. Overall, $76.6 \%$ of all respondents $(n=464)$ reported having had sexual contact at their home after finding a sex partner through any strategy or at any of the venues. As expected, respondents from cruising venues were less likely to have sexual contact at home after finding a casual sex partner though this difference was not statistically significant.

\section{Drug and alcohol use}

The respondents reported using a range of different drugs in the previous 12 months, just before or during sexual contact (table 5.1). The drugs included alkyl nitrites (poppers), 3,4-methylenedioxymethamphetamine (ecstasy or XTC), cannabis (hashish) and amfetamine (speed). Combinations of all of the above drugs were also reported. Significantly higher rates of use of alkyl nitrites (poppers), sildenafil citrate (Viagra), 3,4methylenedioxymethamphetamine (ecstasy or XTC), gamma-hydroxybutanoic/acid/gamma-butyrolactone (GHB/GBL) and benzoylmethylecgonine (cocaine) use were reported by respondents in cruising venues compared with those in the other venue types. Excessive alcohol use was also reported. Respondents at young MSM venues used significantly more alcohol than those at regular gay clubs/venues.

\section{Discussion}

The study in this chapter is the first in Belgium to estimate HIV prevalence among MSM visiting different types of venue. The lack of such research in the past may be due to the overall lack of knowledge of MSM populations and to difficulties in reaching these men for population-based research. The MSM sexual subculture is extremely diverse and caters for specific sexual desires. HIV prevalence research tends to focus primarily on cruising venues, where sexual contact on the premises is possible. By analysing three different types of venue, we were able to differentiate between specific venue types and our findings thus contribute to developing targeted prevention strategies. 
Recruiting MSM from different settings and taking blood samples through a finger prick seemed feasible and was generally well accepted. However, a limitation of our study was that five of the 12 owners of the venues that were initially approached declined to participate in the study. They rarely gave a meaningful explanation for not participating. Further research could shed light on the venue owners' motivation for refusal. The exclusion of these venues limited the application of the time-location sampling framework and the representativeness of the data for the MSM scene in Flanders. In addition, some of the men did not want to provide a blood sample as they said they feared the pain caused by a finger prick. Given the setting in which the samples were collected, this could have been said to hide the other reasons for refusing to be tested; however, this could not be explored in more detail in our study. Further, selfcompletion of the questionnaire in these venues resulted in some questions not being answered. Nevertheless, use of principles of the time-location sampling methodology means that our results should be representative for MSM present at the venues that were visited in the cities of Antwerp and Ghent, but the results cannot be generalised to the overall population of MSM in Flanders or the whole of Belgium. It is noteworthy, however, that analysis of the respondents' place of residence (by postal code) showed that the Belgian MSM in the study came from all over the country.

Our study found that the prevalence of HIV infection in men in the MSM venues that we analysed ranged from $14.5 \%$ in cruising venues, to $4.9 \%$ in regular gay clubs/venues, to $1.4 \%$ at young MSM venues. These differences in prevalence can be partly explained by differences in age. As the age of MSM at cruising venues was on average higher and HIV infection is more prevalent in older age groups, it is not surprising to find more HIV infections within these settings. However, in MSM aged 25 years and under who were present at cruising venues, the prevalence was $10 \%$. These young men frequented a greater variety of settings and used diverse strategies to find sexual partners, while they reported less frequent HIV testing.

Our prevalence data are in line with other European venue-based research among MSM, which found a range of prevalence estimates. A study in the United Kingdom in 2007 found the prevalence of HIV infection in MSM to be $9.0 \%$ in Manchester, $12.0 \%$ in London, and $14.0 \%$ in Brighton, and about a third of infections were unknown by the respondents [169]. In Switzerland, the estimated prevalence of HIV infection among MSM in Geneva in 2005 was 11\% [170]. More recently, in Barcelona, Spain, the figure was $17.0 \%$; in Verona, Italy, 11.8\%; in Bratislava, Slovakia, 6.1\%; in Bucharest, Romania, 4.6\%; in Ljubljana, Slovenia, 5.1\%; and in Prague, Czech Republic, 2.6\%. Among MSM aged under 25 years, the prevalence was $4.9 \%$ in Verona, Italy, and $12.5 \%$ in Barcelona, Spain, in 2008 to 2009 [164]. The most recent European study, among MSM in Paris, France, in 2009 found a prevalence of $17.7 \%$, of whom $19.7 \%$ were unaware of their status [165]. However, caution has to be exercised when comparing these results as the data were collected in different urban contexts and time periods, using different methodologies. In our study, the percentage of men unaware of their HIV-positive status was 
lower across all settings (14.3\%), although it was relatively high in the regular gay clubs/venues (30.0\%) and young MSM venues (25.0\%). This finding could be explained by a lower uptake of HIV testing by younger MSM.

We found relatively similar but high rates of testing for HIV during the last 12 months, compared with results from a similar study in 2009 in France, a neighbouring country (where the rate of HIV testing was 63.0\%) [165]. Respondents in the cruising venues in our study had been tested significantly more frequently for both HIV and other STIS than those from the other venue types. The higher uptake of lifetime testing in MSM in cruising venues corresponds to the higher risk of exposure within the settings they frequent. Further, the MSM present at cruising venues are generally older and may therefore have known about or experienced HIV screening for a longer time.

A majority of the men in our study reported condom use consistently during the last anal sexual contact with a casual partner, across all strata. However, HIV-positive men who were aware of their serostatus reported less condom use with casual partners and/or sex-buddies. Further, prevalence of HIV infection was highest among the participants from cruising venues - where sex in public is possible on site - even after stratifying by age group. Although it may appear that a certain group of HIV-positive MSM take no preventive measures at all, this may not always be the case. Research has shown that it is within the sexual networks of MSM that harm reduction strategies such as strategic positioning (HIV-positive men assume the receptive or 'passive' position, while HIV-negative men take the insertive or 'active' position) and serosorting (HIVpositive men have sex only with other HIV-positive men, while HIV-negative men only do so with other HIV-negative men) are widely practised and accepted as forms of preventive behavior [161]. Within epidemiological research this process of seroadaptation has often been ignored [171]. However, as a substantial number of HIV-positive respondents in our study believed themselves to be HIV negative, these strategies cannot be considered as reliable.

The use of certain drugs was higher among participants in the cruising venues. Drug use and sexual risk behavior among MSM attending these sex venues were reported to be high, as was reported in a study in 2009 on highly sexually active MSM attending cruising venues and parties in New York, United States [32]. From a public health perspective, prevention strategies for HIV/STIs and drug consumption are generally difficult to control in MSM venues, as they are privately owned. The relationship between drug taking, mental health and sexual risk behavior is pivotal in understanding the HIV epidemic among MSM, not only among men attending these venues but for the whole community [46]. The use of poppers and Viagra has been shown to be associated with recent seroconversion [142] and sexual risk behavior [172-175]. While the purpose of using these drugs is the enhancement of sexual experience [175], interventions tackling multiple drug use need to be part of prevention strategies for the specific high-risk subgroup of users, including HIV-positive men [176]. 
With regard to venues frequented or strategies used by MSM to seek sexual partners, there appear to be differences according to age group. For instance, data from the Netherlands suggest that younger MSM seek out sexual contact more frequently through the Internet and friends, and at regular gay bars or parties, whereas older MSM prefer saunas, public places (e.g. public parks and car parks), 'darkrooms' (darkened rooms, sometimes located in a cruising bar, gay sauna or other place where sexual activity is possible), sex cinemas and sex clubs [177]. In our study, the role of the Internet appeared to be important. A majority of the respondents sought sexual partners on the Internet and then met in their homes. Therefore it is imperative that new interventions focus on providing information on HIV infection and other STIs on the Internet and work through digital interaction on changing sexual risk behavior.

The complexity of the psychological, biological and social-structural elements that define the HIV epidemic among MSM requires a combination prevention solution. Our data show clearly that targeting only one element is not enough [161]. Our results constitute the evidence base for local targeted prevention, for policy changes directed at these specific settings and they form a baseline for analysing trends in HIV prevalence to inform prevention planning and monitor progress. We know from residence analysis that one in five men participating in the study came from neighbouring countries. Further, as the epidemiology of HIV infection among Belgian MSM mirrors developments in most western countries, there is a need for cross-border cooperation on research and development of interventions and policies [178]. Within such a framework, we could move towards a European-wide HIV prevention plan for MSM, as has been suggested [123]. 



\section{CHAPTER 6}

\section{International mobility, sexual behavior and HIV-related characteristics of men who have sex with men residing in Belgium}

This chapter is co-authored by Christiane Nöstlinger, Harm Hospers and Marie Laga and is accepted for publication in BMC Public Health, under the same title. ${ }^{11}$

\footnotetext{
${ }^{11}$ accepted for publication as: Vanden Berghe W, Nöstlinger C, Hospers H, Laga M; International mobility, sexual behavior and HIV-related characteristics of men who have sex with men residing in Belgium in BMC Public Health
} 



\section{Introduction}

European men who have sex with men continue to be disproportionally affected by the human immunodeficiency virus (HIV). In most western European countries, including Belgium, the number of yearly diagnoses of new (HIV) infections in men who have sex with men (MSM) remains high [4;7]. Several factors are contributing to the rates of new HIV infections among MSM, including an increase in sexual risk taking combined with a high prevalence of HIV infection in some networks of MSM [29;45;164]. It has also been suggested that travel behavior and sexual mobility could potentially be a factor in the spread of HIV and sexually transmitted infections (STI) among European MSM [4;29]. Travelling has been considered an important component of gay lifestyle and identity, as gay men travel to destinations where they can socialize with other gay men and in some cases avoid social constraints and intolerance [179]. For some gay men, social and sexual networking are highly intertwined and sexual identity is a central factor for some gay men in deciding on the travel destination [180]. Furthermore, globalization and European integration have resulted in shifts in travel decision making, among other reasons because of cheaper flights, which made gay men and other MSM even more mobile than before. These processes have not developed to the same extent across Europe, and some countries have a different general tourism profile than others [181;182]. At the European level, most Western European countries have been at the international forefront in implementing legal equality and anti-discrimination laws for lesbians, gays, bisexuals and transgenders (LGBT). In this changing context, some bigger cities such as Barcelona, Berlin or Paris but also Belgian Antwerp have invested in and attracted more LGBT tourism by means of different social marketing strategies. These cities offer a diverse mixture of cultural and festive experiences directed at sexual minorities and especially MSM, mirroring the diversity of gay subculture. These efforts seem to influence the choice of travel destination for MSM. For instance, results from the recent European MSM Internet study (EMIS) showed that Spain, Germany and France were the countries where a majority of MSM traveled to [183]. The factors above may explain the higher probability of finding more gay men and in a broader sense, MSM, in a given travel destination.

There is a need to better understand the dynamics that are at the basis of the European HIV/STI epidemics among MSM, in particular how sexual networks across countries may contribute to the current HIV epidemic among European MSM. However, little attention has been paid thus far to investigate sexual behavior of gay men while travelling. The present study presented in this chapter aims at filling this gap by analysing HIV-related individual and contextual characteristics of MSM residing in Belgium travelling abroad. Belgium functions here as a case study for sexual behavior among mobile MSM in the European context. We use data from the first pan-European internet survey EMIS to explore individual characteristics, sexual behaviors and their contex- 
tual determinants of MSM who were residing in Belgium at the time of data collection and who reported having had sexual contact abroad in the last 12 months.

\section{Methods}

\section{Dataset}

The European MSM Internet survey recruited participants between June 4th and August 31rd 2010. MSM from 38 different European countries, including the $27 \mathrm{EU}$ Member States completed an online questionnaire on sexual health, which was presented in 25 languages. An offline and online recruitment campaign with the support of many LGBT organizations across all countries preceded the data collection to motivate respondents to participate. The use and support of gay social online networks Gayromeo, Manhunt, Qruiser, Qguys and Gaydar were instrumental in reaching the target population. In total 174209 MSM participated in the study. Respondents completed the questionnaire in an average of 20 minutes. More information on the EMIS project and its methodology can be found on www.EMIS-project.eu, in a number of publications [184;185] and in the EMIS final report. The EMIS study was approved by the Research Ethics Committee of the University of Portsmouth, UK (REC application number 08/09:21)

\section{Measures}

\section{Background characteristics}

Respondents reported on their age, education, sexual identity, level of urbanization (i.e. living in a city with more than 500000 inhabitants), occupation, nationality, EMIS expat (living in one of the 38 EMIS countries but not in the country of birth) and relationship status.

Sexual and HIV/STI related behavior, drug use and health aspects in the last 12 months With regards to sexual practices, we assessed whether participants had anal sex and if so, whether condoms were used with casual and steady partners during 12 months before the study. We refer to anal sex without the use of condoms as unprotected anal intercourse or UAI. We assessed perceived seroconcordant UAI with a casual partner in the last 12 months. The participants also reported on HIV and STI testing behavior (Syphilis, Gonorrhea, Chlamydia, anal/genital warts, anal/genital herpes, Hepatitis B and C) and diagnoses during the last 12 months, the current HIV serostatus, the number of non-steady sex partners. We assessed recreational drugs typically associated with sex and parties referring to them in this paper as party drugs (XTC, amphetamine, crystal, mephedrone, GHB, ketamine, cocaine), poppers, and erectile enhancing medi- 
cation use. HIV positive participants reported whether they were taking antiretroviral treatment (ART) and their HIV viral load during the last check-up.

\section{Sexual contact abroad}

Respondents reported whether they have had any sexual contact with casual partners abroad in the last 12 months. Subsequently, more detailed questions were asked related to the last sexual contact abroad: country in which it took place; how and where the sexual partner was met, whether they engaged in anal sex and if so whether condoms were used.

\section{Statistics}

Data analysis was performed using IBM SPSS statistics version 20. To assess differences in proportions and means according to having had sex abroad, Mann-Whitney U-tests were performed for continuous variables, and chi squares were calculated for categorical variables. Univariate and multivariate logistic regression was used to calculate odds ratios and 95\% confidence intervals for the different background, risk and contextual factors comparing MSM on the basis of having had sex abroad in the last 12 months and having performed unprotected anal intercourse (UAI) during the last sexual encounter abroad. Adding variables to the models for the multivariate analysis was based on significance of the univariate analyses. Differences in proportions and means between three different groups (i.e. HIV positive, HIV negative, and untested men) on the basis of self-reported HIV-status were tested for statistical significance using analysis of variance (ANOVA) and Tukey's post-hoc test.

\section{Results}

\section{Description of the total sample of MSM residing in Belgium}

The total EMIS sample of MSM residing in Belgium comprised 3982 men. We excluded 84 participants who said they never had sex with another man and 38 men who did not answer the questions on sexual contact abroad. The total number of eligible men for analysis was 3860 (table 6.1). Mean age was 35.2 (SD:11.4) years old. Of Belgian resident MSM, $64.6 \%$ ( $\mathrm{n}: 2493)$ were higher educated, 5.2\% ( $\mathrm{n}: 200)$ were unemployed and $45.5 \%$ (n:1758) were in a steady relationship. A total of 955 (24.7\%) men were expatriates and $43.3 \%$ ( $n: 1674$ ) resided in a large city. Concerning sexual identity, $85.4 \%$ ( $n: 3298)$ reported to identify as homosexual, 9\% (n:348) as bisexual. During the last 12 months, $85 \%$ ( $n: 3281)$ of respondents reported having had anal sex, 39.2\% ( $n: 1514)$ had UAI with a steady partner and $25.7 \%$ ( $n: 993)$ had UAI with casual partner(s). Overall, 43.7\% ( $\mathrm{n:1688)}$ ) of MSM had an HIV test in the last 12 months and 10.4\% (n:332) reported being HIV positive. A total of 1562 (40.5\%) respondents had been tested for STI 
in the last 12 months and the most frequently reported STI were Syphilis (7.7\%, n:121), Gonorrhea $(8.8 \%, \mathrm{n}: 137)$ and Chlamydia $(8.3 \%, \mathrm{n}: 130)$. For all respondents, substance use in the last 12 months included consuming party drugs (17.7\%, n:683), poppers $(38.9 \%, n: 1500)$ and erectile enhancers (19.5\%, n:751). Of central interest to this study is that $39.1 \%$ ( $n: 1510)$ of Belgian resident MSM reported having had sexual contact abroad with a casual partner in the last 12 months. We will refer to this group of MSM as "sexually mobile men".

\section{MSM residing in Belgium: Differences according to having had sexual contact abroad in the last 12 months.}

Table 6.1 displays the bivariate analysis of the different background, sexual risk and contextual characteristics of MSM residing in Belgium according to having had sex abroad with a casual partner in the last 12 months. Significant differences are reported between sexually mobile MSM compared to those men residing in Belgium who did not have sex abroad. Sexually mobile men were on average significantly older (37.2 vs. 34.2 years old, $\mathrm{p}<0.001)$, had a higher education $(71.3 \%$ vs. $60.3 \%, p<0.001)$, were more often living in Belgium as an expatriate (38.5\% vs.15.9\%, $\mathrm{p}<0.001)$, and resided more often in a large city $(54.8 \%$ vs. $36 \%, p<0.001)$ compared to men who did not have sex abroad. Also, mobile men identified more as homosexual or gay $(89.0 \%$ vs. $83.1 \%$, $\mathrm{p}<0.001)$ and less often as bisexual (6.1\% vs. $10.9 \%, \mathrm{p}<0.001)$. Further, HIV testing $(47.5 \%$ vs. $41.3 \%, p<0.001)$ and STI testing (53.3\% vs. $32.2 \%, p<0.001)$ in the last 12 months was more often reported and a higher percentage of sexually mobile men were HIV positive $(15.2 \%$ vs. $6.8 \%$, p<0.001). Higher numbers of diagnoses of Syphilis $(9.3 \%$ vs. $6.1 \%, p<0.001)$, Gonorrhea ( $11.4 \%$ vs. $5.9 \%, p<0.001)$, Chlamydia ( $11.8 \%$ vs. $4.6 \%$, $\mathrm{p}<0.001))$, anal/genital warts $(6.7 \%$ vs. $5.8 \%, \mathrm{p}<0.01)$, current infection of hepatitis $\mathrm{C}$ ( $2 \%$ vs. $1.5 \%, p<0.05)$ during the last 12 months and lifetime infection of hepatitis $B$ ( $19 \%$ vs. $18 \%, p<0.001)$ were reported by mobile men compared to men who did not have sex abroad. Mobile men more often had anal sex (93.1\% vs. $79.1 \%, p<0.001)$ and more unprotected anal sex with casual partner(s) $(36.5 \%$ vs. $18.6 \%, p<0.001)$ in the last 12 months. They also had a higher number of non-steady sex partners in the last 12 months ( 11 to 20 vs. 2 partners, $p<0.001$ ), used more party drugs ( $26.9 \%$ vs. 11.8 , $\mathrm{p}<0.001)$, poppers $(56.3 \%$ vs. $27.7 \%, \mathrm{p}<0.001)$ and erection enhancing substances $(30.8 \%$ vs. $12.2 \%, p<0.001)$ in the last 12 months compared to Belgian resident MSM who did not have any sexual contact abroad. Countries where a majority of mobile men had sexual contacts during the last 12 months included France (18.1\%), Spain (15.7\%), Germany (10.6\%) and The Netherlands (9.1\%). 
Table 6.1 HIV related individual and contextual characteristics of MSM residing in Belgium according to having had sexual contact abroad in the last 12 months

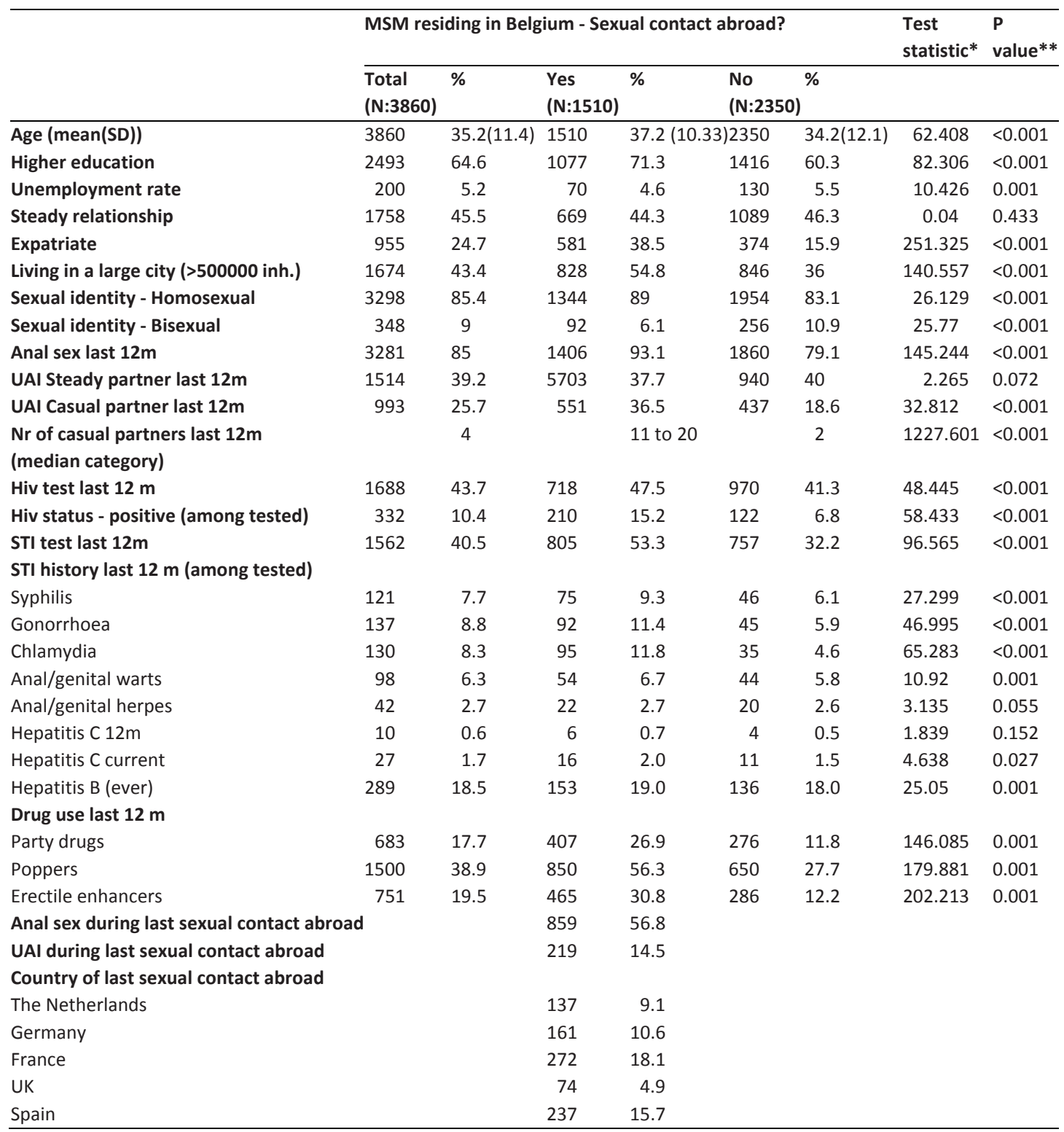

*Test statistics: $U$ value for continuous variables. $\chi^{2}$ for categorical variables ${ }^{*} p$ values: Mann-Whitney $U$ test for continuous variables and $\chi^{2}$ for categorical variable 


\section{Determinants of unprotected anal intercourse during the last sexual encounter abroad among sexually mobile men}

Table 6.2 shows the results of univariate and multivariate logistic analyses with UAI during the last sexual encounter abroad as the dependent variable. Mobile men who practiced UAI during their last sexual encounter abroad were less likely to be living in a large city (OR:0.62, 95\% Cl:0.45-0,86, $\mathrm{p}<0.01$ ) and more likely to be HIV positive (OR:6.20, 95\% Cl:4.23-9.06, p<0.001) ), to have been diagnosed HIV positive in the last 12 months (OR:3.07, 95\% Cl:1.07-8.80, $\mathrm{p}<0.05$ ), to have been diagnosed with any STI in the last 12 months (OR:2.55; 95\% Cl:1.77-3.67, $\mathrm{p}<0.05)$, to have used partydrugs (OR:2.22, 95\% Cl:1.59-3.09, $\mathrm{p}<0.001$ ), poppers (OR:1.52, 95\% Cl:1.07-2.14, $\mathrm{p}<0.001$ ) and erection enhancing substances (OR:2.23, 95\% Cl:1.61-3.09, $\mathrm{p}<0.001$ ) compared to MSM who did not have UAI with their last sexual partner abroad. Men having had UAI in the last 12 months were more likely to have done so in a neighbouring country of Belgium (OR: 1.66, 95\% Cl:1.21-2.29, p<0.001).

Multivariate analysis with having had UAI abroad as the dependent variable showed that, when controlling for variables significant in the univariate models, the odds for having had UAI during the last sexual encounter abroad were 3,88 times higher for HIV positive men (95\% Cl:1.14-10.67, $\mathrm{p}<0.01), 1.76$ higher for men being diagnosed with any STI in the last 12 months $(95 \% \mathrm{Cl}: 1.1-2.83, \mathrm{p}<0.05)$ and 0.67 lower for men who reside in a large city $(95 \% \mathrm{Cl}: 0.46-0.98, \mathrm{p}<0.05)$.

\section{Sexual behavior, drug use and STI history in the last 12 months according to HIV test status among sexually mobile men}

Table 6.3 shows characteristics of the last sexual contact abroad according to participants' HIV test status. Of the HIV positive men, $62 \%$ were on ART and $57 \%$ had an undetectable viral load. HIV positive men reported significantly more often to have had unprotected sex with a casual partner (73.9 vs. $34 \%$ vs. $27.1 \%, p<0.001)$, practiced more seroconcordant UAI with a casual partner in the last 12 months (52.8\% vs. $15.8 \%$ vs.12.9\%, $\mathrm{p}<0.001$ ) and had a higher number of casual sex partners during the last 12 months than HIV negative and untested men (more than 50 vs. 11 to 20 partners, $\mathrm{p}<0.001)$. Concerning STI history, HIV positive men reported significantly more Syphilis ( $43.9 \%$ vs. $18.8 \%$ vs. $8.3 \%, p<0.001$ ) and Chlamydia ( $19.7 \%$ vs. $4.3 \%$ vs. $3.4 \%$ ) during the last 12 months and more current infections of Hepatitis C ( $14.6 \%$ vs. $1.9 \%$ vs. $8.3 \%)$, $\mathrm{p}<0.001)$; than HIV negative and untested men. Party drugs ( $62.7 \%$ vs. $22.2 \%$ vs. $12.9 \%$, p<0.001), poppers ( 62.7 vs. $26.6 \%$ vs. $13.8 \%$ ) and erection enhancing substances $(79.8 \%$ vs. $54.2 \%$ vs. $33.6 \%$ ) were used significantly more often by HIV positive men than by HIV negative and untested men. 


\section{Characteristics of the last sexual encounter abroad according to HIV test status among sexually mobile men}

HIV-positive men reported higher numbers of anal sex (82.9\% vs. $56.1 \%$; $59.5 \%$, $\mathrm{p}<0.001$ ) and also more occasions of unprotected anal sex than HIV negative and untested men (47.2\% vs. $10.3 \%$; $8.6 \%$, $p<0.001$ ). HIV positive men also met their last sex partner abroad significantly more often in sex clubs and darkrooms $(19.7 \%$ vs. 9.6\%;3.4\%, $p<0.001$ ) than their HIV-negative or untested counterparts.

Table 6.2 Univariate and multivariate logistic regression with unprotected anal intercourse during the last sexual encounter of MSM residing in Belgium as dependent variable

\begin{tabular}{|c|c|c|c|c|c|c|c|c|}
\hline \multirow[b]{4}{*}{ Age $>=\mathbf{3 0}$ years old } & \multicolumn{8}{|c|}{ UAI during last sexual encounter abroad } \\
\hline & \multicolumn{4}{|c|}{ Univariate } & \multicolumn{4}{|c|}{ Multivariate } \\
\hline & \multirow{2}{*}{$\frac{\mathbf{P}}{0.940}$} & \multirow{2}{*}{$\frac{\text { OR }}{1.01}$} & \multicolumn{2}{|c|}{$95 \% \mathrm{Cl}$} & \multirow[t]{2}{*}{$\mathbf{P}$} & \multirow[t]{2}{*}{ OR } & \multicolumn{2}{|c|}{$95 \% \mathrm{Cl}$} \\
\hline & & & 0.71 & 1.44 & & & & \\
\hline Higher education & 0.153 & 0.77 & 0.54 & 1.10 & & & & \\
\hline Steady relationship & 0.208 & 1.23 & 0.89 & 1.69 & & & & \\
\hline Expatriate & 0.480 & 0.89 & 0.64 & 1.24 & & & & \\
\hline Living in a large city (>500000 inh.) & 0.004 & 0.62 & 0.45 & 0.86 & 0.041 & 0.67 & 0.46 & 0.98 \\
\hline Diagnosed HIV positive last $12 \mathrm{~m}$ & 0.036 & 3.07 & 1.07 & 8.81 & & & & \\
\hline Diagnosed with any STI last $12 \mathrm{~m}$ & $<0.001$ & 2.55 & 1.77 & 3.68 & 0.019 & 1.76 & 1.10 & 2.83 \\
\hline Hiv status - positive & 0.001 & 6.20 & 4.24 & 9.07 & 0.009 & 3.88 & 1.41 & 10.67 \\
\hline \multicolumn{9}{|c|}{ Number of non- steady partners last $12 \mathrm{~m}$ ( 1 to 5 ) } \\
\hline 6 to 20 & 0.345 & 0.81 & 0.53 & 1.25 & & & & \\
\hline $20+$ & 0.306 & 1.24 & 0.82 & 1.87 & & & & \\
\hline Party drugs & $<0.001$ & 2.22 & 1.60 & 3.10 & 0.912 & 1.03 & 0.63 & 1.69 \\
\hline Poppers & $<0.001$ & 1.52 & 1.08 & 2.14 & 0.632 & 0.90 & 0.60 & 1.36 \\
\hline Erectile enhancers & $<0.001$ & 2.23 & 1.61 & 3.09 & 0.757 & 1.07 & 0.69 & 1.68 \\
\hline Sexual contact in neighbouring country & $<0.001$ & 1.67 & 1.21 & 2.30 & 0.711 & 1.08 & 0.73 & 1.59 \\
\hline \multicolumn{9}{|l|}{ Meeting place last sexual abroad } \\
\hline Website & 0.321 & 0.85 & 0.62 & 1.17 & & & & \\
\hline Gay bar/disco/nightclub & 0.923 & 1.02 & 0.67 & 1.55 & & & & \\
\hline Sex club/Darkroom/Gay Sauna & 0.701 & 1.07 & 0.77 & 1.47 & & & & \\
\hline
\end{tabular}


Table 6.3 Sexual behavior, drug use and STI history; Characteristics of the last sexual contact abroad according to HIV test status among MSM residing in Belgium

\begin{tabular}{|c|c|c|c|c|c|c|c|c|}
\hline & \multicolumn{2}{|c|}{ Hiv positive $(P)$} & \multicolumn{2}{|c|}{ Hiv negative (N) } & \multicolumn{2}{|c|}{ Untested (U) } & \multirow{2}{*}{$\begin{array}{l}\text { Anova - } \\
\text { P value }\end{array}$} & \multirow{2}{*}{$\begin{array}{l}\text { Tukey's } \\
\text { test }\end{array}$} \\
\hline & $\mathbf{N}$ & $\%$ & $\mathbf{N}$ & $\%$ & $\mathbf{N}$ & $\%$ & & \\
\hline Age (mean(SD)) & 193 & $40(9.47)$ & 1117 & $36.99(10.5)$ & 116 & $34.38(12.59)$ & ) $<0.001$ & $P \neq N \neq U$ \\
\hline On antiretroviral therapy & 129 & 62 & & & & & & \\
\hline Viral load (last check-up) undetectable & 114 & 57 & & & & & & \\
\hline Anal sex last $12 \mathrm{~m}$ & 186 & 96.4 & 1041 & 92.5 & 106 & 85.5 & 0.038 & $\mathrm{P} \neq \mathrm{U}$ \\
\hline UAI Steady partner last $12 \mathrm{~m}$ & 94 & 48.7 & 425 & 61.2 & 31 & 54 & 0.002 & $P \neq N, U$ \\
\hline UAI Casual partner last $12 \mathrm{~m}$ & 137 & 71 & 347 & 34 & 28 & 27.1 & $<0.001$ & $P \neq N, U$ \\
\hline $\begin{array}{l}\text { Perceived seroconcordant UAI with a casual } \\
\text { partner last } 12 \mathrm{~m}\end{array}$ & 102 & 52.8 & 172 & 15.4 & 15 & 12.9 & $<0.001$ & $\mathrm{P} \neq \mathrm{N}, \mathrm{U}$ \\
\hline $\begin{array}{l}\text { Nr of casual partners last } 12 \mathrm{~m} \text { (median cate- } \\
\text { gory) }\end{array}$ & & $\begin{array}{l}\text { More than } \\
50\end{array}$ & & 11 to 20 & & 11 to 20 & $<0.001$ & $P \neq N \neq U$ \\
\hline STI test last $12 \mathrm{~m}$ & 82 & 42.5 & 160 & 14.5 & 12 & 10.3 & $<0.001$ & $\mathrm{P} \neq \mathrm{N}, \mathrm{U}$ \\
\hline \multicolumn{9}{|l|}{$\begin{array}{l}\text { STI history last } 12 \mathrm{~m} \text { (among tested for any } \\
\text { STI) }\end{array}$} \\
\hline Syphilis & 36 & 43.9 & 30 & 18.8 & 1 & 8.3 & $<0.001$ & $\mathrm{P} \neq \mathrm{N}, \mathrm{U}$ \\
\hline Gonorrhoea & 29 & 35.4 & 53 & 33.1 & 5 & 41.7 & $<0.001$ & $U \neq P, N$ \\
\hline Chlamydia & 38 & 46.3 & 48 & 30.0 & 4 & 33.3 & $<0.001$ & $\mathrm{P} \neq \mathrm{N}, \mathrm{U}$ \\
\hline Anal/genital warts & 14 & 17.1 & 32 & 20.0 & 5 & 41.7 & & $\mathrm{P} \neq \mathrm{N}$ \\
\hline Anal/genital herpes & 3 & 3.7 & 16 & 10.0 & 0 & 0.0 & 0.865 & \\
\hline Hepatitis C $12 \mathrm{~m}$ & 3 & 3.7 & 1 & 0.6 & 0 & 0.0 & $<0.001$ & $P \neq N, U$ \\
\hline Hepatitis C current & 12 & 14.6 & 3 & 1.9 & 1 & 8.3 & $<0.001$ & $\mathrm{P} \neq \mathrm{N}, \mathrm{U}$ \\
\hline Hepatitis B (ever) & 42 & 51.2 & 89 & 55.6 & 5 & 41.7 & $<0.001$ & $\mathrm{P}, \mathrm{N} \neq \mathrm{U}$ \\
\hline \multicolumn{9}{|l|}{ Drug use last $12 \mathrm{~m}$} \\
\hline Party drugs & 121 & 62.7 & 248 & 22.2 & 15 & 12.9 & $<0.001$ & $\mathrm{P} \neq \mathrm{N}, \mathrm{U}$ \\
\hline Poppers & 121 & 62.7 & 297 & 26.6 & 16 & 13.8 & $<0.001$ & $P \neq N \neq U$ \\
\hline Viagra & 154 & 79.8 & 605 & 54.2 & 39 & 33.6 & $<0.001$ & $P \neq N \neq U$ \\
\hline Anal sex during last sexual contact abroad & 160 & 82.9 & 627 & 56.1 & 69 & 59.5 & $<0.001$ & $\mathrm{P} \neq \mathrm{N}, \mathrm{U}$ \\
\hline UAI during last sexual contact abroad & 91 & 47.2 & 115 & 10.3 & 10 & 8.6 & $<0.001$ & $\mathrm{P} \neq \mathrm{N}, \mathrm{U}$ \\
\hline \multicolumn{9}{|l|}{ Meeting place for last sexual contact abroad } \\
\hline Gay bar/disco/nightclub & 34 & 17.6 & 220 & 19.7 & 14 & 12.1 & 0.147 & \\
\hline Sex club/Darkroom & 38 & 19.7 & 107 & 9.6 & 4 & 3.4 & $<0.001$ & $P \neq N, U$ \\
\hline A Gay Sauna & 22 & 11.4 & 176 & 15.8 & 17 & 14.7 & 0.247 & \\
\hline Public cruising location & 20 & 10.4 & 116 & 10.4 & 13 & 11.2 & 0.985 & \\
\hline Website & 71 & 36.8 & 372 & 33.3 & 51 & 44.0 & 0.177 & \\
\hline
\end{tabular}

*Total $\mathrm{n}$ for sexual contact abroad among MSM residing in Belgium $=1510$, may differ due to missing values on HIV test status 


\section{Discussion}

The study presented in this chapter used data from the European Internet MSM Survey (EMIS) to investigate sexual behavior of MSM who were sexually active when travelling abroad in the last 12 months prior to the survey. Our results for the case of Belgium show that HIV and STI are highly prevalent among travelling MSM, and that they adopt more sexual risk behavior (i.e. they scored higher on sexual risk indicators) than MSM who were not sexually active abroad. This evidence supports cross-border development of prevention activities for HIV and STI among MSM. MSM residing in Belgium who had sexual contact abroad were more likely to be expatriates and to be living in a bigger city. This finding can probably be explained by the substantial population of expatriates living in Brussels and working at its many European and international institutions. Belgian resident MSM having had sex abroad were also better educated and on average older than their counterparts who did not report any sexual activity abroad. Being able to travel implies disposable income to do so. Similar results were found in a study on gay resorts [186]. This study also demonstrates that sexual identity does play a role in travel behavior as was suggested in other studies $[179 ; 187 ; 188]$. Significantly more sexually mobile MSM identified as homosexual or gay and less often as bisexual. The majority of MSM residing in Belgium who had sex abroad mostly did so in Belgium's neighboring countries: Germany, France, The Netherlands and the United Kingdom, but also in Spain. Local evidence corroborates the cross border mobility. Of the 642 participants in a recent venue-based HIV prevalence study among MSM in Antwerp, Belgium, 1 in 5 men were of non-Belgian nationality, mostly Dutch [29]. These findings are in line with the mobility dynamics of European MSM. According to the EMIS final report, Spain and Germany are the most frequented countries for sex abroad [183]. Our findings showed that the proportion of HIV-positive men was higher among sexually mobile men. This may be due to a higher number of casual sex partners and more UAl with these casual sex partners although it cannot be established to what extent seroconversion affected the sexual behavior of the now positive men. Mobile men were also tested for HIV and STI more frequently during the last 12 months. However, mobile positive men reported higher rates of STI and substance use, and lower rates of condom use during anal sex while seroconcordant UAI with a casual partner in the last 12 months was significantly higher compared to negative and untested men. This is in line with other research pointing to the fact that MSM and specifically some networks of HIV positive MSM are highly mobile and apply additional risk reduction strategies next to condom use based on their own and their partner's HIV-status, HIV treatment and viral load status [44;189]. However, these strategies do not seem to protect well against other STIs. Over the last years networks of HIV positive men have been confronted with several co-occurring epidemics of for instance Lymphogranuloma Venereum (LGV) [190] and more recently Hepatitis C $[4 ; 9 ; 10 ; 191]$. Our study corroborated a link between the use of specific types of substance use, a higher number of non-steady part- 
ners and visiting patterns of specific venues where sexual contact is facilitated, which has also been established in other research $[29 ; 32 ; 44 ; 137 ; 192]$. Over one third of mobile men searched for a sex partner through the Internet for their last sexual encounter abroad, confirming findings from other studies [193] An important finding in our study is that Belgian resident men who tested HIV positive in the last 12 months were more likely to report unprotected anal intercourse abroad. This finding suggests that international sexual mobility may well have contributed to recent infections with HIV among European MSM. However, the data does not allow to pinpoint the exact moment of seroconversion in the last 12 months and an HIV positive diagnosis during that period may well have influenced the individual's sexual behavior and eventually the likelihood of performing UAI. It has to be stressed that these results cannot be generalized to all MSM, HIV negative or positive, because a majority of the study participants were recruited through specific Internet sites aiming at social and sexual networking. Being more active on these Internet sites could be an indicator of heightened sexual activity. However, the strengths of this study are its large sample size and anonymity of data collection through the Internet, which may also contribute to the validity of sensitive data [194;195]. Another limitation is that the EMIS survey did not investigate travel motivations or other more in-depth factors connected to travel behavior. As the epidemiology of HIV infection among Belgian MSM mirrors developments in its neighboring countries, the findings underline the need for development of cross-border HIV and STI interventions with coherent messages and prevention policies for MSM. Systematic cross-border cooperation and exchange of epidemiological and behavioral data for the development of prevention activities for MSM at a regional European level should inform future prevention effort for the target population. Further research should explore in more detail the purpose of travelling and context-related characteristics that lead MSM to be sexually active when being abroad. This could inform the development of targeted prevention campaigns supporting mobile MSM to reduce high risk behaviors. The presented evidence also underscores the need for multiple-behavior interventions targeting not only sexual behavior but also substance use. In this context, multiple-behavior interventions could have a greater impact on public health than singlebehavior interventions $[153 ; 154]$. Further research is needed on how to develop effective multiple-behavior interventions for this target group, which also must be tailored to the needs of specific subgroups such as HIV positive men $[44 ; 128 ; 132 ; 156]$ and HIV negative men, who are at greater risk for infections with HIV/STI. 
CHAPTER 7

General discussion 

Sexual minority populations are disproportionately affected by specific health outcomes. There is a need to better understand individual determinants but also inter- and intragroup dynamics at different ecological levels that explain these health disparities. The aim of the research in this thesis was to describe results from different Belgian and European research projects on health outcomes among LGB individuals, gay and other MSM in particular. The focus was on mental health outcomes among LGB populations and secondly on sexual health among gay and other men who have sex with men. In this chapter the results from the different empirical studies are discussed in the light of future health interventions.

\section{Health outcomes among sexual minorities}

\section{Mental health outcomes among sexual minorities}

Prevalence data on depression in the general population shows the effects of sex, age and education. Respectively women, youth and the lower educated report lower mental health outcomes $[68 ; 70 ; 71 ; 99]$. In this thesis, mental health was measured by means of the Center of Epidemiologic Studies Depression (CES-D) scale [99], assessing nonclinical self-reported depression. This scale has shown its validity in many populations and can therefore be used as a basis for comparison. The study in this thesis (chapter 1 ) among a sexual minority population in Flanders confirms the same associations when studying age and education as relevant determinants for mental health. Younger and less educated LGB individuals report more depressive symptoms. However, we did not find significant differences in depression between men and women. Investigating the same background variables for LGB youth (under 26 years old) did reveal significant differences related to age, education and sex. LGB youth reporting more depressive symptoms are younger, less educated and more often female. Among a sample of LGB youth (chapter 2), 36.8\% scored above the cutoff point of 16 on the CES-D scale, constituting a possible indication of clinical depression, and $22.9 \%$ above the cutoff of 21 , constituting a high risk for depression. As mentioned above, younger lesbian or bisexual women do seem to suffer more from depression. Further, sexual identity is a significant determinant of depression: bisexuality among women is related to lowered mental health. In a sample of MSM (chapter 4), $29.3 \%$ scored above the cutoff point of 21 on the CES-D indicating symptoms of more severe depression [134]. The discussion on whether mental health outcomes between gay men and lesbian women can be compared has been going on for some time. It is suggested that sex differences in mental health outcomes are partly caused by biological factors [103]. Also, men and women apply other coping strategies. Gay men's coping strategies are more related to emotions compared to heterosexual men. These emotional coping strategies are typically found for women. Not finding a difference between men and women for an LGB 
sample could indicate similarities in biological determinants on the one hand and similar coping styles with stress on the other hand [196].

\section{HIV/STI prevalence among men who have sex with men}

The HIV epidemic among MSM in Belgium is peaking with a high number of new infections every year [7]. The proportion of HIV infections among Belgian MSM within all new infections has risen considerably since 2002 , from $23.5 \%$ to $46.6 \%$. New HIV infections among non-Belgian individuals infected through homo or bisexual contact are also rising. These epidemiological developments are noted while HIV and STI testing rates among Belgian men are among the highest in Europe [197]. This dissertation confirms these high and stable testing rates measured at different moments in time since 2006, based on data from the different cross-sectional studies (chapter 3,4,5). Populationbased HIV prevalence estimates are needed to assess the burden of disease in MSM and to make realistic projections for health-service needs and prevention planning. $A$ venue-based, cross-sectional study reported on HIV prevalence and behavior among MSM in Flanders (Antwerp and Ghent). Using time-location sampling, we found that HIV prevalence in MSM who attended different types of venue ranged from a high of $14.5 \%$ (95\% Cl: 8.9-20.1; $n=22$ in cruising venues to $4.9 \%$ in more general gay venues to $1.4 \%$ at younger MSM venues. Of those who tested HIV positive ( $N=35)$, five were unaware of their HIV status or self-reported as being HIV negative $(14,3 \%)$. Our prevalence data are in line with other European venue-based research among MSM $[164 ; 165 ; 169 ; 170]$. Results from the European Men who have sex with Men Internet Survey (EMIS) also confirm similar magnitudes of self-reported HIV and STI prevalence among MSM residing in Belgium. A reflection on prevalence estimates through different methods can be found later in this chapter. Furthermore, our results show higher STI rates among HIV positive men. In addition, the different studies in this thesis repeatedly show higher rates of sexually transmitted infections among specific subpopulations of HIV positive men such as Gonorrhea, Syphilis and Chlamydia, as well as emerging and recurring breakouts of specific "new" STI's, such as LGV and Hepatitis C. These STI epidemics among HIV positive men have been equally noted in other European countries $[10 ; 191 ; 198]$.

\section{Syndemic outcomes for men who have sex with men}

This dissertation (chapter 4) serves as the first evidence for the existence of syndemics among HIV negative men in Belgium. Syndemic theory describes the synergestic interactions of two or more co-existent diseases that result into excess disease burden. Men who have sex with men (MSM) are confronted with different health problems. Next to a higher HIV prevalence and a higher reporting of depressive symptoms, there is also evidence of elevated substance use and sexual compulsivity occurring simultaneously 
$[36 ; 44 ; 45 ; 199 ; 200]$. Results in this dissertation show that in the Belgian context, for HIV negative men, significantly more drug use was reported for those with higher sexual sensation seeking scores alongside a higher number of sexual partners and more depressive symptoms. Although we did not find significant differences for the use of alcohol and other drugs by UAI practice, the different syndemic factors intercorrelated significantly with the use of drugs. These drugs include Poppers, Viagra and drugs associated with the party scene for MSM (Cocaine, GHB/GBL, Ecstacy). Similar dynamics for drug use and number of partners were found for HIV positive men having had sexual contact abroad. Although some of the drugs cited are used to enhance sexual pleasure (Poppers, Erectile enhancers (Viagra)) and are not necessarily related to abuse and dependency, it is clear that, for HIV negative men, in the context of a possible syndemic, the co-occurrence of lowered mental health, higher overall drug use, more sexual partners and possible compulsivity, and higher STI rates are related to risk of an HIV infection. Similarly, for HIV positive men, drug use and multiple partners in combination with prevention strategies based on perceived seroconcordancy involving less condom use are related to higher STI rates. One of the objectives of this dissertation was to investigate a possible association between mental health and sexual health among MSM. In the past there has been some doubt whether such an association exists [42]. Our results confirm that depressive symptoms and unprotected anal intercourse are related and need to be understood in the syndemic context (depression, drug use, sexual compulsivity) mentioned above. However, we did not find evidence for possible interactions of depressive symptoms with elements of social-cognitive models such as the theory of planned behavior [15] or the health belief model [13], predicting UAI, including risk perception of UAI and peer norms regarding condom use.

\section{Other determinants of UAl among MSM}

The different studies (chapter 4 and 6) in this dissertation looked at determinants of sexual risk, defined as having unprotected anal intercourse, at different ecological levels. Determinants at individual and social cognitive level have already been discussed in the syndemic context. It has to be stressed that across the different studies, a majority of men used condoms consistently during sexual contact with a casual partner; however, HIV-positive men who were aware of their serostatus reported significantly less condom use with casual partners. For HIV negative men, a major determining factor of UAl established in this thesis is perceived social norms regarding condom use by peers but also by venue visitors. It would appear that UAI is more often performed and perceived as normal within the context of specific social networks or settings. At the sociocultural level specific cruising settings and sex clubs were reported to be places with a higher HIV prevalence and attracted proportionally more HIV positive men. MSM visiting these venues used significantly less condoms with casual partners and had a higher 
number of partners in the preceding year. Venue-based sampling also made apparent that one in five respondents present in MSM venues in Flanders were of non-Belgian nationality; mostly Dutch. This finding led to the investigation of sexual risk of MSM while travelling abroad (chapter 6). Our results for the case of Belgium show that HIV and STI are highly prevalent among travelling MSM, and that they report more sexual risk behavior than MSM who were not sexually active abroad. Different sexual behavioral patterns were identified according to HIV test status among sexually mobile men. Less condoms were used with casual partners. However, these men did have significantly more perceived seroconcordant UAI with their casual partners signifying other prevention strategies. These strategies are not successful in avoiding STI infection, possibly contributing to the high STI rates among HIV positive men. Finally, the Internet was confirmed as a medium through which a majority of men find casual partners. It was also observed that most of the men dating online meet at a private home.

\section{Explaining health disparities among sexual minorities: Expanding the minority stress model}

The explanatory model and ecological framework used throughout this dissertation, the minority stress model, has been partly validated by means of the results of two different studies (chapter 1 and 2). This model describes the effects of minority stress, that comes on top of general life stress, on health outcomes, initially only on mental health but as has recently been demonstrated, also on sexual risk [54]. In this context elements from syndemic theory and minority stress theory can be merged. The outer layers of the minority stress theory depict the higher ecological levels determining minority stress health outcomes while syndemic theory focuses on the co-occurrence and interactions of different health outcomes including sexual risk and mental health. Stressors can be external, such as the experience of discrimination, and internal, such as internalized homonegativity. Both studies on minority stress showed strong effects of proximal minority stressors, internalized homonegativity and stigma consciousness, on mental health outcomes. Structural factors suggested in the proposed model were not included in our studies but a recent study based on the EMIS data demonstrated that social structural factors such as a country's legal climate towards sexual minorities, the Gini coefficient and the level of urbanisation are associated with internalized homonegativity [54].

Further, the studies in this thesis confirmed that the effects of stress on health outcomes are mediated or somewhat buffered through sources of social support. Experiencing more support from family and friends, and in the case of LGB youth, from a confidant, does lead to lower levels of stress and eventually to a more positive outlook on life. Throughout the different studies we did not only focus on positive sources of social support but also on unsupportive social interactions. These negative social interactions were strongly associated with lower mental health outcomes and more sexual 
risk. The studies in this dissertation provide evidence for including this important variable into the greater explanatory model capturing the whole spectrum of social support. Other local studies have shown the effect and function of sources of social support and the social network as a whole, on the lives of LGB individuals [59;201;202]. For instance, because of social stigma, some individuals do not feel welcome anymore in their family environment after coming out as LGB and more often choose friends for support, the so called "family of choice" [203].

\section{Reflecting on the methods}

The data for the studies in this thesis was collected through different methods. Comparing HIV-related indicators for men who have sex with men on the basis of data collection methods, whether venue-based or through online surveys seems to produce similar and robust results. Reaching hard to reach population such as MSM requires different methods in order to maximize sample diversity [194]. A recent study on the EMIS results [194] showed that comparison of self-reported HIV prevalence as measured in EMIS with estimates from for example venue-based sampling methods (timelocation sampling, see chapter 5 ) are highly correlated and thus imply similar selection biases. For most countries, such as Belgium, self-reported EMIS prevalence is higher than measured prevalence. This is suggested to be a consequence of a combination of different time points of measurement, measurement errors for small sample sizes, different sampling methods, and an indicator-inherent overestimate of prevalence among the untested fraction of MSM.

\section{Implications for future prevention efforts}

Based on the explanatory model and the findings of this thesis multilevel combination prevention components should be part of prevention programs for sexual minority populations in Belgium. It has been suggested that reducing internalized homonegativity through attention to LGB human rights may be appropriate for HIV reduction intervention among MSM [54]. At the societal level continuous awareness raising campaigns on LGB specific health issues targeting family and school environments as well as broader campaigns on reducing stigma and promoting social acceptance of sexual minorities should be part of combination prevention solutions to eventually better health outcomes. LGB youth and young lesbian or bisexual girls in particular are a vulnerable group in terms of their mental well-being. Mental health interventions should be tailored according to target group such a LGB youth, bisexuals and lesbian women. The Flemish government already implemented broader general population campaigns on mental health but more targeted approaches seem warranted. For MSM, the results in this thesis demonstrate that multifactorial, intertwined factors contribute to the explanation of UAI among HIV negative MSM at risk for HIV infection. This thesis underlines 
the need for an integrated sexual health approach for MSM. In the context of syndemics, there is a need to move towards a new holistic framework [47;152]. The cooccurrence of lowered mental health, sexual compulsivity and drug use make the implementation of HIV/STI prevention strategies more difficult. Not only for HIV negative men, but also targeting HIV positive men, the evidence suggests that there is a potential for the implementation of multiple-behavior interventions [153;154]. Among HIV negative men addressing mental health, substance use, whether dependency has developed or not, and the higher propensity to take sexual risks in this population is pivotal in controlling the HIV epidemic. The same approach holds for HIV positive men with a specific focus on the prevention of STI's in the context of risk reduction strategies such as perceived seroconcordancy. Interventions for HIV and STI can be implemented through the Internet or venue-based. Further, for specific groups of HIV positive MSM, there should be an emphasis on prevention at cruising settings or sex clubs. In short, a tailored preventive approach is warranted for specific subgroups such as young MSM [204], HIV positive men [44;128;132;156] and HIV negative men [205-207] at greater risk for HIV/STI infection. In these different contexts a multilevel and temporal prevention approach also implies analysing and improving individual, interpersonal and socio-cultural risk factors and in the case of young MSM, in a syndemic lifecourse perspective. In addition, new preventive interventions for MSM need to be developed focusing on social norming regarding sexual risk behavior and condom use. These interventions should be functional at the level of the individual, the social network and the community. Further, in supporting MSM in developing positive coping strategies to deal with the of psychosocial problems related to sexual risk behavior, researchers and service providers should aim at understanding the resilience among the same target group. There is definitely merit in resiliency theory [208]. This theory stipulates that interventions among affected groups should rather focus on the capacity of an individual to cope successfully with adversity at different ecological levels. Focusing on reinforcing resiliency factors, in this thesis mainly social support mechanisms, in buffering stress outcomes, should be part of future interventions. Finally, the research in this thesis on HIV prevalence and international mobility dynamics further demonstrated that at the regional European level, there is a need for cross-border cooperation on research and development of interventions and policies [178]. Within such a framework, we could move towards a European-wide HIV prevention plan for MSM.

\section{Future research recommendations}

Future research lines could focus on further validation of the minority stress model including all elements of the proposed multi-level model. While recent research has focused on other health outcomes than mental health as an outcome of the model it is clear that this has to be situated within a syndemic health outcome framework. Internalized homonegativity and stigma consciousness are substantial predictors of health 
outcomes and should be studied more closely. A better understanding of the interactions between syndemic factors but also of protective and coping factors needs to be high on the research agenda in order to better inform future interventions. There is continuous need for knowledge on condom use and its psycho-cognitive predictors. In this context, we need to better understand the association between mental and sexual health and more concretely how depressive symptoms interact with psycho-cognitive determinants as risk perception and perceived social norms. Further, more knowledge is needed on how peer norms regarding condom use whether venue-based or within the social network, affect sexual risk behavior. More qualitative research is needed on the concrete translation of risk reduction strategies from counseling to behavior in specific HIV positive subgroups. Next, while the studies in this thesis have focused on European LGB populations and MSM, also in the context of international mobility, analyses of health outcomes on the basis of migrancy background seem warranted. Finally, for Belgium, there is need for continuous evaluation of the current prevention programs and promoted sexual health strategies.

\section{Strengths and limitations}

Some strengths and limitations should be noted for the research in this thesis. Strengths include all studies being based on large and diverse samples. Furthermore, the different projects were organized following the principles of community participatory research involving members of the community and prevention organisations from set-up to implementation of the projects. A first limitation is the use of cross-sectional data throughout the different studies, which makes longitudinal comparison impossible. Furthermore, in the case of the Zzzip survey, items on the theoretical models had to be dropped due to the already lengthy questionnaire within the context of this policy research project. Next, there was a sole focus on depressive symptoms as a mental health outcome. Similarly, for the studies on HIV risk we defined sexual risk as anal penetrative intercourse while a sexual episode usually consists of multiple sexual practices. Next to internalized stress outcomes - such as depression, feelings of loneliness and self-esteem - but also externalized stress outcomes like deviant behavior (at school, towards alcohol, criminality, etc.) should be included in one explanatory model. Concerning the minority stress model, the list of life stressors should be expanded to include daily hassles and life events while the notion of discrimination as an external minority stressor should go beyond the working environment. Data described in chapter 1, 2(Zzzip), 3 (FAQ ${ }^{2}$ ) and 5(EMIS) were collected by means of the Internet. This method has shown considerable validity in reaching hard to reach populations such as sexual minorities, its shortcomings are self-selection and underrepresentation of older age groups, or other groups who have no access to computers [147]. This has to be taken into account when interpreting the outcomes of analyses. A limitation throughout all projects was temporal disparity in relation to the different items and scales that 
were used. For instance the CES-D items are based on feelings during the last week, while questions on sexual behavior referred to the last 6 months. Different recall times may be possibly confusing for respondents eventually leading to different levels of recall bias. Venue-based sampling also had its limitations. When implementing this type of methodology, success is highly dependent on participation of the community and venue owners. Self-completion of a questionnaire in these venues resulted in some questions not being answered. The results from the different studies cannot be generalised to the overall population of LGB's or MSM in Flanders or the whole of Belgium. It is noteworthy, however, that, for all studies, analysis of the respondents' place of residence (by postal code) showed that the Belgian LGB population in the studies came from all over the country.

\section{Policy recommendations}

The results reported in this thesis research confirm that sexual minority populations are disproportionately affected by lowered health outcomes compared with the general population. As mentioned in the introduction of this thesis, Belgium has implemented equal rights for LGB populations that continue to hold a, often hidden, minority position in society. These minorities will continue to be minorities dealing with specific stressors in their individual lives. Preservation and expansion of existing prevention and care strategies aimed at this target group is and remains essential. Focusing on health and resiliency during the life course of sexual minority youth also seems important. In addition, support for youth in general on sexual identity development is pivotal. Regarding HIV among MSM, these investments will determine the further course of the HIV epidemic in Belgium greatly. Our results constitute an evidence base for local targeted prevention policy, venue- and internet-based and they form a baseline for analyzing trends in health outcome prevalence to inform prevention planning and monitor progress. The outcomes of this thesis can be used for more advocacy and a better coordination among the various policy areas of the Flemish and Belgian Federal governments. Within the policy area of Equal Opportunities there is a specific focus on LGBT populations but HIV risk is part of the Health and Well-being strategy. More consultation is warranted. Given the diversity among sexual minority populations and the mental health (support) needs in general, but certainly concerning sexual health, there is a need more for interactive tailored (customized) prevention. This implies an extension of the sexuological and psychological care within the health care systems but also by offering more interactive and individually targeted prevention methods online and offline. Therefore, more coordination between care and prevention seems necessary. In view of international mobility of MSM at the European level more coordination and more cross-border cooperation concerning the development of interventions and prevention guidelines is needed. Within this framework, we can grow towards a European HIV plan for MSM, with regional and local accents. 


\section{Concluding remarks}

The aim of the research in this thesis was to describe and explain health outcomes among sexual minority populations in Belgium. Different studies provided insight into mental health disparities among LGB populations and secondly on sexual health risks among gay and other men who have sex with men. Minority stress theory was used to analyze and discuss the effects of both general and minority stressors on mental health outcomes. Local evidence was found for the co-occurrence of mental and sexual health related problems in the context of a syndemic among a population of Flemish men who have sex with men. This thesis also reported on the first venue-based bio-behavioral HIV prevalence study in Flanders. The final study described and discussed the effects of international mobility on the HIV epidemic of MSM residing in Belgium. Results from the studies in this thesis have already served as and will form a further basis for possible directions of the future of health interventions among LGB populations and HIV prevention among MSM for Belgium and Europe. 



\section{Reference List}

1. Ward J, Schneider B. The Reaches of Heteronormativity. Gender \& Society 2009;23(4):433-9.

2. Dewaele A, Cox N, Vanden Berghe W, Vincke J. De maatschappelijke positie van holebi's en hun sociale netwerken. Antwerpen: Steunpunt Gelijkekansenbeleid - Consortium UA/UHasselt; 2006.

3. Poelman M, Smits D. Agressie tegen holebi's in Brussel Stad. Brussel: EHSAL/Nieuwland; 2006.

4. European Centre for Disease Prevention and Control. Techical report: STI and HIV prevention in men who have sex with men in Europe. Stockholm: ECDC; 2013.

5. Kinsey AC, Pomeroy WB, Martin CE. Sexual behavior in the human male. 1948.

6. Buysse A, Caen M, Dewaele A, Enzlin P, Lievens J, T'Sjoen G, et al. Sexpert: Basisgegevens van de survey naar seksuele gezondheid in Vlaanderen. Gent: Academia Press; 2013.

7. Sasse A, Defraye A. HIV/AIDS in België, semestrieel rapport (toestand op 31 december 2011). Wetenschappelijk Instituut voor Volksgezondheid; 2012 Dec.

8. Ward H, de Vries HJC, Van de Laar M. S15. 4 Re-emergence of lymphogranuloma venereum in Europe and the public health response. Sexually Transmitted Infections 2011;87(Suppl 1):A19-A20.

9. Bottieau E, Apers L, Van Esbroeck M, Vandenbruaene M, Florence E. Hepatitis C virus infection in HIVinfected men who have sex with men: sustained rising incidence in Antwerp, Belgium, 2001-2009. Eurosurveillance 2010;15(39):18-25.

10. van de Laar TJW, Matthews GV, Prins M, Danta M. Acute hepatitis C in HIV-infected men who have sex with men: an emerging sexually transmitted infection. Aids 2010;24(12):1799-812.

11. Van Griensven GJP, De Vroome E, De Wolf F, Goudsmit J, Roos M, Coutinho R. Risk factors for progression of Human Immunodeficiency Virus (HIV) infection among seropositive homosexual men. American journal of epidemiology 1990;132(2):203-10.

12. Rosenstock I. Health Education and Behavior 1974;2(4):354-86.

13. Fisher JD, Fisher WA. Theoretical approaches to individual-level change in Hiv risk behavior. In: Peterson JL, DiClemente RJ, editors. Handbook of Hiv prevention.New York: Plenum; 2000. p. 3-55.

14. Ajzen I, Fishbein M. Understanding practices and predicting social behavior. NJ:Prentince Hall: Engelwood Cliffs; 1980.

15. Ajzen I. The theory of planned behavior. Organizational behavior and human decision processes 1991;50(2):179-211.

16. Stolte IG, Dukers NH, Geskus RB, Coutinho RA, de Wit JB. Homosexual men change to risky sex when perceiving less threat of Hiv/AIDS since availability of HAART: a longitudinal study. Aids 2004;18:303-9.

17. Vincke J, Bolton R, de Vleeschouwer P. The cognitive structure of the domain of safe and unsafe gay sexual behaviour in Belgium. Aids Care-Psychological and Socio-Medical Aspects of Aids/Hiv 2001;13(1):57-70.

18. Vincke J, Bolton R. Beyond the sexual monad: Combining complementary cognitions to explain and predict unsafe sex among gay men. Human Organization 1997;56(1):38-46.

19. Kalichman SC, Johnson JR, Adair V, Rompa D, Multhauf K, Kelly JA. Sexual sensation seeking: Scale development and predicting AIDS-risk behavior among homosexually active men. Journal of personality assessment 1994;62(3):385-97.

20. Bancroft J, Janssen E, Strong D, Carnes L, Vukadinovic Z, Long JS. Sexual risk-taking in gay men: The relevance of sexual arousability, mood, and sensation seeking. Archives of Sexual Behavior 2003;32(6):555-72. 
21. Bancroft J, Carnes L, Janssen E. Unprotected anal intercourse in HIV-positive and HIV-negative gay men: The relevance of sexual arousability, mood, sensation seeking, and erectile problems. Archives of Sexual Behavior 2005;34(3):299-305.

22. Kashubeck-West S, Szymanski DM. Risky sexual behavior in gay and bisexual men - Internalized heterosexism, sensation seeking, and substance use. Counseling Psychologist 2008;36(4):595-614.

23. Coleman E, Horvath KJ, Miner M, Ross MW, Oakes M, Rosser B. Compulsive sexual behavior and risk for unsafe sex among internet using men who have sex with men. Archives of Sexual Behavior 2010;39(5):1045-53.

24. Grov C, Parsons JT, Bimbi DS. Sexual compulsivity and sexual risk in gay and bisexual men. Archives of Sexual Behavior 2010;39(4):940-9.

25. Vincke J, Bolton R, Mak R, Blank S. Coming Out and Aids-Related High-Risk Sexual-Behavior. Archives of Sexual Behavior 1993;22(6):559-86.

26. Dudley MG, Rostosky SS, Korfhage BA, Zimmerman RS. Correlates of high-risk sexual behavior among young men who have sex with men. Aids Education and Prevention 2004;16(4):328-40.

27. Fenton KA, Imrie J. Increasing rates of sexually transmitted diseases in homosexual men in western Europe and the United States: Why? Infectious Disease Clinics of North America 2005;19(2):311-31.

28. Read TRH, Hocking J, Sinnott V, Hellard M. Risk factors for incident HIV infection in men having sex with men: a case-control study. Sexual Health 2007;4(1):35-9.

29. Vanden Berghe W, Nostlinger C, Buve A, Beelaert G, Fransen K, Laga M. A venue-based HIV prevalence and behavioural study among men who have sex with men in Antwerp and Ghent, Flanders, Belgium, October 2009 to March 2010. Eurosurveillance 2011;16(28):10-7.

30. Jenness SM, Neaigus A, Hagan H, Wendel T, Gelpi-Acosta C, Murrill CS. Reconsidering the internet as an HIV/STD risk for men who have sex with men. Aids and Behavior 2010;14(6):1353-61.

31. Lyons A, Smith AMA, Grierson JW, von Doussa H. Australian men's sexual practices in saunas, sex clubs and other male sex on premises venues. Sexual Health 2010;7(2):186-92.

32. McNeely J, Silvera R, Torres K, Bernstein K, Aberg J, Gourevitch M, et al. Current substance misuse and Hiv risk behavior Among highly sexually active men who have sex with men (MSM) attending commercial sex venues, events and parties (CSVEP) in New York City. Journal of General Internal Medicine 2010;25:250.

33. van Heeringen $C$, Vincke J. Suicidal acts and ideation in homosexual and bisexual young people: a study of prevalence and risk factors. Social Psychiatry and Psychiatric Epidemiology 2000;35(11):494-9.

34. Schoonacker M, Dumon E, Louckx F. Welebi. Onderzoek naar het mentaal en sociaal welbevinden van lesbische en biseksuele meisjes. Brussel; 2009.

35. Guadamuz TE, Friedman MS, Marshal MP, Herrick AL, Lim SH, Wei C, et al. Health, sexual health, and syndemics: Toward a Better Approach to STI and HIV Preventive Interventions for Men Who Have Sex with Men (MSM) in the United States. The New Public Health and STD/HIV Prevention. Springer New York; 2013. p. 251-72.

36. Jie W, Ciyong L, Xueqing D, Hui W, Lingyao H. A syndemic of psychosocial problems places the MSM (Men Who Have Sex with Men) population at greater risk of HIV infection. PloS one 2012;7(3):e32312.

37. Singer MC, Erickson PI, Badiane L, Diaz R, Ortiz D, Abraham T, et al. Syndemics, sex and the city: Understanding sexually transmitted diseases in social and cultural context. Social science \& medicine 2006;63(8):2010-21.

38. Singer M, Clair S. Syndemics and public health: Reconceptualizing disease in bio-social context. Medical anthropology quarterly 2003;17(4):423-41.

39. Stall R, Paul JP, Greenwood G, Pollack LM, Bein E, Crosby GM, et al. Alcohol use, drug use and alcoholrelated problems among men who have sex with men: the Urban Men's Health Study. Addiction 2001;96(11):1589-601.

40. Carvalho AF, Lewis RJ, Derlega VJ, Winstead BA, Viggiano C. Internalized sexual minority stressors and same-sex intimate partner violence. Journal of family violence 2011;26(7):501-9. 
41. Koblin BA, Torian L, Xu G, Guilin V, Makki H, Mackellar D, et al. Violence and HIV-related risk among young men who have sex with men. Aids Care-Psychological and Socio-Medical Aspects of Aids/Hiv 2006;18(8):961-7.

42. Crepaz N, Marks G. Are negative affective states associated with HIV sexual risk behaviors? A metaanalytic review. Health Psychology 2001 Jul;20(4):291-9.

43. Kalichman SC, Weinhardt L. Negative affect and sexual risk behavior: comment on Crepaz and Marks (2001). Health Psychology 2001;20(4):300-1.

44. Kurtz SP, Buttram ME, Surratt HL, Stall RD. Resilience, syndemic factors, and serosorting behaviors among HIV-positive and HIV-negative substance-using MSM. Aids Education and Prevention 2012;24(3):193-205.

45. Parsons JT, Grov C, Golub SA. Sexual compulsivity, co-occurring psychosocial health problems, and HIV risk among gay and bisexual men: Further evidence of a syndemic. American Journal of Public Health 2012;102(1).

46. Safren SA, Traeger L, Skeer MR, O'Cleirigh C, Meade CS, Covahey C, et al. Testing a social-cognitive model of HIV transmission risk behaviors in HIV-infected MSM with and without depression. Health Psychology 2010;29(2):215-21.

47. Safren SA, Reisner SL, Herrick A, Mimiaga MI, Stall RD. Mental health and HIV risk in men who have sex with men. Journal of Acquired Immune Deficiency Syndromes 2010;55:S74-S77.

48. Pearlin LI. Stress and mental health: A conceptual overview. In: Horwitz AV, Scheid TL, editors. A handbook for the study of mental health: Social contexts, theories, and systems.New York, NY, US: Cambridge University Press; 1999. p. 161-75.

49. Pearlin LI. The sociological study of stress. Journal of health and social behavior 1989;241-56.

50. Meyer IH. Prejudice, social stress, and mental health in lesbian, gay, and bisexual populations: Conceptual issues and research evidence. Psychological Bulletin 2003;129(5):674-97.

51. Meyer IH. Minority stress and mental-health in gay men. Journal of Health and Social Behavior 1995;36(1):38-56.

52. Kuyper L, Fokkema T. Minority stress and mental health among Dutch LGBs: Examination of differences between sex and sexual orientation. Journal of Counseling Psychology 2011;58(2).

53. Lehavot K, Simoni JM. The impact of minority stress on mental health and substance use among sexual minority women. Journal of consulting and clinical psychology 2011;79(2):159-70.

54. Ross MW, Schmidt A.J., Hospers HJ, Breveglieri M, Furegato M, Weatherburn P, et al. Internalised homonegativity predicts HIV-associated risk behavior in European men who have sex with men in a 38country cross-sectional study: some public health implications of homophobia. BMJ Open 2013;3(2).

55. Meyer $\mathrm{IH}$. Prejudice, social stress, and mental health in lesbian, gay, and bisexual populations: conceptual issues and research evidence. Psychological bulletin 2003;129(5):674-97.

56. Thoits PA. Sociological approaches to mental illness. A handbook for the study of mental health 1999;121-38.

57. Cohen S, Wills TA. Stress, social support, and the buffering hypothesis. Psychological bulletin 1985;98(2):310-57.

58. Vincke J, van Heeringen K. Confidant support and the mental wellbeing of lesbian and gay young adults: A longitudinal analysis. Journal of Community \& Applied Social Psychology 2002;12(3):181-93.

59. Vincke J, van Heeringen K. Confidant support and the mental wellbeing of lesbian and gay young adults: A longitudinal analysis. Journal of Community \& Applied Social Psychology 2002;12(3):181-93.

60. D'Augelli AR, Hershberger SL, Pilkington NW. Lesbian, gay, and bisexual youth and their families: Disclosure of sexual orientation and its consequences. American journal of orthopsychiatry 1998;68(3):361-71.

61. Ingram KM, Betz NE, Mindes EJ, Schmitt MM, Smith NG. Unsupportive responses from others concerning a stressful life event: Development of the Unsupportive Social Interactions Inventory. Journal of Social and Clinical Psychology 2001;20(2):173-207. 
62. Ingram KM, Jones DA, Fass RJ, Neidig JL, Song YS. Social support and unsupportive social interactions: Their association with depression among people living with HIV. AIDS care 1999;11(3):313-29.

63. Weatherburn P, Schmidt A.J., Hickson F, Reid D, Berg RC, Hospers HJ, et al. The European Men-whohave-sex-with-men Internet Survey (EMIS): Design and Methods. Sexuality Research and Social Policy 2013.

64. Sandfort TG, De Graaf R, Van Bijl R, Schnabel P. Same-sex sexual behaviour and psychiatric disorders. Archives of general psychiatry 2001;58:85-91.

65. Wethington E, Kessler RC. Perceived support, received support, and adjustment to stressful life events. Journal of health and social behavior 1986;78-89.

66. Aneshensel CS, Rutter CM, Lachenbruch PA. Social structure, stress, and mental health: Competing conceptual and analytic models. American Sociological Review 1991;56(2):166-78.

67. Large MD, Marcussen K. Extending identity theory to predict differential forms and degrees of psychological distress. Social Psychology Quarterly 2000;63(1):49-59.

68. Rosenfield S. Sex differences in depression; do women always have higher rates? Journal of health and social behavior 1980;21:33-42.

69. Mirowsky J, Ross CE. Sex differences in distress: Real or artifact? American Sociological Review 1995;60(3):449-68.

70. Mirowsky J, Ross CE. Age and depression. Journal of health and social behavior 1992;33(3):187-205.

71. Kessler RC, McRae Jr JA. The effect of wives' employment on the mental health of married men and women. American Sociological Review 1982;47(2):216-27.

72. Ross CE, Van Willigen M. Education and the subjective quality of life. Journal of health and social behavior 1997;38(3):275-97.

73. Diamond LM. What does sexual orientation orient? A biobehavioral model distinguishing romantic love and sexual desire. Psychological review 2003;110(1):173-92.

74. Diamond LM. Sexual identity, attractions, and behavior among young sexual-minority women over a 2year period. Developmental psychology 2000;36(2):241-50.

75. Graber J, Archibald A. Psychosocial change at puberty and beyond: Understanding adolescent sexuality and sexual orientation. In: D'Augelli AR, Patterson C, editors. Lesbian, gay, and bisexual identities and youth: Psychological perspectives.New York: Oxford University Press; 2001. p. 3-26.

76. Troiden DR. The formation of homosexual identities. Journal of Homosexuality 1989;17(1-2):43-74.

77. D'Augelli AR, Hershberger SL. Lesbian, gay, and bisexual youth in community settings: Personal challenges and mental health problems. American journal of community psychology 1993;21(4):421-48.

78. Herdt G, Continuing Features H. Introduction: Gay and lesbian youth, emergent identities, and cultural scenes at home and abroad. Journal of Homosexuality 1989;17(1-2):1-42.

79. Weinberg TS. Biology, ideology, and the reification of developmental stages in the study of homosexual identities. Journal of Homosexuality 1985;10(3-4):77-84.

80. Van Wyk PH, Geist CS. Psychosocial development of heterosexual, bisexual, and homosexual behavior. Archives of Sexual Behavior 1984;13(6):505-44.

81. Dempsey D, Hillier L, Harrison L. Gendered (s) explorations among same-sex attracted young people in Australia. Journal of adolescence 2001;24(1):67-81.

82. Savin-Williams RC, Diamond LM. Sexual identity trajectories among sexual-minority youths: Gender comparisons. Archives of Sexual Behavior 2000;29(6):607-27.

83. Fergusson DM, Horwood $\amalg$, Beautrais AL. Is sexual orientation related to mental health problems and suicidality in young people? Archives of general psychiatry 1999;56(10):876-80.

84. Blake SM, Ledsky R, Lehman T, Goodenow C, Sawyer R, Hack T. Preventing sexual risk behaviors among gay, lesbian, and bisexual adolescents: The benefits of gay-sensitive HIV instruction in schools. American journal of public health 2001;91(6):940-6.

85. DuRant RH, Krowchuk DP, Sinal SH. Victimization, use of violence, and drug use at school among male adolescents who engage in same-sex sexual behavior. The Journal of pediatrics 1998;133(1):113-8. 
86. Garofalo R, Mustanski B, Johnson A, Emerson E. Exploring Factors That Underlie Racial/Ethnic Disparities in HIV Risk among Young Men Who Have Sex with Men. Journal of Urban Health-Bulletin of the New York Academy of Medicine 2010;87(2):318-23.

87. Scheer S, Parks CA, McFarland W, Page-Shafer K, Delgado V, Ruiz JD, et al. Self-reported sexual identity, sexual behaviors and health risks: Examples from a population-based survey of young women. Journal of Lesbian Studies 2002;7(1):69-83.

88. Meyer IH. Prejudice, social stress, and mental health in lesbian, gay, and bisexual populations: conceptual issues and research evidence. Psychological bulletin 2003;129(5):647-97.

89. Brooks VR. Minority stress and lesbian women. Lexington Books Lexington, MA; 1981.

90. DiPlacido J. Minority stress among lesbians, gay men, and bisexuals: A consequence of heterosexism, homophobia, and stigmatization. 1998.

91. Rosser BS, Ross MW. A Gay Life Events Scale (GALES) for homosexual men. Journal of Gay \& Lesbian Psychotherapy 1989;1(2):87-101.

92. Shidlo A. Internalized homophobia: Conceptual and empirical issues in measurement.: Sage Publications, Inc; 1994.

93. Lewis RJ, Derlega VJ, Griffin JL, Krowinski AC. Stressors for gay men and lesbians: Life stress, gay-related stress, stigma consciousness, and depressive symptoms. Journal of Social and Clinical Psychology 2003;22(6):716-29.

94. Goffman E. Frame analysis: An essay on the organization of experience. 1986.

95. Pachankis JE, Goldfried MR. Social anxiety in young gay men. Journal of Anxiety Disorders 2006;20(8):996-1015.

96. Pinel EC. Stigma consciousness: The psychological legacy of social stereotypes. Journal of personality and social psychology 1999;76:114-28.

97. Cohen GL, Garcia J. " I am us": negative stereotypes as collective threats. Journal of personality and social psychology 2005;89(4).

98. Ross MW. Beyond the biological model: New directions in bisexual and homosexual research. Journal of Homosexuality 1985;10(3-4):63-70.

99. Radloff L.S. The CES-D Scale: A self-report depression scale for research in the general population. Applied Psychological Measurement 1977;(1):385-401.

100. Mayfield W. The development of an internalized homonegativity inventory for gay men. Journal of Homosexuality 2001;41(2):53-76.

101. Bouma J, Ranchor AV, Sanderman R, van Sonderen E. CES-D. Noordelijk centrum voor gezondheidsvraagstukken, Groningen 1995.

102. Rahman Q, Wilson GD. Born gay? The psychobiology of human sexual orientation. Personality and individual differences 2003;34(8):1337-82.

103. Savin-Williams RC, Cohen KM, Joyner K, Rieger G. Rejecting the refutation that never was: reply to Meyer's (2010) comments on Savin-Williams, Cohen, Joyner, and Rieger (2010). Archives of Sexual Behavior 2010;40(4):659-61.

104. Lewis NM. Mental health in sexual minorities: Recent indicators, trends, and their relationships to place in North America and Europe. Health \& Place 2009;15(4):1029-45.

105. Meyer IH. Prejudice, social stress, and mental health in lesbian, gay, and bisexual populations: conceptual issues and research evidence. Psychological bulletin 2003;129(5):647-97.

106. Pickery J, Noppe J. Vlamingen over homo's: loopt het beleid voorop? Attitudes tegenover holebi's en holebiseksualiteit in Vlaanderen. Brussel: Studiedienst van de Vlaamse Regering; 2007.

107. Tennant C, Andrews G. A scale to measure the stress of life events. Australasian Psychiatry 1976;10(1):27-32.

108. Van Heeringen C, Vincke J. Suicidal acts and ideation in homosexual and bisexual young people: A study of prevalence and risk factors. Social Psychiatry and Psychiatric Epidemiology 2000;35(11):494-9. 
109. D'Augelli AR, Hershberger SL. Lesbian, gay, and bisexual youth in community settings: Personal challenges and mental health problems. American journal of community psychology 1993;21(4):421-48.

110. Huebner DM, Rebchook GM, Kegeles SM. Experiences of harassment, discrimination, and physical violence among young gay and bisexual men. American journal of public health 2004;94(7):1200-3.

111. D'Augelli AR, Hershberger SL. Lesbian, gay, and bisexual youth in community settings: Personal challenges and mental health problems. American journal of community psychology 1993;21(4):421-48.

112. Lock J, Steiner H. Gay, lesbian, and bisexual youth risks for emotional, physical, and social problems: Results from a community-based survey. Journal of the American Academy of Child \& Adolescent Psychiatry 1999;38(3):297-304.

113. Safren SA, Heimberg RG. Depression, hopelessness, suicidality, and related factors in sexual minority and heterosexual adolescents. Journal of consulting and clinical psychology 1999;67(6).

114. Lindquist N, Hirabayashi G. Coping with marginal situations: The case of gay males. Canadian Journal of Sociology/Cahiers canadiens de sociologie 1979;4(2):87-104.

115. Frable DE, Wortman C, Joseph J. Predicting self-esteem, well-being, and distress in a cohort of gay men: The importance of cultural stigma, personal Visibility, community Networks, and positive identity. Journal of personality 1997;65(3):599-624.

116. Morrow RG, Gill DL. Perceptions of homophobia and heterosexism in physical education. Research quarterly for exercise and sport 2003;74(2):205-14.

117. Whatley SL, Clopton JR. Social support and suicidal ideation in college students. Psychological reports 1992;71(3f):1123-8.

118. Yang B, Clum GA. Life stress, social support, and problem-solving skills predictive of depressive symptoms, hopelessness, and suicide ideation in an Asian student population: A test of a model. Suicide and Life-Threatening Behavior 1994;24(2):127-39.

119. Goldfried MR, Goldfried AP. The importance of parental support in the lives of gay, lesbian, and bisexual individuals. Journal of Clinical Psychology 2001;57(5):681-93.

120. Koch NS, Emrey JA. The Internet and opinion measurement: Surveying marginalized populations. Social Science Quarterly 2001;82(1):131-8.

121. Yoshikawa H, Alan-David Wilson P, Chae DH, Cheng JF. Do family and friendship networks protect against the influence of discrimination on mental health and HIV risk among Asian and Pacific Islander gay men? AIDS Education and Prevention 2004;16(1: Special issue):84-100.

122. Sasse A, Defraye A. HIV/AIDS in België, semestrieel rapport (toestand op 31 december 2009). Wetenschappelijk Instituut voor Volksgezondheid; 2009 Dec.

123. Likatavicius G, Klavs I, Devaux I, Alix J, Nardone A. An increase in newly diagnosed HIV cases reported among men who have sex with men in Europe, 2000-6: implications for a European public health strategy. Sexually Transmitted Infections 2008;84(6):499-505.

124. Sullivan PS, Hamouda O, Delpech V, Geduld JE, Prejean J, Semaille C, et al. Reemergence of the HIV epidemic among men who have sex with men in North America, Western Europe, and Australia, 19962005. Annals of Epidemiology 2009;19(6):423-31.

125. Lhomond B, Saurel-Cubizolles M. Sexual orientation and mental health: A review. Revue D Epidemiologie et de Sante Publique 2009;57(6):437-50.

126. Vanden Berghe W, Dewaele A, Cox N, Vincke J. Minority-specific determinants of mental well-being among lesbian, gay, and bisexual youth. Journal of Applied Social Psychology 2010;40(1):153-66.

127. Koblin BA, Husnik MJ, Colfax G, Huang YJ, Madison M, Mayer K, et al. Risk factors for HIV infection among men who have sex with men. Aids 2006;20(5):731-9.

128. Wolitski RJ, Parsons JT, Gomez CA, Sums and Sumit Study Teams. Prevention with HIV-seropositive men who have sex with men - Lessons from the Seropositive Urban Men's Study (SUMS) and the Seropositive Urban Men's Intervention Trial (SUMIT). Journal of Acquired Immune Deficiency Syndromes 2004;37:S101-S109. 
129. Bancroft J, Vukadinovic Z. Sexual addiction, sexual compulsivity, sexual impulsivity, or what? Toward a theoretical model. Journal of Sex Research 2004;41(3):225-34.

130. Dodge B, Reece M, Herbenick D, Fisher C, Satinsky S, Stupiansky N. Relations between sexually transmitted infection diagnosis and sexual compulsivity in a community-based sample of men who have sex with men. Sexually Transmitted Infections 2008;84(4):324-7.

131. Grov C, Parsons JT, Bimbi DS. Sexual Compulsivity and Sexual Risk in Gay and Bisexual Men. Archives of Sexual Behavior 2010;39(4):940-9.

132. Semple SJ, Zians J, Grant I, Patterson TL. Sexual compulsivity in a sample of HIV-positive methamphetamine-using gay and bisexual men. Aids and Behavior 2006;10(5):587-98.

133. Wood AM, Taylor PJ, Joseph S. Does the CES-D measure a continuum from depression to happiness? Comparing substantive and artifactual models. Psychiatry Research 2010;177(1):120-3.

134. Weissman M, Sholomskas D, Pottenger M, Prusoff B, Locke B. Assessing depressive symptoms in five psychiatric populations: a validation study. American Journal of Epidemiology 1977;106(3):203-14.

135. Zimet GD, Powell SS, Farley GK, Werkman S, Berkoff KA. Psychometric characteristics of the multidimensional scale of perceived social support. Journal of personality assessment 2012;55:610-7.

136. Starks TJ, Golub SA, Kelly BC, Parsons JT. The problem of "just for fun": Patterns of use situations among active club drug users. Addictive Behaviors 2010;35(12):1067-73.

137. Grov C. HIV risk and substance use in men who have sex with men surveyed in bathhouses, bars/clubs, and on Craigslist. org: Venue of recruitment matters. Aids and Behavior 2012;16(4):807-17.

138. Tsui HY, Lau JTF. Comparison of risk behaviors and socio-cultural profile of men who have sex with men survey respondents recruited via venues and the internet. Bmc Public Health 2010;10(232).

139. Barrett DC, Bolan G, Joy D, Counts K, Doll L, Harrison J. Coping Strategies, substance use, sexual activity, and HIV sexual risks in a sample of gay male STD patients. Journal of Applied Social Psychology 1995;25(12):1058-72.

140. McCabe SE, Bostwick WB, Hughes TL, West BT, Boyd CJ. The relationship between discrimination and substance use disorders among lesbian, gay, and bisexual adults in the United States. American Journal of Public Health 2010;100(10):1946-52.

141. Lelutiu-Weinberger C, Pachankis JE, Golub SA, Walker JJ, Bamonte AJ, Parsons JT. Age cohort differences in the effects of gay-related stigma, anxiety and identification with the gay community on sexual risk and substance use. Aids and Behavior 2011;1-10.

142. Carey JW, Mejia R, Bingham T, Ciesielski C, Gelaude D, Herbst JH, et al. Drug use, high-risk sex behaviors, and increased risk for recent HIV infection among men who have sex with men in Chicago and Los Angeles. Aids and Behavior 2009;13(6):1084-96.

143. Mimiaga MJ, Fair AD, Mayer KH, Koenen K, Gortmaker S, Tetu AM, et al. Experiences and sexual behaviors of HIV-infected MSM who acquired HIV in the context of crystal methamphetamine use. Aids Education and Prevention 2008;20(1):30-41.

144. Halkitis PN, Moeller RW, Siconolfi DE, Jerome RC, Rogers M, Schillinger J. Methamphetamine and polysubstance use among gym-attending men who have sex with men in New York City. Annals of Behavioral Medicine 2008;35(1):41-8.

145. Rosser BS, Oakes JM, Horvath KJ, Konstan JA, Danilenko GP, Peterson JL. HIV sexual risk behavior by men who use the Internet to seek sex with men: results of the Men INTernet Sex Study-II (MINTS-II). Aids and Behavior 2009;13(3):488-98.

146. Mackellar DA, Valleroy LA, Secura GM, Behel S, Bingham T, Celentano DD, et al. Unrecognized HIV infection, risk behaviors, and perceptions of risk among young men who have sex with men Opportunities for advancing HIV prevention in the third decade of HIV/AIDS. Jaids-Journal of Acquired Immune Deficiency Syndromes 2005;38(5):603-14.

147. Mustanski BS, Garofalo R, Emerson EM. Mental health disorders, psychological distress, and suicidality in a diverse sample of lesbian, gay, bisexual, and transgender youths. American Journal of Public Health 2010;100(12):2426-32. 
148. Hamilton CJ, Mahalik JR. Minority stress, masculinity, and social norms predicting gay men's health risk behaviors. Journal of Counseling Psychology 2009;56(1):132-41.

149. Hatzenbuehler ML, Nolen-Hoeksema S, Erickson SJ. Minority stress predictors of HIV risk behavior, substance use, and depressive symptoms: Results from a prospective study of bereaved gay men. Health Psychology 2008;27(4):455-62.

150. McKechnie ML, Bavinton BR, Zablotska IB. Understanding of norms regarding sexual practices among gay men: Literature Review. Aids and Behavior 2012;1-10.

151. Alessi EJ, Martin JI. Conducting an internet-based survey: benefits, pitfalls and lessons learned. Social Work Research 2010;34(2):122-8.

152. Wolitski RJ, Valdiserri RO, Denning PH, Levine WC. Are we headed for a resurgence of the HIV epidemic among men who have sex with men? American Journal of Public Health 2001;91(6):883-8.

153. Prochaska JJ, Spring B, Nigg CR. Multiple health behavior change research: An introduction and overview. Preventive medicine 2008;46(3):181-8.

154. Prochaska JJ, Nigg CR, Spring B, Velicer WF, Prochaska JO. The benefits and challenges of multiple health behavior change in research and in practice. Preventive medicine 2010;50(1):26-9.

155. Salomon EA, Mimiaga MJ, Husnik MJ, Welles SL, Manseau MW, Montenegro AB, et al. Depressive Symptoms, Utilization of Mental Health Care, Substance Use and Sexual Risk Among Young Men Who have Sex with Men in EXPLORE: Implications for Age-Specific Interventions. Aids and Behavior 2009;13(4):811-21.

156. Brennan DJ, Welles SL, Miner MH, Ross MW, Rosser BRS, Positive Connections Team. HIV treatment optimism and unsafe anal intercourse among HIV-positive men who have sex with men: Findings from the positive connections study. Aids Education and Prevention 2010;22(2):126-37.

157. European Centre for Disease Prevention and Control (ECDC)/World Health Organization Regional Office for Europe. HIV/AIDS surveillance in Europe 2009. Stockholm: ECDC; 2010.

158. Le Vu, Le Strat Y, Barin F, Pillonel J, Cazein F, Bousquet V, et al. Population-based HIV-1 incidence in France, 2003-08: a modelling analysis. Lancet Infectious Diseases 2010;10(10):682-7.

159. Sasse A, Defraye A. HIV/AIDS in België, semestrieel rapport (toestand op 31 december 2009);Wetenschappelijk Instituut voor Volksgezondheid. 2009 Dec 31.

160. Folch C, Casabona J, Munoz R, Gonzalez V, Zaragoza K. Increase in the prevalence of HIV and in associated risk behaviors in men who have sex with men: 12 years of behavioral surveillance surveys in Catalonia (Spain). Gaceta Sanitaria 2010;24(1):40-6.

161. Hart GJ, Elford J. Sexual risk behaviour of men who have sex with men: emerging patterns and new challenges. Current Opinion in Infectious Diseases 2010;23(1):39-44.

162. Martens V, Huynen P. Connaissances et comportements des hommes qui ont des rapports sexuels avec des hommes à l'égard du VIH/Sida en Communauté française de Belgique. Archives of Public Health 2006;64:13-26.

163. Defraye A, Sasse A. SOA-surveillance in AIDS Referentiecentra in België - Jaarrapport 2008. Wetenschappelijk Instituut voor Volksgezondheid; 2009 Sep.

164. Mirandola M, Toda CF, Krampac I, Nita I, Stanekova D, Stehlikova D, et al. Hiv Bio-Behavioural Survey Among Men Who Have Sex with Men in Barcelona, Bratislava, Bucharest, Ljubljana, Prague and Verona, 2008-2009. Eurosurveillance 2009;14(48):22-9.

165. Velter A, Barin F, Bouyssou A, Guinard J, Le Vu S, Pillonel J, et al. High prevalence and incidence of hiv infection among men who have sex with men recruited in commercial gay venues in Paris (France): Prevagay 2009 survey. 2010.

166. Sifakis F, Hylton JB, Flynn C, Solomon L, MacKellar DA, Valleroy LA, et al. Prevalence of HIV Infection and Prior HIV Testing among Young Men Who have Sex with Men. The Baltimore Young Men's Survey. Aids and Behavior 2010;14(4):904-12.

167. Joint United Nations Programme on HIV/AIDS (UNAIDS). Monitoring the Declaration of Commitment on HIV/AIDS: guidelines on construction of core indicators: 2008 reporting. Geneva: UNAIDS; 2008. 
168. Lambert G, Cox J, Tremblay F, Tremblay C, Alary M, Lavoie, et al. Recent HIV testing behaviour among men who have sex with men (MSM) in Montreal: results from the ARGUS 2005 survey. 2006.

169. Dodds JP, Johnson AM, Parry JV. A tale of three cities: persisting high HIV prevalence, risk behaviour and undiagnosed infection in community samples of men who have sex with men (vol 83, pg 392-6, 2007). Sexually Transmitted Infections 2007;83:500.

170. Haüsermann M, Wang J. Les premiers résultats de l'enquête sur la santé des hommes gais de Genève. 2005 Jun.

171. McConnell JJ, Bragg L, Shiboski S, Grant RM. Sexual seroadaptation: Lessons for prevention and sex research from a cohort of HIV-positive men who have sex with men. Plos One 2010;5(1).

172. Kim AA, Kent CK, Klausner JD. Increased risk of HIV and sexually transmitted disease transmission among gay or bisexual men who use Viagra, San Francisco 2000-2001. Aids 2006;16(10):1425-8.

173. Nettles CD, Benotsch EG, Uban KA. Sexual risk behaviors among men who have sex with men using erectile dysfunction medications. Aids Patient Care and Stds 2009;23(12):1017-23.

174. Spindler HH, Scheer S, Chen SY, Klausner JD, Katz MH, Valleroy LA, et al. Wagra, methamphetamine, and HIV risk: Results from a probability sample of MSM, San Francisco. Sexually Transmitted Diseases 2007;34(8):586-91.

175. Prestage G, Grierson J, Bradley J, Hurley M, Hudson J. The role of drugs during group sex among gay men in Australia. Sexual Health 2009;6(4):310-7.

176. Mayer KH, O'Cleirigh C, Skeer M, Covahey C, Leidolf E, Vanderwarker R, et al. Which HIV-infected men who have sex with men in care are engaging in risky sex and acquiring sexually transmitted infections: findings from a Boston community health centre. Sexually Transmitted Infections 2010;86(1):66-70.

177. Hospers HJ, Roos E, Zuilhof W. Schorer monitor 2009. Universiteit Maastricht - Schorer; 2009.

178. Beyrer C. Global Prevention of HIV Infection for Neglected Populations: Men Who Have Sex with Men. Clinical Infectious Diseases 2010;50:S108-S113.

179. Herrera S, Scott D. "We gotta get out of this place!" Leisure travel among gay men living in a small city. Tourism Review International 2005;8(3):249-62.

180. Casey ME. Tourist gay(ze) or transnational sex: Australian gay men's holiday desires. Leisure Studies 2009;28(2):157-72.

181. Shaw G. Life style and changes in tourist consumption: The British experience. In: Reuber P, editor. Postmoderne Freizeitstile und Freizeiträume. 2005. p. 21-45.

182. Dunne G, Flanagan S, Buckley J. Towards an understanding of international city break level. International Journal of Tourism Research 2010;12(5):409-15.

183. The EMIS network. The European Men-Who-Have-Sex-With-Men Internet Survey. Findings from 38 countries. Stockholm: European Centre for Disease Prevention and Control; 2013.

184. Berg RC, Ross MW, Weatherburn P, Schmidt AJ. Structural and environmental factors are associated with internalised homonegativity in men who have sex with men: Findings from the European MSM Internet Survey (EMIS) in 38 countries. Social science \& medicine 2012.

185. Marcus U, Schmidt AJ, Breveglieri M, Davila PF, Ferrer L, Folch C, et al. S15. 3 European MSM Internet Survey (EMIS): differences in sexually transmissible infection testing in European countries. Sexually Transmitted Infections 2011;87(Suppl 1):A19.

186. Kaufman MR, Fuhrel-Forbis AR, Kalichman SC, Eaton LA, Cain D, Cherry C, et al. On holiday: A risk behavior profile for men who have vacationed at gay resorts. Journal of Homosexuality 2009;56(8):1134-44.

187. Fernández Dávila P, Folch C, Ferrer L, Casabona J, Hickson F, amut A, et al. Mobile men who have sex with men: An exploration in European residents of sexual risk taking while travelling abroad. 2012.

188. Hughes HL. Gay men, travel and HIV risk. Tourism Management 1999;20(3):377-8. 
189. Rosser BRS, Horvath KJ, Hatfield LA, Peterson JL, Jacoby S, Stately A. Predictors of HIV disclosure to secondary partners and sexual risk behavior among a high-risk sample of HIV-positive MSM: results from six epicenters in the US. Aids Care-Psychological and Socio-Medical Aspects of Aids/Hiv 2008;20(8):925-30.

190. Gotz HM, Ossewaarde JM, Nieuwenhuis RF, van der Meijden WI, Dees J, hio B. A cluster of lymphogranuloma venereum among homosexual men in Rotterdam with implications for other countries in Western Europe. Nederlands Tijdschrift voor Geneeskunde 2004 Feb 28;9:441-2.

191. Schmidt AJ, Rockstroh JK, Vogel M, der Heiden MA, Baillot A, Krznaric I, et al. Trouble with bleeding: risk factors for acute hepatitis $\mathrm{C}$ among HIV-positive gay men from Germany-A case-control study. PloS one 2011;6(3):1.

192. van Kesteren NMC, Hospers HJ, Kok G. Sexual risk behavior among HIV-positive men who have sex with men: A literature review. Patient Education and Counseling 2007;65(1):5-20.

193. Benotsch EG, Martin AM, Espil FM, Nettles CD, Seal DW, Pinkerton SD. Internet Use, Recreational Travel, and HIV Risk Behaviors in Men Who Have Sex With Men. Journal of Community Health 2011;36(3):398-405.

194. Marcus U, Hickson F, Weatherburn P, Schmidt AJ. Prevalence of HIV among MSM in Europe: comparison of self-reported diagnoses from a large scale internet survey and existing national estimates. BMC Public Health 2012;12(987).

195. Berg RC, Ross MW, Weatherburn P, Schmidt AJ. Structural and environmental factors are associated with internalised homonegativity in men who have sex with men: Findings from the European MSM Internet Survey (EMIS) in 38 countries. Social science \& medicine 2012.

196. Sandfort TG, Bakker F, Schellevis F, Vanwesenbeeck I. Coping styles as mediator of sexual orientationrelated health differences. Archives of Sexual Behavior 2009;38(2):253-63.

197. EMIS associated partners (vertaling: Harm Hospers UM. EMIS:De Europese MSM internet survey: Community rapport 1. 2010 May.

198. Bradshaw D, Matthews G, Danta M. Sexually transmitted hepatitis C infection: the new epidemic in MSM? Current opinion in infectious diseases 2013;26(1):66-72.

199. Guadamuz TE, Friedman MS, Marshal MP, Herrick AL, Lim SH, Wei C, et al. Health, sexual health, and syndemics: Toward a Better Approach to STI and HIV Preventive Interventions for Men Who Have Sex with Men (MSM) in the United States. The New Public Health and STD/HIV Prevention. Springer New York; 2013. p. 251-72.

200. Kurtz SP, Buttram ME, Surratt HL, Stall RD. Resilience, syndemic factoRs, and seRosoRting behavioRs among hiv-positive and hiv-negative substance-using msm. Aids Education and Prevention 2012;24(3):193-205.

201. Vincke J, Bolton R. The social support of Flemish gay men: An exploratory study. Journal of Homosexuality 1996;31(4):107-21.

202. Vincke J, Bolton R. Social Support, Depression, and Self-Acceptance Among Gay Men. Human Relations 1994;47(9):1049-62.

203. Dewaele A, Cox N, Van den Berghe W, Vincke J. Families of Choice? Exploring the Supportive Networks of Lesbians, Gay Men, and Bisexuals. Journal of Applied Social Psychology 2011;41(2):312-31.

204. Salomon EA, Mimiaga MJ, Husnik MJ, Welles SL, Manseau MW, Montenegro AB, et al. Depressive Symptoms, Utilization of Mental Health Care, Substance Use and Sexual Risk Among Young Men Who have Sex with Men in EXPLORE: Implications for Age-Specific Interventions. Aids and Behavior 2009;13(4):811-21.

205. Kurtz SP, Buttram ME, Surratt HL, Stall RD. Resilience, syndemic factoRs, and seRosoRting behavioRs among hiv-positive and hiv-negative substance-using msm. Aids Education and Prevention 2012;24(3):193-205. 
206. Mansergh G, Koblin BA, McKirnan DJ, Hudson SM, Flores SA, Wiegand RE, et al. An Intervention to Reduce HIV Risk Behavior of Substance-Using Men Who Have Sex with Men: A Two-Group Randomized Trial with a Nonrandomized Third Group. Plos Medicine 2010;7(8).

207. Berg R. The Effectiveness of Behavioural and Psychosocial Hiv/Sti Prevention Interventions for Msm in Europe: A Systematic Review. Eurosurveillance 2009;14(48):35-43.

208. Patterson C, D'Augelli AR. Handbook of Psychology and Sexual Orientation. New York: Oxford University Press; 2013. 



\section{English summary}

Sexual minority populations are disproportionately affected by specific health outcomes. There is a need to better understand determinants and dynamics at different ecological levels that explain these health disparities. The chapters in this thesis each look at different aspects of explaining, firstly, mental health outcomes among LGB populations, and secondly, sexual health outcomes (HIV/STI risk) among gay and other men who have sex with men (MSM) living in Belgium. Chapter 2 and 3 are based on the results of the Zzzip project, a population based online study on the societal position of lesbians, gays and bisexuals (LGB) in Flanders. Chapter 2 uses social and minority stress theory to analyze and discuss the effects of both general and minority stressors on mental health among a general population of LGB's. This study finds further evidence for individual and social determinants of depressive symptoms conceptualized within a adapted version of the minority stress model among a Flemish LGB population. Chapter 3 also uses minority stress theory in conceptualizing and modeling minority specific determinants of lowered mental health among LGB youth. This study was conducted on the basis of a subsample of LGB youth younger than 26 years old from the Zzzip database. The results add to further evidence validating the minority stress approach in explaining health disparities among sexual minority populations. Chapter 4 functions as a key chapter in looking at co-occurrence of mental and sexual health related problems in the context of syndemic theory among an online population of HIV negative Flemish men who have sex with men who had at least one episode of anal penetrative sex with casual partners in the last six months prior to the study. The results of this study provides further evidence of a syndemic among HIV negative MSM. A syndemic can be defined as a synergestic interaction of two or more co-existent diseases that result into excess disease burden. MSM are confronted with different health problems. Next to a higher HIV prevalence and a higher reporting of depressive symptoms, there is also evidence of elevated substance use and sexual compulsivity occurring simultaneously. In addition, the results in this chapter confirm the significant association between depressive symptoms and unprotected anal intercourse among subgroups of men who have sex with men. In chapter 5 the results of a venue- based bio-behavioral HIV prevalence study in Flanders $\left(\mathrm{FAQ}^{2}\right)$ are presented. Using time-location sampling, we found that HIV prevalence in MSM who attended different types of venues ranged from a high of $14.5 \%$ in cruising venues to $4.9 \%$ in more general gay venues to $1.4 \%$ at younger MSM venues. Of those who tested HIV positive, $14.3 \%$ were unaware of their HIV status or self-reported as being HIV negative. Chapter 6 discusses international mobility, HIV related characteristics and sexual behavior of MSM residing in Belgium. For this 
study the Belgian results of the European Men who have sex with Men Internet Study (EMIS) are used. Our results for the case of Belgium show that HIV and STI are highly prevalent among travelling MSM, and that they adopt more sexual risk behavior (i.e. they scored higher on sexual risk indicators) than MSM who were not sexually active abroad. Finally, in Chapter 7 results from the different chapters and studies are discussed next to possible directions for the future of health interventions among LGB populations and HIV prevention among MSM for Belgium and Europe.

The aim of the research in this thesis was to describe and explain health outcomes among sexual minority populations in Belgium. Different studies provided insight into mental health disparities among LGB populations and secondly on sexual health risks among gay and other men who have sex with men. Results from the studies in this thesis have already served and will form a further basis for possible directions of the future of health interventions among LGB populations and HIV prevention among MSM for Belgium and Europe. 


\section{Nederlandse samenvatting}

Seksuele minderheden worden onevenredig getroffen door specifieke negatieve gezondheidsuitkomsten. Er is een behoefte om de determinanten en dynamieken beter te begrijpen, die aan de basis van deze gezondheidsverschillen liggen, en dit op de verschillende ecologische niveaus. De hoofdstukken in dit proefschrift gaan elk afzonderlijk in op verschillende aspecten in het proberen te verklaren van op de eerste plaats, mentale gezondheidsuitkomsten bij homo's, lesbiennes en biseksuelen (holebi's), en ten tweede, seksuele gezondheidsuitkomsten ( risico op HIV / SOA ) bij homoseksuele en andere mannen die seks hebben met mannen (MSM) wonend in België. Hoofdstuk 2 en 3 zijn gebaseerd op de resultaten van het Zzzip project, een online populatieonderzoek naar de maatschappelijke positie van holebi's in Vlaanderen. Hoofdstuk 2 maakt gebruik van sociale en minderheidsstresstheorie om de effecten van zowel algemene als minderheidsstressoren op mentale gezondheid bij holebi's te analyseren en te bespreken. Deze studie toont het effect aan van individuele en sociale determinanten op depressieve symptomen geconceptualiseerd binnen een aangepaste versie van het minderheidsstressmodel bij Vlaamse holebi's. Hoofdstuk 3 maakt ook gebruik van minderheidsstresstheorie in het conceptualiseren en modelleren van minderheidsspecifieke determinanten van verminderde mentale gezondheid bij holebi-jongeren. Deze studie werd uitgevoerd op basis van een subgroep van holebi-jongeren jonger dan 26 jaar oud uit de Zzzip database. De resultaten kunnen dienen als verder bewijs en validatie van de minderheidsstressbenadering in het verklaren van gezondheidsverschillen bij seksuele minderheidsgroepen. Hoofdstuk 4 fungeert als een belangrijk hoofdstuk in het bestuderen van de associatie tussen mentale en seksuele gezondheidsgerelateerde problemen, in het kader van syndemie theorie, bij een online populatie van HIV negatieve Vlaamse MSM die minstens een episode van anale seks gehad hebben met losse partners in de zes maanden voorafgaand aan de studie. De resultaten van deze studie leveren verder bewijs van een syndemie onder HIV negatieve MSM. Een syndemie kan worden gedefinieerd als een synergetische interactie van twee of meer co-existente ziekten die resulteren in een verhoogde ziektelast. MSM worden geconfronteerd met verschillende gezondheidsproblemen. Naast een hogere prevalentie van HIV en een hogere rapportage van depressieve symptomen, zijn er ook aanwijzingen van verhoogd middelengebruik en seksuele dwangmatigheid, die tegelijkertijd plaatsvinden. Verder bevestigen de resultaten in dit hoofdstuk de significante associatie tussen depressieve symptomen en onbeschermde anale seks bij subgroepen van MSM. In hoofdstuk 5 worden de resultaten van een biologisch en gedragsmatig HIV-prevalentie-onderzoek in Vlaanderen $\left(F A Q{ }^{2}\right)$ gepresenteerd. Met behulp van tijd-locatie sampling, vonden we dat de HIV- 
prevalentie bij MSM die op verschillende soorten locaties aanwezig waren varieerde van een piek van $14,5 \%$ in cruising locaties tot $4,9 \%$ in de meer algemene gay scene tot $1,4 \%$ op plaatsen waar jongere MSM samenkomen. Van degenen die HIV positief testen waren 14,3\% daar niet van bewust of rapporteerden HIV negatief te zijn. Hoofdstuk 6 bespreekt internationale mobiliteit, HIV gerelateerde kenmerken en seksueel gedrag van MSM die in België verblijven. Voor deze studie worden de Belgische resultaten van de Europese mannen die seks hebben met mannen Internet Studie (EMIS) gebruikt. Onze resultaten voor België tonen aan dat HIV en SOA veel voorkomen onder reizende MSM, en dat deze groep meer seksueel risicogedrag (d.w.z. ze scoorden hoger op seksuele risico-indicatoren) aangeven dan MSM die niet seksueel actief geweest zijn in het buitenland. Tenslotte worden in hoofdstuk 7 de opvallendste resultaten van de verschillende hoofdstukken en studies besproken naast mogelijke richtingen voor de toekomst van de gezondheidsinterventies bij holebi's en HIV-preventie bij MSM voor België en Europa.

Het doel van het onderzoek in dit proefschrift was om gezondheidsuitkomsten bij seksuele minderheden in België te beschrijven en te verklaren. Verschillende studies gaven inzicht over mentale gezondheidsuitkomsten bij holebi's en ten tweede over seksuele gezondheidsrisico's onder homoseksuele en andere MSM. De resultaten van de studies in dit proefschrift hebben al gediend en zullen verder als basis dienen voor mogelijke toekomstige gezondheidsinterventies bij holebi's en HIV-preventie onder MSM in België en Europa. 


\section{Acknowledgements}

Door mijn opleiding en ervaring geloof ik sterk in de mobiliserende kracht van het collectief al begrijp ik nu meer dan ooit welke impact individuen kunnen hebben op het levenspad van één enkele persoon. Ik was nooit op dit punt van mijn carrière of leven gekomen zonder de steun van mijn directe omgeving. Ik wil dan ook een aantal mensen uitdrukkelijk bedanken:

Allereerst mijn vriend Sven, mijn thuis, mijn anker in de soms wat woelige zee.

Mijn ouders, voor het feit dat ze meegegroeid zijn en zich ook voortdurend hebben aangepast aan nieuwe situaties, met behoud van hun kritische zelf weliswaar. Mijn broer, de fysieke en spirituele reden waarom ik het idee van "normaal doen" altijd als iets hilarisch ervaren heb.

Mijn spreekwoordelijke schoonfamilie die me van dag één hebben opgenomen in hun gezin.

Mijn goede vrienden voor de zotte momenten, de steun, de vele discussies en kritische inzichten. En zelfs hulp bij dataverzameling...

Mijn geweldige socioloog-collega's uit "de tijd in Gent" met in het bijzonder Nele, mijn soul - and roommate voor vele jaren, Alexis en het team van John.

Mijn huidige collega's op het ITG. Mijn team, een groep van briljante en veel te bescheiden vrouwen (en een aantal geweldige mannen).

Marie, voor haar blind geloof in me en de kans die ze me gegeven heeft op het ITG. Ik heb van haar geleerd dat wetenschap gerust wat activistisch mag zijn.

Harm. Bedankt voor dit laatste jaar. Je goede raad, je luisterend oor en nuchterheid zijn zeker doorslaggevend geweest.

Dank aan Sensoa, als organisatie maar evenzeer alle medewerkers, voor de steun en het blijvend engagement. Dank ook aan alle andere partnerorganisaties.

Ik ben begonnen met te stellen dat individuen een grote impact kunnen hebben. Wel, er is één iemand, die er vandaag niet meer bij kan zijn, die, als ik zo terug kijk, wel eens de grootste impact zou kunnen gehad hebben op mij. Professor John Vincke (sociologie, UGent) was mijn eerste promotor en mentor. Hij zag iets in mij op een moment dat ik eigenlijk niet te veel in mezelf zag. Hij is een bron geweest van een groeiend zelfrespect niet alleen voor mezelf maar voor vele andere holebi's, en hij wordt gemist.

Ten laatste wil ik publiekelijk toch nog de duizenden onzichtbare mannen en vrouwen bedanken die mij en anderen toelieten hun leven in cijfers en letters uit te drukken. 


\section{Curriculum Vitae}

Wim Vanden Berghe was born on the $15^{\text {th }}$ of November 1979 in Brugge, Flanders, Belgium. He completed his secondary school in 1997 at the Koninklijk Atheneum 1 BruggeCentrum. In 2003 he obtained his master's degree in sociology cum laude at Ghent University and subsequently worked at the same institution as a sociologist on health issues among sexual minorities. At the sociology department, he coordinated several research projects on mental health outcomes and sexual risk behavior among men who have sex with men (MSM) using quantitative and qualitative methods within the team of the late professor John Vincke. Since 2009, he has been working as a researcher at the department of public health (and IHAC) of the Institute of Tropical Medicine (ITM), Antwerp under the supervision of professor Marie Laga. In this function, he coordinated and was involved in several policy and research projects on HIV prevalence and HIV related sexual behavior of MSM in Belgium and Europe. Apart from research, he has been involved in education at the sociology department, Ghent University and ITM, Antwerp teaching both methodological and theoretical courses. 